\title{
Effects of the physical state of tropospheric ammonium-sulfate-nitrate particles on global aerosol direct radiative forcing
}

\author{
S. T. Martin ${ }^{1}$, H.-M. Hung ${ }^{1}$, R. J. Park ${ }^{1,2}$, D. J. Jacob ${ }^{1,2}$, R. J. D. Spurr ${ }^{3}$, K. V. Chance ${ }^{3}$, and M. Chin ${ }^{4,5}$ \\ ${ }^{1}$ Division of Engineering and Applied Sciences, Harvard University, USA \\ ${ }^{2}$ Department of Earth and Planetary Sciences, Harvard University, USA \\ ${ }^{3}$ Harvard-Smithsonian Center for Astrophysics, USA \\ ${ }^{4}$ School of Earth and Atmospheric Sciences, Georgia Institute of Technology, USA \\ ${ }^{5}$ Laboratory for Atmospheres, NASA Goddard Space Flight Center, USA
}

Received: 5 July 2003 - Published in Atmos. Chem. Phys. Discuss.: 29 October 2003

Revised: 22 January 2004 - Accepted: 23 January 2004 - Published: 4 February 2004

\begin{abstract}
The effect of aqueous versus crystalline sulfatenitrate-ammonium tropospheric particles on global aerosol direct radiative forcing is assessed. A global threedimensional chemical transport model predicts sulfate, nitrate, and ammonium aerosol mass. An aerosol thermodynamics model is called twice, once for the upper side (US) and once for lower side (LS) of the hysteresis loop of particle phase. On the LS, the sulfate mass budget is $40 \%$ solid ammonium sulfate, $12 \%$ letovicite, $11 \%$ ammonium bisulfate, and $37 \%$ aqueous. The LS nitrate mass budget is $26 \%$ solid ammonium nitrate, $7 \%$ aqueous, and $67 \%$ gas-phase nitric acid release due to increased volatility upon crystallization. The LS ammonium budget is $45 \%$ solid ammonium sulfate, $10 \%$ letovicite, $6 \%$ ammonium bisulfate, $4 \%$ ammonium nitrate, $7 \%$ ammonia release due to increased volatility, and $28 \%$ aqueous. LS aerosol water mass partitions as $22 \%$ effloresced to the gas-phase and $78 \%$ remaining as aerosol mass. The predicted US/LS global fields of aerosol mass are employed in a Mie scattering model to generate global US/LS aerosol optical properties, including scattering efficiency, single scattering albedo, and asymmetry parameter. Global annual average LS optical depth and mass scattering efficiency are, respectively, 0.023 and $10.7 \mathrm{~m}^{2}$ (g $\left.\mathrm{SO}_{4}^{2-}\right)^{-1}$, which compare to US values of 0.030 and $13.9 \mathrm{~m}^{2}$ $\left(\mathrm{g} \mathrm{SO}_{4}^{2-}\right)^{-1}$. Radiative transport is computed, first for a base case having no aerosol and then for the two global fields corresponding to the US and LS of the hysteresis loop. Regional, global, seasonal, and annual averages of top-ofthe-atmosphere aerosol radiative forcing on the LS and US $\left(F_{L}\right.$ and $F_{U}$, respectively, in $\mathrm{W} \mathrm{m}^{-2}$ ) are calculated. Including both anthropogenic and natural emissions, we obtain global annual averages of $F_{L}=-0.750, F_{U}=-0.930$, and
\end{abstract}

Correspondence to: S. T. Martin

(scot_martin@harvard.edu)
$\Delta F_{U, L}=24 \%$ for full sky calculations without clouds and $F_{L}=-0.485, F_{U}=-0.605$, and $\Delta F_{U, L}=25 \%$ when clouds are included. Regionally, $\Delta F_{U, L}=48 \%$ over the USA, $55 \%$ over Europe, and $34 \%$ over East Asia. Seasonally, $\Delta F_{U, L}$ varies from $18 \%$ in DJF to $75 \%$ in SON over the USA. The global annual average contribution from anthropogenic aerosol is $F_{L}=-0.314$ and $F_{U}=-0.404$, which yield normalized direct radiative forcings $(G)$ of $G_{L}=-205 \mathrm{~W}$ (g $\left.\mathrm{SO}_{4}^{2-}\right)^{-1}$ and $G_{U}=-264 \mathrm{~W}\left(\mathrm{~g} \mathrm{SO}_{4}^{2-}\right)^{-1}$.

\section{Introduction}

Atmospheric aerosols significantly influence radiative transfer by scattering and absorbing radiation (Houghton et al., 2001). The optical effects are strongly regulated by relative humidity $(\mathrm{RH})$ because hygroscopic components absorb water, changing both particle diameter and wavelengthdependent refractive indices (Martin, 2000).

Sulfate particles are the largest contributions to the global anthropogenic accumulation mode aerosol mass budget. Because they are nonabsorptive in the visible region of the electromagnetic spectrum, they provide the most significant anthropogenic cooling contribution to global direct radiative forcing (Charlson et al., 1992; Seinfeld, 1996; Haywood et al., 1997; Haywood and Boucher, 2000; Adams et al., 2001; Houghton et al., 2001; Jacobson, 2001a). Model predictions of the global distribution of anthropogenic and natural aerosol optical depth suggest that $40-60 \%$ of the annual average $550 \mathrm{~nm}$ aerosol optical depth over North America, Europe, and Asia and 28\% over the globe is attributable to sulfate aerosol (Chin et al., 2002; Penner et al., 2002). 

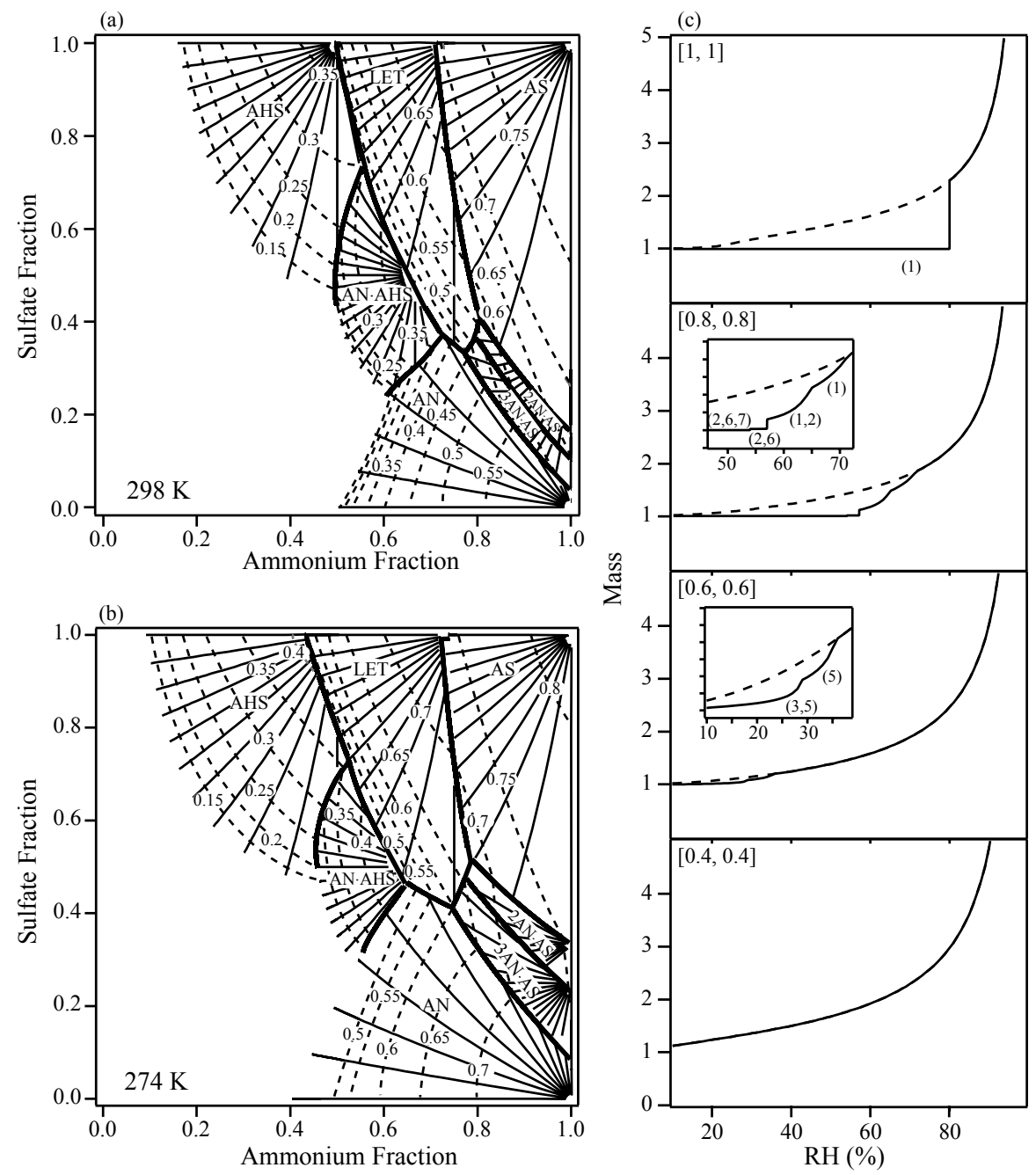

Fig. 1. (a), (b) $X-Y$ chemical composition plots showing the thermodynamically favorable phase with decreasing RH at 298 and $274 \mathrm{~K}$. (c) Relative mass with changing RH for the US and LS of the hysteresis loop for several chemical compositions [X, Y] at $298 \mathrm{~K}$. Solids formed are shown in parentheses. Residual aqueous phase is present unless the relative mass is unity. $\mathrm{Key}_{\text {to }}$ solids: $1,\left(\mathrm{NH}_{4}\right)_{2} \mathrm{SO}_{4}(\mathrm{AS})$; 2, $\left(\mathrm{NH}_{4}\right)_{3} \mathrm{H}\left(\mathrm{SO}_{4}\right)_{2}(\mathrm{LET}) ; 3, \mathrm{NH}_{4} \mathrm{HSO}_{4}(\mathrm{AHS}) ; 4, \mathrm{NH}_{4} \mathrm{NO}_{3}(\mathrm{AN}) ; 5, \mathrm{NH}_{4} \mathrm{NO}_{3} \cdot \mathrm{NH}_{4} \mathrm{HSO}_{4}(\mathrm{AN} \cdot \mathrm{AHS}) ; 6,\left(\mathrm{NH}_{4} \mathrm{NO}_{3}\right)_{2} \cdot\left(\mathrm{NH}_{4}\right)_{2} \mathrm{SO}_{4}$ (2AN.AS); $7,\left(\mathrm{NH}_{4} \mathrm{NO}_{3}\right)_{3} \cdot\left(\mathrm{NH}_{4}\right)_{2} \mathrm{SO}_{4}(3 \mathrm{AN} \cdot \mathrm{AS})$.

In the atmosphere, $\mathrm{HNO}_{3}(\mathrm{~g})$ and $\mathrm{NH}_{3}(\mathrm{~g})$ condense onto nonvolatile sulfate particles, yielding ionic particles of sulfate $\left(\mathrm{SO}_{4}^{2-}\right)$, nitrate $\left(\mathrm{NO}_{3}^{-}\right)$, ammonium $\left(\mathrm{NH}_{4}^{+}\right)$, and proton $\left(\mathrm{H}^{+}\right)$. The $\mathrm{SO}_{4}^{2-}-\mathrm{NO}_{3}^{-}-\mathrm{NH}_{4}^{+}-\mathrm{H}^{+}-\mathrm{H}_{2} \mathrm{O}$ (SNA) particles are aqueous or crystalline (Martin, 2000). Their physical state affects the magnitude of aerosol direct radiative forcing, the partitioning of volatile species such as $\mathrm{HNO}_{3}$ between gas and particle (Seinfeld and Pandis, 1998; Adams et al., 1999; Ansari and Pandis, 2000; Metzger et al., 2002), the rates of heterogeneous chemical reactions such as $\mathrm{N}_{2} \mathrm{O}_{5}$ hydrolysis (Mozurkewich and Calvert, 1988; Dentener and Crutzen, 1993; Hu and Abbatt, 1997; Kane et al., 2001), and the distributions and concentrations of $\mathrm{O}_{3}$ via coupling of $\mathrm{NO}_{\mathrm{y}}$ and $\mathrm{O}_{\mathrm{x}}$ chemistry (Dentener and Crutzen, 1993; Jacob, 2000; Liao et al., 2003).
Treatment of aerosol phase in models is complicated by bifurcations between equilibrium and metastable branches of hygroscopic growth: physical state depends on the RH history in an air parcel. Ammonium sulfate, for example, is crystalline up to $80 \%$ RH (cf. $[1,1]$ in Fig. 1c). At the deliquescence relative humidity (DRH) of $80 \%$ at $298 \mathrm{~K}$, crystalline particles take up water and transform into aqueous droplets containing dissolved $\mathrm{NH}_{4}^{+}(\mathrm{aq})$ and $\mathrm{SO}_{4}^{2-}(\mathrm{aq})$ ions. When RH decreases, aqueous ammonium sulfate particles do not crystallize by homogeneous nucleation until the crystallization RH (CRH) of 35\% is reached (efflorescence). Thus, between $35 \%$ and $80 \% \mathrm{RH}$, particles may be either aqueous or crystalline, depending on the RH history. This bifurcation is called the hysteresis loop (cf. Fig. 1c). Crystalline particles below the DRH follow the lower side (LS) (equilibrium 
branch) of the hysteresis loop while aqueous particles above the $\mathrm{CRH}$ follow the upper side (US) (metastable branch). The major aim of our work is to compare the global aerosol direct radiative forcing $F_{L}$ and $F_{U}$ of SNA aerosol following the LS and US of the hysteresis loop.

\subsection{Dependence of light scattering efficiency on aerosol phase}

The reduction in intensity $I$ of a directed beam along a path of thickness $\Delta z(\mathrm{~km})$ is:

$\frac{I_{z+\Delta z}}{I_{z}}=\exp (-\sigma \Delta z)=\exp (-\tau)$

where optical depth $\tau$ is $\sigma \Delta z$ and $\sigma\left(\mathrm{km}^{-1}\right)$ is the light scattering efficiency. Because light scattering by accumulation mode aerosol increases with the cross-section area of the particles, (mass) $)^{2 / 3}$ is an approximate predictor of the dependence of $\sigma\left(\mathrm{km}^{-1}\right)$ on aerosol phase, overlooking variations in particle density, refractive index, and shape. Figure 1c shows the predicted relative particle mass on the US and LS of the hysteresis loop for ionic compositions varying from acidic to neutralized.

The four hygroscopic growth curves in Fig. 1c are calculated (Clegg et al., 1998) for chemical compositions [0.4, $0.4],[0.6,0.6],[0.8,0.8]$, and $[1,1]$, where the coordinates $[X, Y]$ refer to the SNA phase diagram shown at $298 \mathrm{~K}$ in Fig. 1a. The four corners of Fig. $1 \mathrm{a}$ are the poles $\mathrm{H}_{2} \mathrm{SO}_{4}$ (SA), $\left(\mathrm{NH}_{4}\right)_{2} \mathrm{SO}_{4}(\mathrm{AS}), \mathrm{NH}_{4} \mathrm{NO}_{3}(\mathrm{AN})$, and $\mathrm{HNO}_{3}$ (NA) (Potukuchi and Wexler, 1995a,b). Coordinate $X$ is the cation mole fraction arising from $\mathrm{NH}_{4}^{+}$, with the balance coming from $\mathrm{H}^{+}$. It is also the degree of neutralization. Coordinate $Y$ is the anion mole fraction arising from $\mathrm{SO}_{4}^{2-}$, with the balance coming from $\mathrm{NO}_{3}^{-}$. Coordinate $\mathrm{Z}$ is relative humidity and comes out of the page towards the reader.

There are seven possible solid phases that crystallize from SNA. Regions separated by heavy black lines (Figs. 1a, b) show the first solid that reaches saturation with falling $\mathrm{RH}$, although solid formation occurs only on the LS of the hysteresis loop. The contour value of the dashed lines specifies the RH at which solid saturation occurs for an evaporating aqueous solution. The thin solid lines show the composition trajectory of the residual aqueous phase after a solid has formed and assuming no exchange of $\mathrm{NH}_{3}$ or $\mathrm{HNO}_{3}$ with the gas-phase. In the atmosphere, exchange of $\mathrm{H}_{2} \mathrm{O}, \mathrm{NH}_{3}$, and $\mathrm{HNO}_{3}$ between gas- and particle-phases must be considered, so the liquid composition trajectories are somewhat different.

The LS behavior predicted by the phase diagram can be complex (Wexler and Clegg, 2002) (cf. Fig. 1c). For instance, an aqueous [0.8,0.8] solution is predicted to form ammonium sulfate at $72 \% \mathrm{RH}$. As ammonium sulfate is removed from solution, the remaining aqueous phase becomes more acidic and more nitrified, as indicated by the trajectory of the solid line. At $65 \% \mathrm{RH}$, the residual solution is predicted to saturate with letovicite, and two solids begin

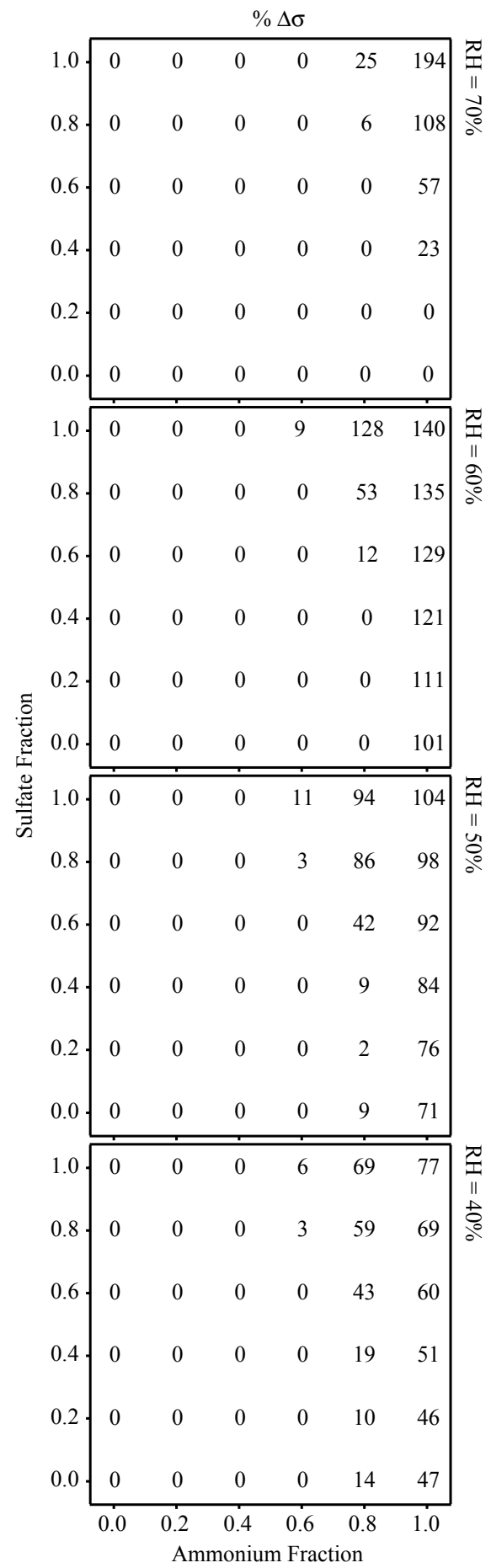

Fig. 2. Percent change in scattering efficiency $(\% \Delta \sigma)$ for particles on the US and LS of the hysteresis loop at 40, 50, 60, and 70\% $\mathrm{RH}$ and $298 \mathrm{~K}$. Conditions: $\lambda=500 \mathrm{~nm}$, no equilibration with gasphase, $82 \mathrm{~nm}$ dry mode diameter with geometric standard deviation of 2.0, and 11 diameter bins. For reference $\sigma[1,1]_{\mathrm{dry}}=0.01 \mathrm{~km}^{-1}$ for $3 \mu \mathrm{g} \mathrm{m}^{-3}$ dry $\left(\mathrm{NH}_{4}\right)_{2} \mathrm{SO}_{4}$ mass. Further details on calculation of optical properties are provided in Sect. 4. 
Table 1. Spectral bands and real and imaginary optical constants employed in the calculations of aerosol optical properties.

\begin{tabular}{cccccc}
\hline Band & Wavenumber $\left(\mathrm{cm}^{-1}\right)$ & Wavelength $(\mathrm{nm})$ & Spectral range $\left(\mathrm{cm}^{-1}\right)$ & $n$ & $k$ \\
\hline 1 & 31700 & 315 & $31250-32260$ & 1.46 & $10^{-7.5}$ \\
2 & 28000 & 357 & $25000-31250$ & 1.46 & $10^{-7.5}$ \\
3 & 20000 & 500 & $14280-25000$ & 1.46 & $10^{-7.5}$ \\
4 & 12000 & 833 & $8200-14280$ & 1.40 & $10^{-7.0}$ \\
5 & 6000 & 1667 & $4400-8200$ & 1.40 & $10^{-3.5}$ \\
\hline
\end{tabular}

precipitating. The solution increases its nitrate content until $57 \% \mathrm{RH}$, at which point the ammonium sulfate and letovicite crystals and the remaining aqueous phase combine to form 2AN.AS, letovicite, and residual aqueous phase. At 54\% $\mathrm{RH}$, the last of the aqueous phase crystallizes, and the three crystals are letovicite, $2 \mathrm{AN} \cdot \mathrm{AS}$, and 3AN.AS.

Acidic solutions, such as $[0.4,0.4]$, have a much simpler behavior because they remain liquid even at low RH. There is no hysteresis loop for these acidic solutions. Slightly more neutralized solutions such as $[0.6,0.6]$ have a hysteresis loop and form solids, yet the crystalline particles retain an outer aqueous layer of altered ionic composition. Due to this strong dependence of the hysteresis loop on aerosol chemical composition, a global chemical transport model (CTM) of this system must include both aerosol acidity and nitrate.

The effect of $[X, Y]$ on the percent change of $\sigma(\% \Delta \sigma)$ at $500 \mathrm{~nm}$ for aerosol on the LS versus US of the hysteresis loop is shown in Fig. 2 for several RH values. For example, $\% \Delta \sigma[1,1]_{\mathrm{dry}}=194 \%$ at $70 \% \mathrm{RH}$. The largest differences are obtained for $[X, Y]$ approaching the AS pole, regardless of RH. However, the range of compositions having non-zero values increases with lower RH. The explanation is found in Figs. 1a, c, which together show that solids are increasingly thermodynamically favored throughout $[X, Y]$ space with decreasing RH and that the mass difference between the US and LS of the hysteresis loop increases with rising RH. For some compositions, however, $\% \Delta \sigma$ is maximum at $\mathrm{RH}$ values below those at which a solid phase first forms. For example, $\% \Delta \sigma[0.8,0.8]$ increases from $6 \%$ to $53 \%$ as $\mathrm{RH}$ falls from $70 \%$ to $60 \%$. This behavior is understood by examining the complex crystallization pathway of $[0.8,0.8]$, which involves a progression through several solid phases (Fig. 1c).

Figures 1a, b, which are drawn for 298 and 274 K, respectively, further show that solid formation and hence the hysteresis loop depend strongly on temperature. The stability regions of LET, 2AN.AS, and 3AN.AS expand at the expense of AS, AN, and AHS. There is a general uplifting of the RH for solid formation with decreasing temperature, as indicated by the contour values in Fig. 1b, which are approximately 5\% greater than those in Fig. 1a. In the atmosphere, differences between the US and LS of the hysteresis loop are greater in cold regions such as the middle troposphere (MT) and upper troposphere (UT) year round and the boundary layer (BL) high latitude winter.
1.2 Previous treatments of aerosol phase in global models

Previous global modeling treatments of aerosol phase include: (a) prediction of phase accounting for the hysteresis effect using an RH trajectory analysis but not including nitrate in the aerosol chemical composition and not evaluating the effect of phase on global aerosol direct radiative forcing (Colberg et al., 2003), (b) calculation of the effects of US and LS of the hysteresis loop on aerosol direct radiative forcing (usually assuming fixed aerosol chemical composition of ammonium sulfate) (Pilinis et al., 1995; Haywood et al., 1997; Boucher et al., 1998; Haywood and Boucher, 2000; Jacobson, 2001a), (c) simulation of SNA aerosol and calculation of radiative forcing but with the assumption that the aerosol follows the US of the hysteresis loop (van Dorland et al., 1997; Adams et al., 1999; Adams et al., 2001), and (d) simulation of SNA aerosol composition with calculation of the effect of US versus LS hysteresis loop on forcing (Metzger et al., 2002). A literature survey of approaches to treating hysteresis is provided in Adams et al. (1999).

Previous studies of category $b$ employing fixed chemical composition (usually ammonium sulfate) find $\Delta F_{U, L}=15$ to 20\%. Representative results are given in Table 3 of Boucher and Anderson (1995) and Table 1 of Haywood et al. (1997). An improved approach is to predict SNA aerosol chemical composition (variable chemical composition) (van Dorland et al., 1997; Adams et al., 1999; Adams et al., 2001; Metzger et al., 2002). Adams et al. (2001) calculate $F_{U}$ but not $F_{L}$, instead assuming that the aerosol remains aqueous, even below DRH. Metzger et al. (2002) report $\Delta F_{U, L}=5 \%$. Unfortunately, their results seem anomalous. They have a normalized radiative forcing of $-55 \mathrm{~W}\left(\mathrm{~g} \mathrm{SO}_{4}^{2-}\right)^{-1}$ (inferred from their Figs. $5 \mathrm{~b}$ and $6 \mathrm{a}, \mathrm{b}$ ), which is several times lower than the IPCC summary (Table 6.4, Penner et al., 2001). Since Metzger et al. (2002) depart strongly from other reports, we restrict comparisons of our SNA results to those of Adams et al. (1999, 2001).

Jacobson (2001a) interpolates several sources of off-line data into a combined description of 47 chemical species in each of 17 size bins of different internally mixed compositions. The dominant predicted sulfate, nitrate, and ammonium solids are $\mathrm{CaSO}_{4} \cdot 2 \mathrm{H}_{2} \mathrm{O}(\mathrm{s}), \mathrm{KNO}_{3}(\mathrm{~s})$, and $\mathrm{NH}_{4} \mathrm{Cl}(\mathrm{s})$. The degree of neutralization for ammonium to sulfate is assigned as $50 \%$. The optical calculations assume a black 

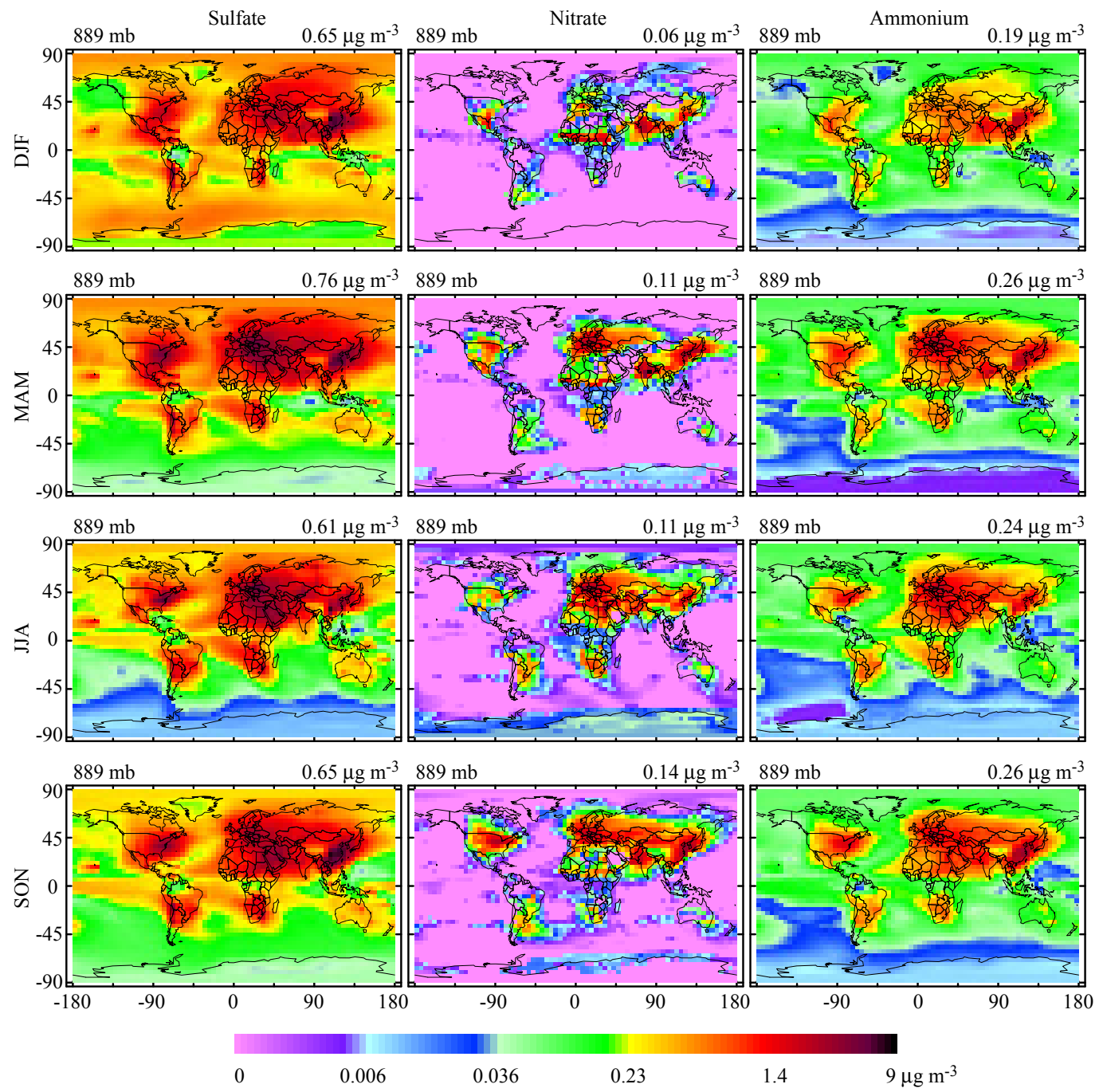

Fig. 3. Predicted seasonal mass concentrations $\left(\mu \mathrm{g} \mathrm{m}^{-3}\right)$ of aqueous sulfate, nitrate, and ammonium in the boundary layer. Average pressure and average loading for the boundary layer are given above each figure.

carbon core. Jacobson (2001a) calculates global aerosol direct radiative forcing for the contrasting cases of assuming the aerosol follows the US versus LS of the hysteresis loop. An effect of $0.05 \mathrm{~W} \mathrm{~m}^{-2}$ of cooling is reported for upper versus lower side behavior. Comparison of this result to ours is difficult because $\Delta F_{U, L}$ depends strongly on global distributions of aerosol chemical composition, particle diameter, and relative humidity and temperature fields. In this paper, we dissect each of these effects in detail. However, similar information is not available in Jacobson (2001a) so that we can make only limited comparisons between our results and those of Jacobson (2001a).

\subsection{Description of our approach}

The global aerosol direct radiative forcings $\left(F_{L}\right.$ and $\left.F_{U}\right)$ for aerosol following the limiting scenarios of LS versus US be- havior on the hysteresis loop are calculated. (1) A global three-dimensional CTM (GEOS-CHEM) predicts seasonal mass distributions of sulfate, nitrate, and ammonium aerosol on a global latitude, longitude, and altitude grid. Heterogeneous chemical reactions and gas-phase partitioning assume the aerosol is on the US of the hysteresis loop. (2) To produce the LS mass field, the chemical content of each grid box is analyzed to assess the thermodynamic driving force for crystallization (ISORROPIA, Nenes et al., 1998). The aerosol water mass field decreases on the LS when crystallization is thermodynamically favorable. The ammonium and nitrate aerosol mass fields also partially decrease because their volatility is greater on the LS than on the US (Ansari and Pandis, 2000). (3) In five shortwave spectral bands (Table 1), LS and US global fields of aerosol optical properties, including mass scattering efficiency, $\beta\left(\mathrm{m}^{2} \mathrm{~g}^{-1}\right)$, single scattering albedo $(\omega)$, and asymmetry parameter $(g)$, are 

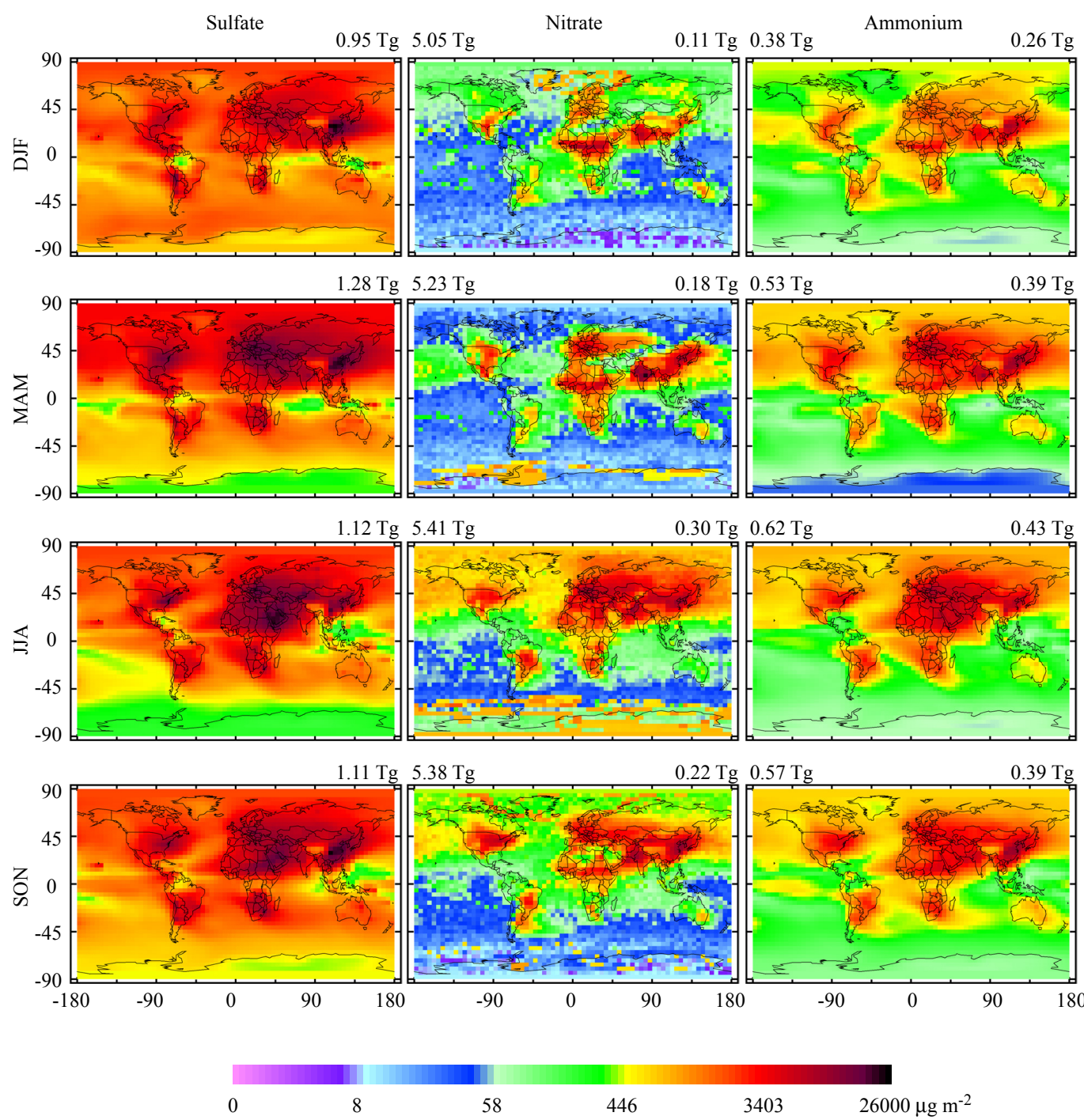

Fig. 4. Predicted seasonal mass column concentrations $\left(\mu \mathrm{g} \mathrm{m}^{-2}\right)$ of aqueous sulfate, nitrate, and ammonium. Total tropospheric burden is shown above each figure on the right $\left(\mathrm{Tg} \mathrm{SO}_{4}^{2-}, \mathrm{Tg} \mathrm{NO}_{3}^{-}\right.$, and $\left.\mathrm{Tg} \mathrm{NH}_{4}^{+}\right)$. On the left is the burden of total nitrate (gas-phase nitric acid plus aerosol nitrate) and total ammonia (gas-phase ammonia plus aerosol ammonium) $\left(\mathrm{Tg} \mathrm{NO}_{3}^{-}\right.$and $\mathrm{Tg} \mathrm{NH}+\mathrm{N}_{4}^{+}$).

calculated with Mie scattering theory. (4) Radiative transport for each longitude-latitude column is computed using the LIDORT discrete ordinate model (Spurr, 2002), first for a base case having no aerosol and then for the two global aerosol fields corresponding to the US and LS of the hysteresis loop. Regional, global, seasonal, and annual averages of $F_{L}$ and $F_{U}$ are calculated in the absence and presence of clouds.

\section{Aerosol mass concentrations and chemical composi- tion}

A global 3D model of atmospheric aerosols and chemistry (GEOS-CHEM v5.03) is employed to predict aerosol sulfate, nitrate, and ammonium mass (Park et al., 2003). Important aspects include $\mathrm{SO}_{2}, \mathrm{NO}_{\mathrm{x}}$, and $\mathrm{NH}_{3}$ emissions, gas-phase and aqueous-phase chemical transformations to form sulfate, nitrate, and ammonium aerosol, and wet and dry deposition to remove species from the atmosphere.

\subsection{Global chemical transport model}

The CTM employs assimilated meteorological observations for 1998 from the Goddard Earth Observing System (GEOS) of the NASA Global Modeling and Assimilation Office (GMAO). The model resolution is $4^{\circ}$ latitude by $5^{\circ}$ longitude with 30 pressure levels. Initial conditions are set by running the model for 12 months (1998). The model is then run a second time for 1998 to collect seasonal results of sulfate, 
nitrate, and ammonium mass concentrations from January 1998 onwards.

Sources of $\mathrm{SO}_{2}, \mathrm{NO}_{\mathrm{x}}$, and $\mathrm{NH}_{3}$ in the model are for 1998 (Park et al., 2003). Major anthropogenic sources include fossil fuel combustion and ore smelting for $\mathrm{SO}_{2}$, fuel combustion and biomass burning for $\mathrm{NO}_{\mathrm{x}}$, and agriculture and biomass burning for $\mathrm{NH}_{3}$. Major natural sources include volcanoes and oceanic phytoplankton for sulfur, lightning, soils, and wildfires for $\mathrm{NO}_{\mathrm{x}}$, and soils and wildfires for $\mathrm{NH}_{3}$. Formation of aerosol sulfate and nitrate by oxidation of $\mathrm{SO}_{2}$ and $\mathrm{NO}_{\mathrm{x}}$ takes place by gas-phase and heterogeneous oxidation processes coupled to the oxidant chemistry in the model (Park et al., 2003). Aerosol and gas losses by wet deposition include scavenging in convective updrafts/anvils and rainout/washout from large-scale precipitation (Liu et al., 2001). Dry deposition follows a standard resistance-inseries scheme based on the work of Wesely (1989) and is implemented as described by Wang et al. (1998).

\subsection{Sulfate, nitrate, and ammonium distributions}

\subsubsection{Tropospheric burdens}

Our annual average tropospheric aerosol sulfate burden is $0.37 \mathrm{Tg} \mathrm{S}\left(0.72 \mathrm{mg} \mathrm{S} \mathrm{m}^{-2}, 1.11 \mathrm{Tg} \mathrm{SO}_{4}^{2-}\right)$, which is less than the average value of $0.77 \mathrm{Tg} \mathrm{S}$ (with a standard deviation of $0.19 \mathrm{Tg} \mathrm{S}$ ) of nine previous studies (see Table 5.5 of Penner et al., 2001). A detailed explanation of this difference is given in Park et al. (2003). Our annual average tropospheric nitrate and ammonium burdens are $0.20 \mathrm{Tg} \mathrm{NO}_{3}^{-}$and $0.37 \mathrm{Tg}$ $\mathrm{NH}_{4}^{+}$, which compare to $0.13 \mathrm{Tg}$ and $0.39 \mathrm{Tg}$, respectively, in Adams et al. (1999) (base run in their Table 9). Metzger et al. (2002) report an average burden of $0.12 \mathrm{Tg} \mathrm{NO}_{3}^{-}$(inferred from their Fig. 5a).

\subsubsection{Column loadings and boundary layer concentrations}

Our seasonal and geographic distributions for BL SNA aerosol mass (Fig. 3) and column burdens (Fig. 4) agree well in form, though smaller in magnitude, with those in the literature: compare sulfate to Plate 2b of Adams et al. (1999), Fig. 4a of Chin et al. (1996), Plate 1 of Kiehl et al. (2000), Fig. 5 of Koch et al. (1999), and Figs. 4a, b of Chin et al. (2000) and compare nitrate and ammonium to Plates 3b, c of Adams et al. (1999). High sulfate concentrations over the eastern USA, Europe, and east Asia arise from $\mathrm{SO}_{2}$ emissions accompanying coal usage, while elevated concentrations over southern Africa and western South America are due to mining and smelting (Spiro et al., 1992).

Because most aerosol sulfate is in the BL (Fig. 3), geographic distributions of column burdens roughly approximate those of the BL (Fig. 4). In comparison, BL concentrations of nitrate and ammonium are less accurate predictors of column burdens. The implication is that nitrate and am- monium are mixed to a greater extent throughout the tropospheric column than sulfate.

One reason for this difference is that sulfate is nonvolatile, whereas $\mathrm{HNO}_{3}(\mathrm{~g})$ and $\mathrm{NH}_{3}(\mathrm{~g})$ are partially volatile. One of several alternative conditions must be met for $\mathrm{HNO}_{3}(\mathrm{~g})$ and $\mathrm{NH}_{3}(\mathrm{~g})$ to condense. For example, under cold conditions $\mathrm{HNO}_{3}(\mathrm{~g})$ condenses to make acidic aerosols. This mechanism is active in the upper atmosphere and in polar regions, but it does not occur at lower latitudes and altitudes because the temperature is too high. $\mathrm{HNO}_{3}(\mathrm{~g})$ also condenses when $\mathrm{NH}_{3}(\mathrm{~g})$ is in excess supply to form $\mathrm{NH}_{4} \mathrm{NO}_{3}$, except for hot summer regions. Thus, aerosol ammonium and nitrate mass are both reduced by warm temperatures and limited by insufficient $\mathrm{NH}_{3}(\mathrm{~g})$ or $\mathrm{HNO}_{3}(\mathrm{~g})$.

A second reason for greater vertical mixing of nitrate and ammonium is that the sources of $\mathrm{NO}_{\mathrm{x}}$ and $\mathrm{NH}_{3}$ are different from those of $\mathrm{SO}_{2}$. The precursor $\mathrm{NO}_{\mathrm{x}}$ emissions in the USA, Europe, and Asia are combustion by-products associated with transportation and power production. Therefore, some nitrate is roughly co-located with sulfate. However, there are also additional emissions. Biomass burning leads to nitrate in Africa, Russia, and South America. Lightning is a significant $\mathrm{NO}_{\mathrm{x}}$ source above the BL. The major ammonia emissions occur in geographic regions having intensive agriculture and livestock industry. The oceans are also a diffuse but important source. Biomass burning is approximately $10 \%$ of the emissions, but it is nevertheless important due to its temporal and geographic coincidence with $\mathrm{NO}_{\mathrm{x}}$ emissions, leading to a synergy in the formation of aerosol $\mathrm{NH}_{4} \mathrm{NO}_{3}$.

Distributions shown in Figs. 3 and 4 are explained by these emission and formation factors. For instance, elevated nitrate concentrations are predicted by ammonium concentrations, though the reverse is not always true because high ammonium also correlates with increased sulfate. USA, Europe, and east Asia have both strong $\mathrm{NO}_{\mathrm{x}}$ and $\mathrm{NH}_{3}$ emissions, and aerosol formation is apparent. However, the aerosol loading over east Asia and India does not increase proportionally to the ten-fold increase in $\mathrm{NH}_{3}$ emissions in these regions because $\mathrm{HNO}_{3}(\mathrm{~g})$ concentrations, while large, are less than $\mathrm{NH}_{3}$. These regions are thus $\mathrm{HNO}_{3}(\mathrm{~g})$ limited, whereas USA and Europe are usually $\mathrm{NH}_{3}$ limited. The latitudes above $60^{\circ} \mathrm{N}$ have elevated nitrate concentrations in the cold seasons, as do those below $60^{\circ} \mathrm{S}$ in the opposite season.

\subsection{Comparisons of model predictions to observations}

Observations of sulfate, nitrate, and ammonium concentrations worldwide are given in Table 7 of Adams et al. (1999). Other important networks are the Clean Air Status and Trends Network (CASTNET) in the United States (EPA, 1999) and the Co-operative Programme for Monitoring and Evaluation of the Long-Range Transmission of Air Pollutants in Europe (EMEP) (Hjellbrekke, 2000). Quantitative evaluations of predicted sulfate, nitrate, and ammonium 

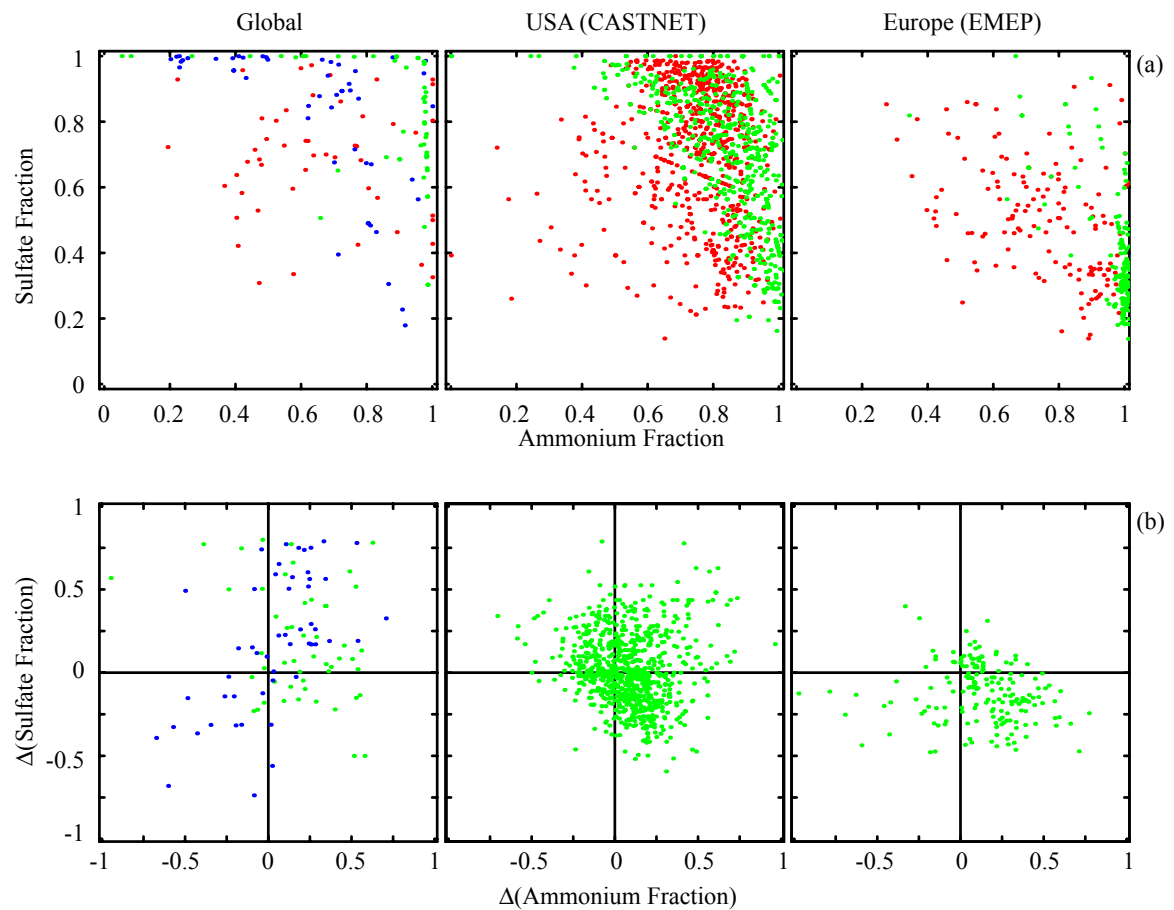

Fig. 5. Comparison of model predictions with surface measurements. (a) Comparison of predicted and measured $[X, Y]$. Red points are measurements, green points represent our model results, and blue points are taken from Adams et al. (1999). (b) Difference quantity

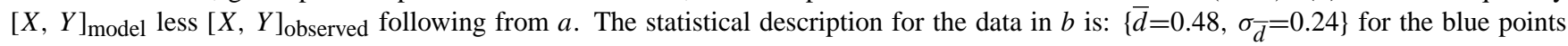
and $\{\{0.44,0.25\},\{0.26,0.16\},\{0.40,0.43\}\}$ for the green points in the three respective columns, as given by $\left(\bar{d}, \sigma_{\bar{d}}\right)$ where $\bar{d}$ is the mean distance between predictions and measurements and $\sigma_{\bar{d}}$ is the standard deviation. The data column "global" is based upon measurements reported in Table 7 of Adams et al. (1999), excluding USA and Europe.

concentrations using observations at CASTNET and EMEP sites are presented in Park et al. (2003). Therein, the model predictions generally reproduce the annual and monthly mean concentrations to within a factor of two and capture the geographic distribution well in those regions.

In contrast to the traditional scatter plots of predicted versus observed loadings (Chin et al., 1996, 2000; Koch et al., 1999; Barth et al., 2000; Park et al., 2003), the relative ratio among SNA species is the key element of our work. Phase predictions depend intensively on $X$ and $Y$ rather than extensively on sulfate, nitrate, and ammonium concentrations (Figs. 1a, b). We thus compare $[X, Y]_{\text {predicted }}$ to $[X, Y]_{\text {observed }}$ in Fig. 5. Because the measurements are limited to sulfate, nitrate, and ammonium, we assume the proton concentration is given by charge balance, allowing us to calculate $[X, Y]_{\text {observed }}$.

In the USA, there is no systematic bias between $[X, Y]_{\text {predicted }}$ and $[X, Y]_{\text {observed }}$ (Fig. 5a). The difference $\left([X, Y]_{\text {predicted }}-[X, Y]_{\text {observed }}\right.$ ) shows a clustering around the origin with no systematic bias (Fig. 5b). In Europe, however, there is a bias in predicted composition in the AN direction, viz. towards the $[1,-1]$ pole in Fig. $5 b$. There is also a bias towards AS for the global predictions for both our results and those of Adams et al. (1999). For both global and European predictions, the bias is explained by overprediction of the ammonium fraction. This result may indicate our ammonia emissions are too strong in some geographical regions and in some seasons (Park et al., 2003).

\subsection{Predicted ammonium and sulfate fractions ( $X$ and $Y$ )}

\subsubsection{Clustering of $[X, Y]$ compositions}

The $[X, Y]$ predictions are shown in Fig. 6 for each model grid box in the BL, MT, UT, and the entire troposphere. The locus of points for the entire troposphere overlaps strongly with compositions having $\% \Delta \sigma>0$ (Fig. 2). The implication is that phase transitions strongly influence the optical properties of tropospheric particles. In the BL, where most aerosol mass resides, aerosol chemical compositions cluster towards the AS pole $[1,1]$. The consequence is an increased impact for phase transitions on the optical properties of BL aerosol (cf. Figs. 2 and 6). Employing areal longitude-latitude averaging (without weighting for aerosol mass), the characteristic average composition in the $\mathrm{BL}$ is $\langle X, Y\rangle=[0.80,0.93]$.

In the MT, aerosol is more acidic. Specifically, $\langle X, Y\rangle$ $=[0.54,0.94]$ in the MT and $\Delta<X, Y>=[-0.26,+0.01]$ as 


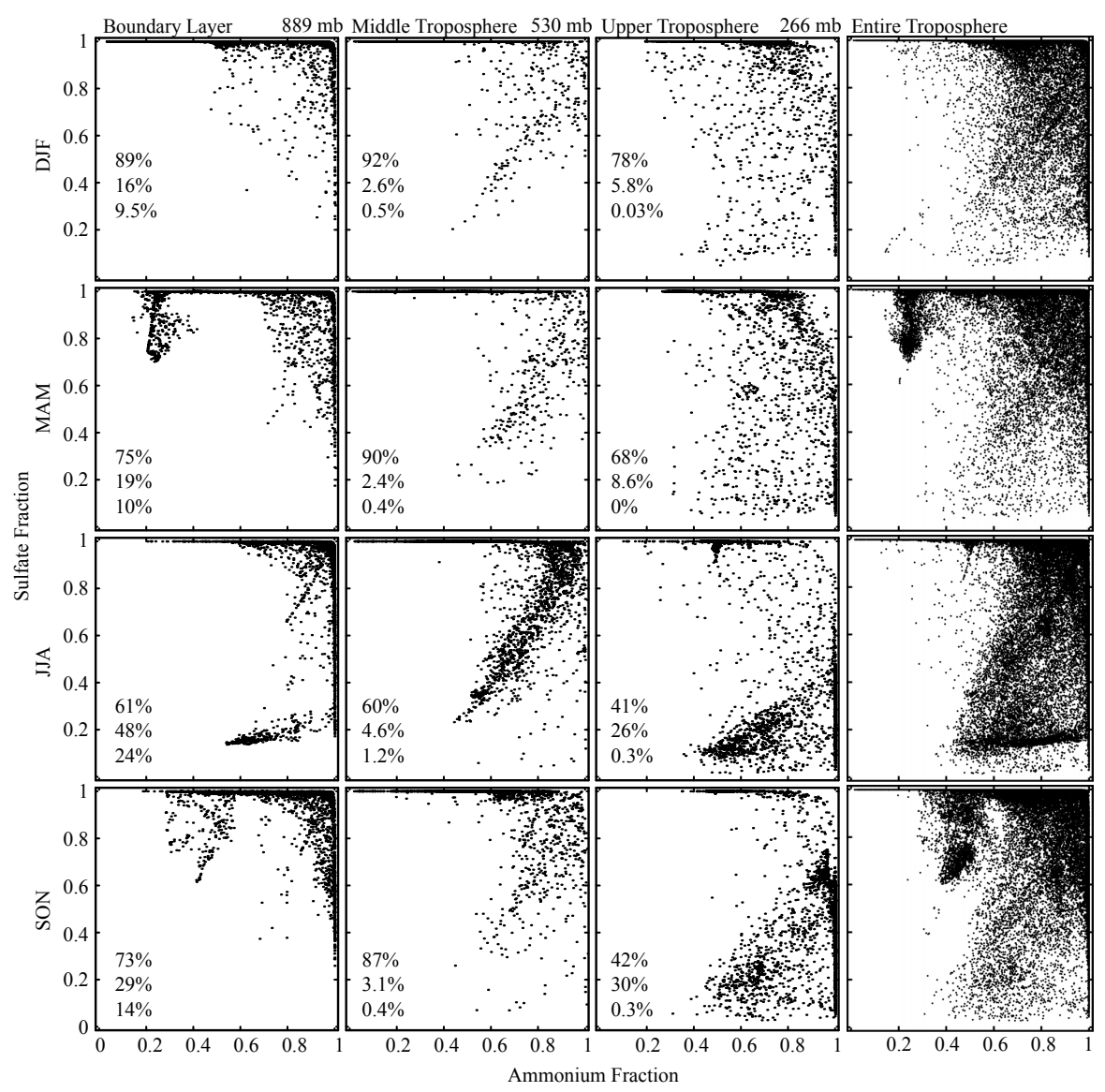

Fig. 6. Predicted aerosol chemical compositions $X, Y$ for all latitude and longitude grid boxes on fixed sigma levels corresponding to the BL, MT, and UT. Plotted on the right are the compositions for all model boxes. Inset percentages: top line, percent of grid boxes containing particles having $Y>0.95$; middle line, $X>0.95$; and bottom line, $X>0.95$ and $Y>0.95$ (i.e., compositions approaching ammonium sulfate).

compared to the BL. Increased acidification results because there are sulfur emissions from volcanoes and aircraft into the MT, while ammonia emissions are absent. Furthermore, nitrate is maintained by in situ sources such as lightning, and some of this nitrate condenses in cold regions. The consequence is a translation of the group of composition points in the direction of increased nitrate (Fig. 6). Further acidification occurs in northern hemisphere winter, partially because the shallower mixing depth in the cold season leads to inefficient vertical mixing of $\mathrm{NH}_{3}$-laden $\mathrm{BL}$ air into the MT and partially because $\mathrm{SO}_{2}$ is less efficiently oxidized in the $\mathrm{BL}$ and thus less efficiently scavenged during lifting into the MT.

Compositions in the UT are largely near the AN pole, especially in June through November. The annual average $<X, Y>$ is $[0.69,0.70]$. The perturbations compared to the BL and MT are $[-0.11,-0.23]$ and $[+0.15,-0.24]$, respectively. The increase in nitrate is explained by condensation of nitric acid at cold upper tropospheric temperatures.

\subsubsection{Global maps of $[X, Y]$ compositions}

Geographic prediction of $[X, Y]$ (Fig. 7) is necessary to model the distribution of aerosol phase. Neutralized aerosol, which is more susceptible to crystallization than acidified aerosol, occurs throughout large regions of the BL. Acidified aerosol is common in regions overlying the oceanic gyres, which are isolated from anthropogenic $\mathrm{NH}_{3}$. In Antarctica $\mathrm{NH}_{4} \mathrm{HSO}_{4}$ aerosol is prevalent, except during the cold austral winter when the aerosol is enriched in ammonium nitrate. In the northern hemisphere, there is much greater acidification in winter than in other seasons. The seasonal dependence arises because sulfate and nitrate precursor emissions vary weakly with time, having a maximum of sulfur emission in winter. In contrast, important ammonia sources have a strong positive temperature dependence and are thus maximum in summer. The imbalance of acidic and alkaline precursor emissions results in more acidified particles in winter. 

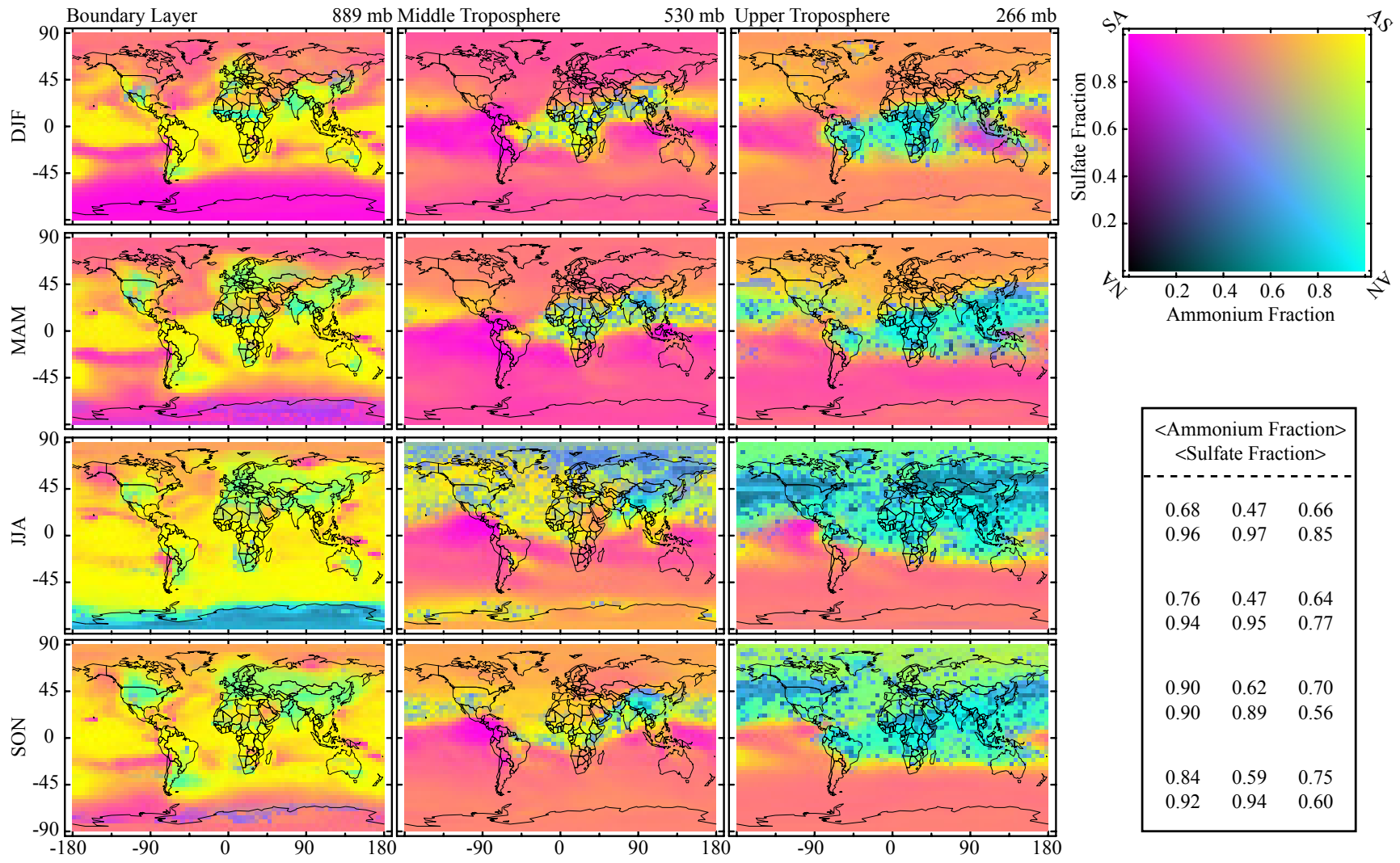

\begin{tabular}{|ccc|}
\hline \multicolumn{3}{c}{$<$ Ammonium Fraction $>$} \\
\multicolumn{2}{c}{$<$ Sulfate Fraction $>$} \\
---- & ---- & ---- \\
0.68 & 0.47 & 0.66 \\
0.96 & 0.97 & 0.85 \\
& & \\
0.76 & 0.47 & 0.64 \\
0.94 & 0.95 & 0.77 \\
& & \\
0.90 & 0.62 & 0.70 \\
0.90 & 0.89 & 0.56 \\
& & \\
0.84 & 0.59 & 0.75 \\
0.92 & 0.94 & 0.60 \\
& & \\
\end{tabular}

Fig. 7. Seasonal global chemical composition plots colored by $X-Y$ composition (see color key in upper right). The right hand side box shows a matrix of four rows and three columns, which correspond in position to the global maps in the main figure. Each entry in the matrix shows the average $X$ in the upper line and the average $Y$ in the lower line (areal-weighted).

\subsubsection{Comparison to previous studies}

Our predictions of SNA aerosol composition (Fig. 6) can be compared to those of Adams et al. (1999) (Plates 4b, c; annual average) and Metzger et al. (2002) (Fig. 3a; January and July 1997, surface layer). Adams et al. (1999) define the degree of neutralization (DON), which equals $X$, and the nitrate-to-sulfate mole ratio (NTS), which is calculable from the relation $Y=1 /(\mathrm{NTS}+1)$. Metzger et al. (2002) provide global distributions of nitrate fraction (NF), which equals $1-Y$. To compare our results to those of Adams et al. (1999) and Metzger et al. (2002), we prepare global DON, NTS, and NF plots (not shown). Our NF global plots agree in all qualitative features with those of Metzger et al. (2002), except that we predict NF approaching unity over Antarctica in the austral winter. The nitrate fraction of Metzger et al. (2002) is also consistently slightly higher than our own global predictions.

Compared to the DON global plots of Adams et al. (1999), we obtain similar general geographic patterns in the lows and highs for the BL, though our results have a consistent offset towards greater neutralization. We obtain $\Delta X=+0.17$ in the $\mathrm{BL},+0.16$ in the MT, and +0.30 in the UT. These changes are relative to base values of $X=0.63,0.38$ and 0.39 . Our predictions for a significantly more neutralized aerosol are explained by a combination of factors. First, because we use lower sulfur emissions (1998 versus 1990) but similar ammonia emissions, a more neutralized aerosol is anticipated. Second, nitric acid monthly average fields employed by Adams et al. (1999) are acknowledged by those authors as too high and thus $X$ is systemically low. Third, because of finer model vertical resolution in our study (20 versus 7 layers), vertical motion such as moist convection is represented more accurately and increased vertical transport results. As a consequence, ammonia gas is transported to the UT, and a more neutralized aerosol results.

These model differences affect the sulfate fraction to a lesser extent. We find $\Delta Y=+0.01$ in the $\mathrm{BL},+0.01$ in the MT, and -0.10 in the UT. These changes are relative to base values of $Y=0.92,0.93$ and 0.80 in Adams et al. (1999). There is thus good agreement in the predicted annual average sulfate fraction. Our NTS global plots in the BL are consistent with the high values predicted by Adams et al. (1999) over central North America, Europe, and East Asia. 


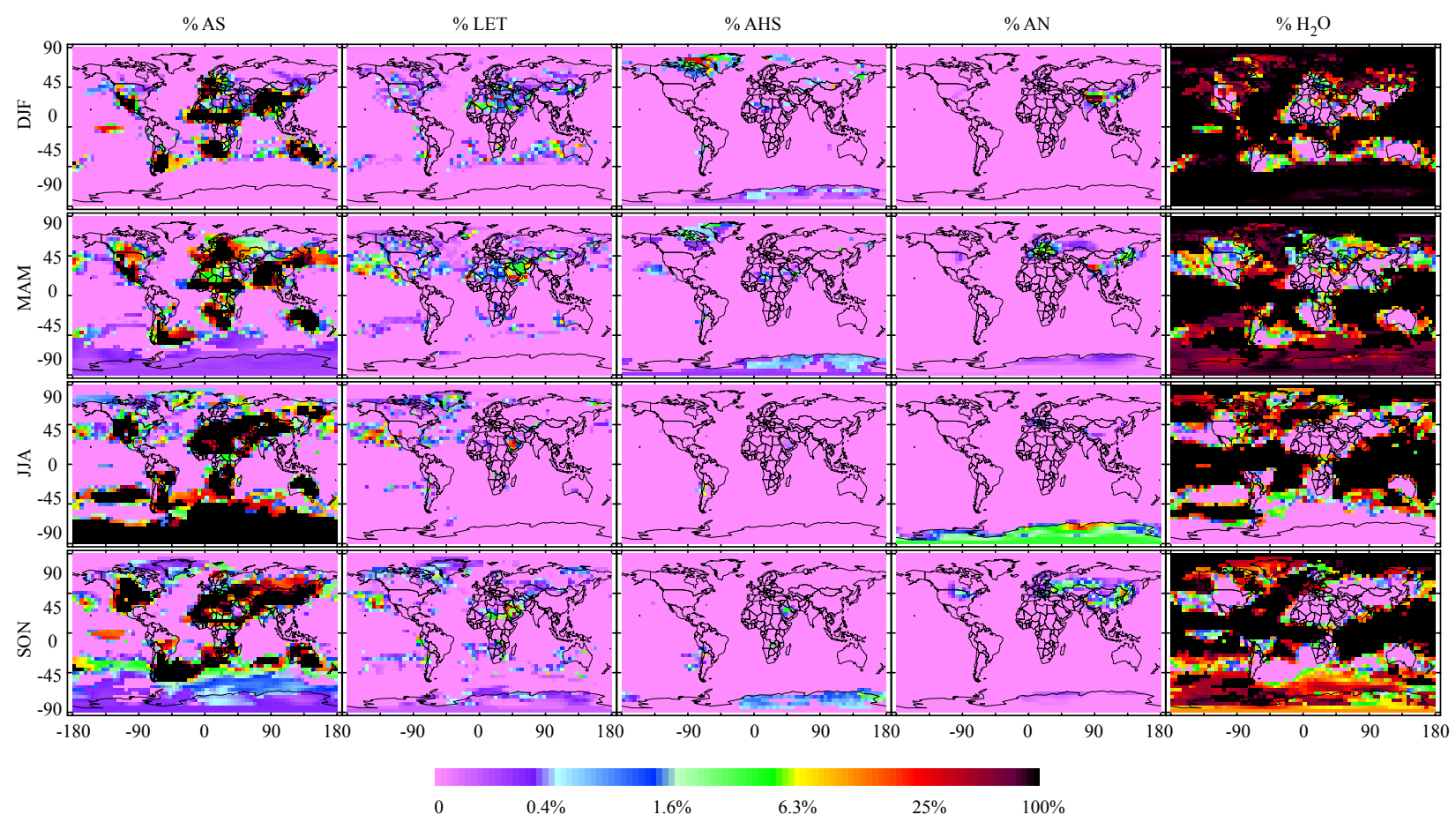

Fig. 8. Predicted partitioning of sulfate among ammonium sulfate (AS), letovicite (LET), and ammonium bisulfate (AHS), of nitrate as ammonium nitrate (AN), and of water as aqueous solution. See text for detailed description. (a) Boundary layer.

\section{Aerosol physical state}

The ISORROPIA thermodynamic model (Nenes et al., 1998) is called for a prediction of SNA aerosol physical state on the LS of the hysteresis loop: input values $\{X, Y\}$ of a grid box are predicted by the CTM, while $\{T, \mathrm{RH}\}$ are monthlyaverage GMAO values. The geographic distribution of the predicted solids formed is shown in Fig. 8 for the BL, MT, and UT. Definitions for the results shown in Fig. 8 are as follows:

$$
\begin{aligned}
& \% \mathrm{AS}=100 \times \frac{n_{\mathrm{AS}}^{L}}{n_{\mathrm{S}}^{U}}, \\
& \% \mathrm{LET}=100 \times \frac{2 n_{\mathrm{LET}}^{L}}{n_{\mathrm{S}}^{U}}, \\
& \% \mathrm{AHS}=100 \times \frac{n_{\mathrm{AHS}}^{L}}{n_{\mathrm{S}}^{U}}, \\
& \% \mathrm{AN}=100 \times \frac{n_{\mathrm{AN}}^{L}}{n_{\mathrm{N}}^{U}}, \\
& \% \mathrm{H}_{2} \mathrm{O}=100 \times \frac{n_{\mathrm{H}_{2} \mathrm{O}}^{L}}{n_{\mathrm{H}_{2} \mathrm{O}}^{U}},
\end{aligned}
$$

where $n$ is moles. Subscripts are ammonium sulfate (AS), letovicite (LET), ammonium bisulfate (AHS), ammonium nitrate $(\mathrm{AN})$, particle water $\left(\mathrm{H}_{2} \mathrm{O}\right)$, aqueous sulfate $(\mathrm{S})$, and aqueous nitrate $(\mathrm{N})$. Superscripts $U$ and $L$ indicate US and
LS of the hysteresis loop. (ISORROPIA's database contains only 4 of 7 SNA solids and thus differs from the AIM model (Clegg et al., 1998), employed by us to prepare Figs. 1 and 2. An intercomparison of thermodynamic models is provided by Zhang et al., 2000.)

When $\% \mathrm{H}_{2} \mathrm{O}=100$, US and LS aerosol water is identical: aqueous particles are not metastable and no solids form. When $\% \mathrm{H}_{2} \mathrm{O}=0$, particles on the LS crystallize entirely and no residual aqueous fraction remains. When $0<\% \mathrm{H}_{2} \mathrm{O}<100 \%$, particles partially crystallize and a residual aqueous layer remains. Sulfate partitioning into solid phases is given by \%AS, \%LET, and \%AHS. Their sum is $100 \%$ when no particle water remains $\left(\% \mathrm{H}_{2} \mathrm{O}=0\right)$. The fraction of US aqueous nitrate crystallizing on the LS into ammonium nitrate is \% AN, whereas another fraction volatilizes as $\mathrm{NH}_{3}(\mathrm{~g})$ and $\mathrm{HNO}_{3}(\mathrm{~g})$. When no particle water remains, $\% \mathrm{AN}$ is generally less than $100 \%$ due to volatilization.

For the complete atmospheric burden (Sect. 2.2.1), the global annual average sulfate mass budget on the LS of the hysteresis loop is $40 \%$ solid AS, $12 \%$ LET, $11 \%$ AHS, and $37 \%$ aqueous. As compared to US aerosol nitrate mass, the LS nitrate mass budget is $26 \%$ solid AN, $67 \%$ nitric acid release due to increased volatility, and $7 \%$ aqueous. As an annual tropospheric average on the US, $3.8 \%$ of nitrate is found in the aerosol phase and $96.2 \%$ in the gas-phase. The LS ammonium budget is $45 \%$ solid AS, $10 \%$ LET, $6 \%$ AHS, $4 \%$ AN, $7 \%$ ammonia release due to increased volatility, and 


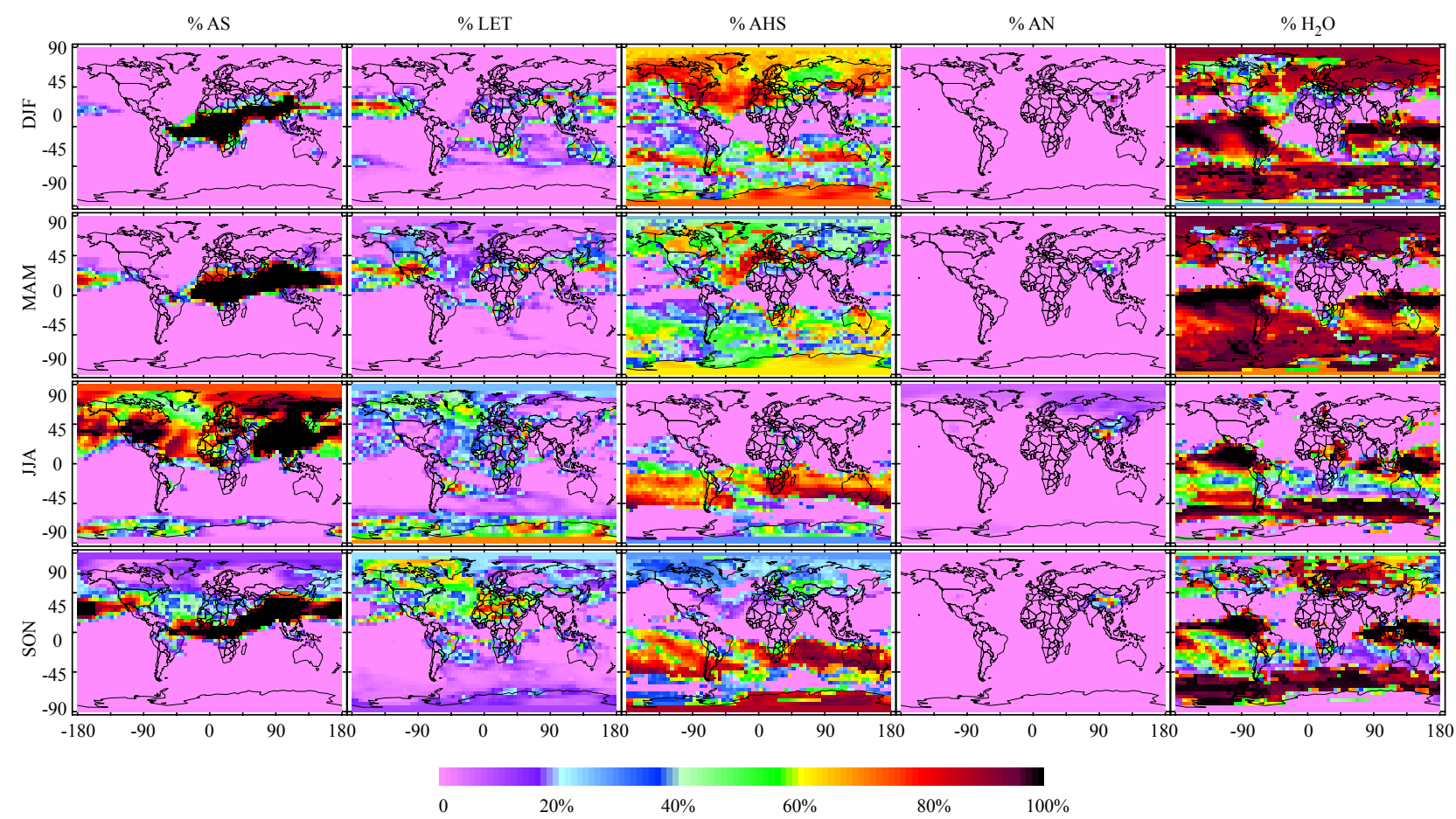

Fig. 8. Continued. (b) Middle troposphere.

$28 \%$ aqueous. LS aerosol water mass partitions as $22 \%$ effloresced to the gas-phase and $78 \%$ remaining as aerosol mass. (The US aerosol water burden is $1.12 \mathrm{Tg}$.)

3.1 Geographic, seasonal, and altitude dependencies of solid formation

Geographic regions having $\% \mathrm{H}_{2} \mathrm{O}<100$ show where solid formation is predicted on the LS of the hysteresis loop (Fig. 8). Explaining why solids form in some locations but not in others requires simultaneous consideration of $[X, Y]$, $\mathrm{RH}$, and temperature $T$ (Figs. 1a, b). Increased neutralization, drying, and cooling are factors favoring crystallization, each of which being a necessary if not sufficient condition.

\subsubsection{Boundary layer}

The expectation value for the global annual average LS water content in the $\mathrm{BL}$ is $<\% \mathrm{H}_{2} \mathrm{O}>=71 \%$ of the US value. The expectation value is calculated with areal longitude-latitude weighting (without weighting for the aerosol mass loading in each grid box). Compared to the oceans, the continents favor water loss and hence crystallization (Fig. 8a). Because neutralization is observed over wide regions of both the continents and the oceans (Fig. 7), neutralization alone is not a sufficient explanation of preferential crystallization over the continents. Rather, solid formation over the continents arises from lower RH, as compared to over the ocean. Figure 8a further shows crystallization in austral winter over Antarctica.
Solid formation is attributed there both to the neutralization (Fig. 7) and cold temperatures.

When solids do form in the BL, AS is the principal form (Fig. 8a), as expected from the neutralized US aqueous aerosol (Fig. 7). Specifically, the expectation values of global annual average BL sulfate aerosol mass with areal weighting are $28 \%$ solid AS, $4 \%$ LET, $1 \%$ AHS, and $67 \%$ aqueous. By comparison, when the aerosol mass loading of each grid box is included in the average, the BL partitioning is $43 \%$ solid AS, $7 \%$ LET, $1 \%$ AHS, and $49 \%$ aqueous. LET and AHS are found in polar regions; the US aqueous aerosol is more acidic in these regions. Letovicite is common in equatorial Africa. Particles composed of all three sulfate solids are predicted in $\mathrm{SON}$ in the Antarctic.

Solid AN is predicted for cold regions, including the poles and the northern winter hemisphere. In other regions such as warm equatorial Africa, for dry aerosol, AN entirely evaporates. This conclusion is reached by noting geographic regions having both $\% \mathrm{H}_{2} \mathrm{O}=0$ and $\% \mathrm{AN}=0$ in Fig. $8 \mathrm{a}$ while simultaneously having significant US aerosol nitrate shown in Fig. 3. When weighted by aerosol mass loading of each grid box, annual average BL nitrate partitions as $15 \% \mathrm{AN}, 72 \%$ volatilized, and $13 \%$ aqueous. A seasonal dependence is predicted for \% AN. In JJA, \%AN is close to zero everywhere outside of Antarctica, whereas in DJF, \%AN $>0$ in most of North America and Asia. Solid AN is significant in Europe in MAM and SON. 


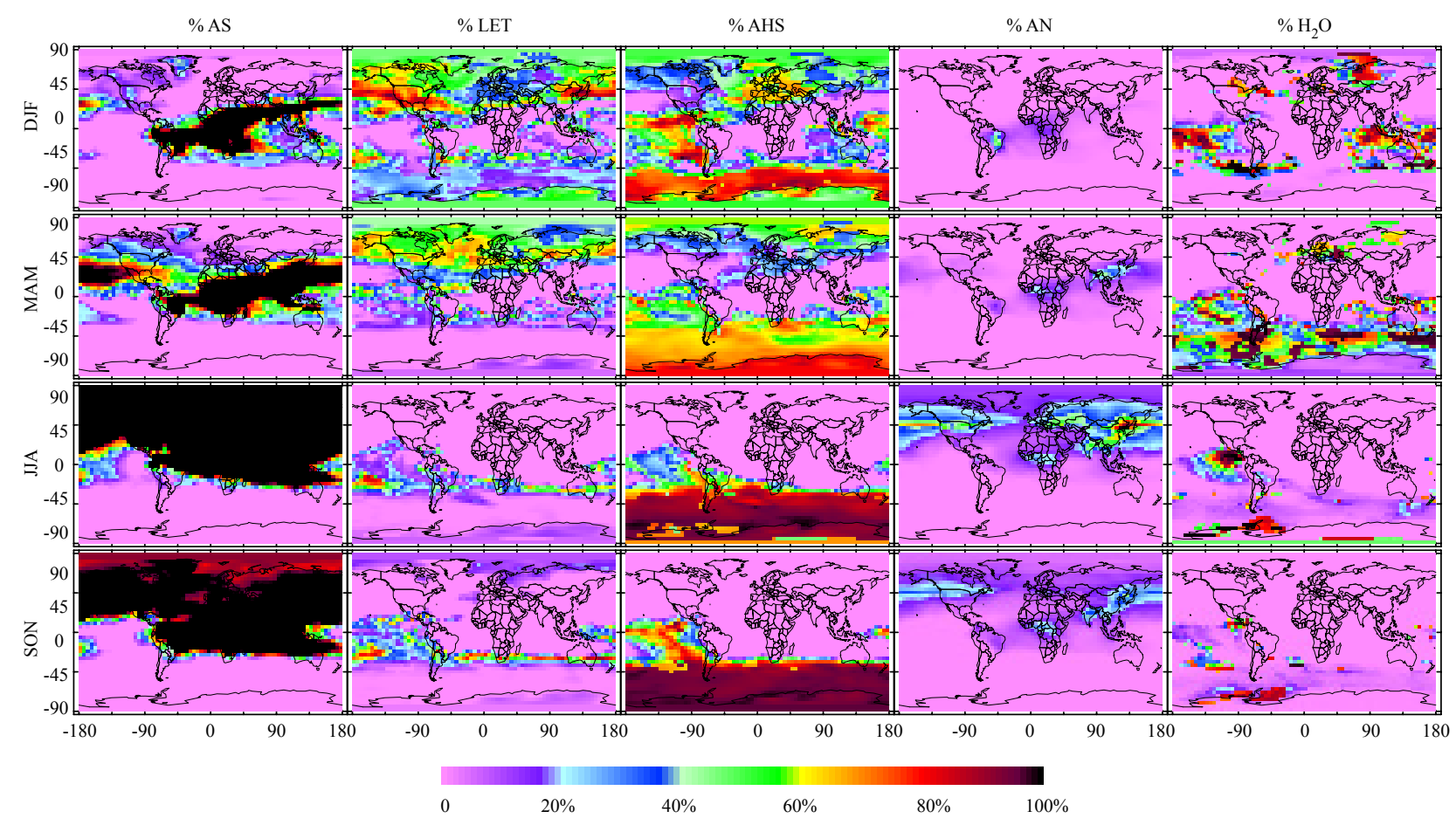

Fig. 8. Continued. (c) Upper troposphere.

\subsubsection{Middle troposphere}

Compared to the BL, the geographic coverage of predicted crystallization increases in the MT (Fig. 8b). $<\% \mathrm{H}_{2} \mathrm{O}>$ drops from $71 \%$ in the BL to $49 \%$ in the MT. Cooling at higher altitude is the principal driver in the overall increase in crystallization (cf. Figs. 1a, b), which leads to a further significant difference in the role of neutralization as a modulator of the patterns of crystallization in the BL and MT. In the BL, because most of the aerosol is neutralized (Fig. 7) and thus of appropriate chemical composition to crystallize, the main modulator is RH. Above the BL, due to low $T$ and $\mathrm{RH}$, many air parcels provide favorable conditions for crystallization; however, the aerosol acidity has greater variability in the MT and thus neutralized aerosol chemical composition modulates crystallization (cf. Figs. 7 and 8b).

Predicted phase partitioning in the MT is shown in Fig. 8b. All three sulfate solids occur in significant amounts, their relative ratios depending upon season and location. The global annual average areal-weighted partitioning is $21 \%$ solid AS, $12 \%$ LET, $31 \%$ AHS, and $36 \%$ aqueous. Although AHS is most significant on an annual basis, AS has the greatest geographic coverage in JJA. Comparisons of $\% \mathrm{H}_{2} \mathrm{O}$ and $\% \mathrm{AS}$ show that formation of AS correlates with loss of all particulate water. In contrast, when AHS predominates, residual particulate aqueous phase remains.

Ammonium nitrate has global coverage in the MT only in JJA. The causative agent is an increase in neutralization and nitrate content in this season (Fig. 7). Ammonium ni- trate is also significant near India due to strong emissions and uplifting. AN is not predicted in the BL over India in JJA (Fig. 8a), yet it is present in the MT (Fig. 8b). Figure 7 shows little change in extent of neutralization. The explanation is the drop in temperature with altitude. When weighted by aerosol mass loading of each grid box, annual average MT nitrate partitions as $17 \% \mathrm{AN}, 82 \% \mathrm{AN}$ volatilized, and $1 \%$ aqueous.

\subsubsection{Upper troposphere}

Predicted phase partitioning in the UT is shown in Fig. 8c. Unlike the MT and in stark contrast to the BL, complete crystallization prevails in most locations. The global annual average $<\% \mathrm{H}_{2} \mathrm{O}>$ is $12 \%$. The driver is cold temperature. An exception is a decrease in crystallization in MAM in the southern hemisphere; this season and location are more acidified than all others (Fig. 7).

The global annual average areal-weighted partitioning is $45 \%$ solid AS, $16 \%$ LET, $30 \%$ AHS, and $9 \%$ aqueous. However, partitioning in the period June through November is distinct from that of December through May. In the JuneNovember period, AS and AN dominate the northern hemisphere while AHS is the prevalent phase in the southern hemisphere. In the December-May period, LET and AHS are dominant, except for the equatorial region where AS is found.

Throughout the year, AN coincides closely with AS. The explanation is in the precursor aqueous chemical composition: significant nitrate content is associated with 


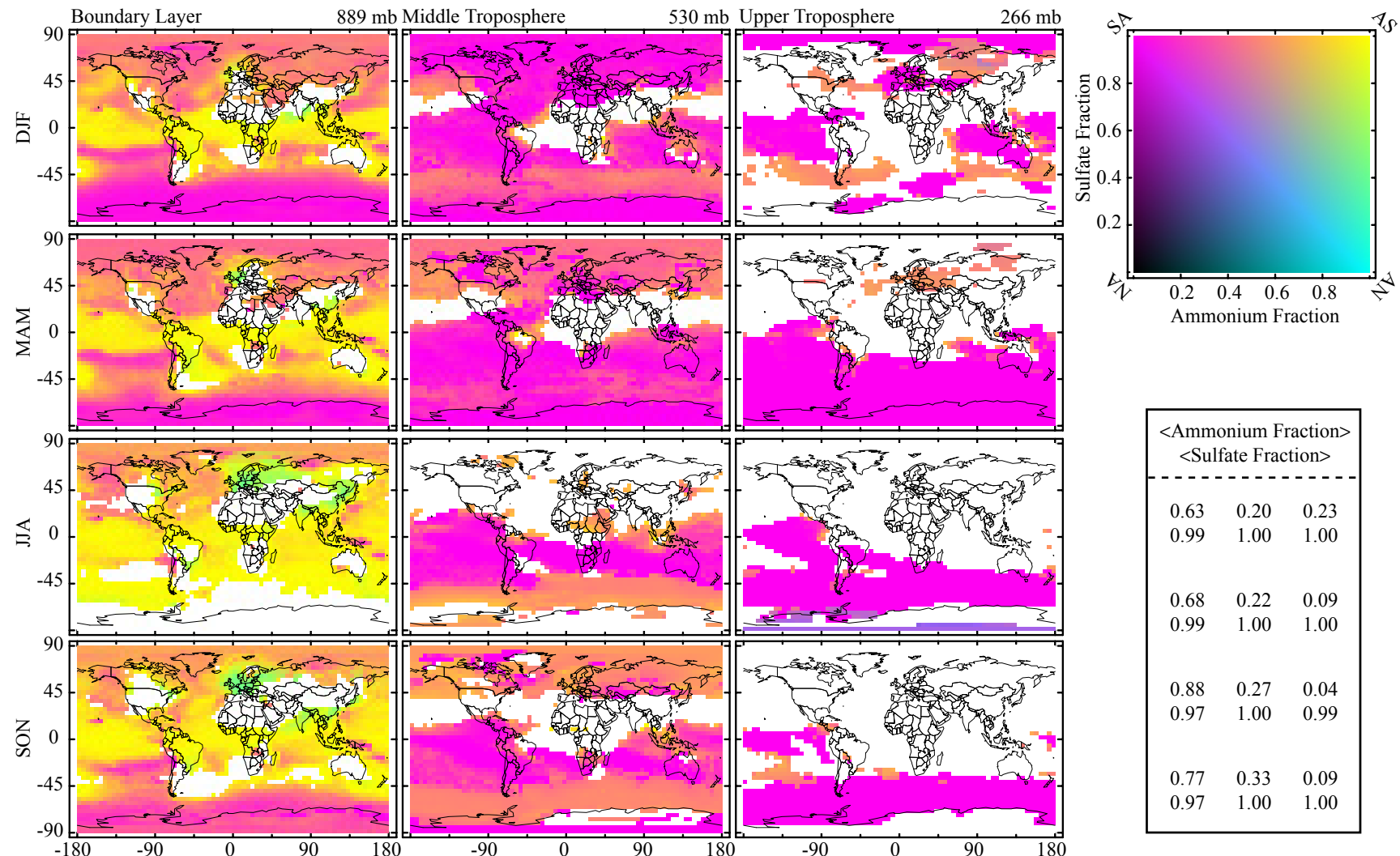

Fig. 9. Predicted aerosol chemical compositions $X, Y$ of residual aqueous content after possible crystallization of solids. See further description in caption to Fig. 6. White areas indicate complete crystallization and thus absence of residual aqueous phase.

neutralization and hence ammonium sulfate (Fig. 7). The same is also true of the BL and MT, and inspection of Figs. 8a, b shows AS and AN solids occur together. However, at warmer temperatures in the LT, AN volatilizes on the LS of the hysteresis loop and thus \%AN solid is low. In contrast, \%AN solid approaches $40 \%$ in the UT as an areal average. When weighted by aerosol mass loading of each grid box, annual average UT nitrate partitions as $66 \%$ AN, $34 \%$ volatilization, and $0.2 \%$ aqueous.

\subsubsection{Comparison to previous studies}

Employing fields of ammonium-to-sulfate ratios from Adams et al. (1999), Colberg et al. (2003) predict AS, LET, and AHS global distributions in the MT in July (Figs. 6 and 7 in Colberg et al., 2003). In Colberg et al. (2003), the aerosol is restricted to aqueous $\mathrm{SO}_{4}^{2-}-\mathrm{NH}_{4}^{+}-\mathrm{H}^{+}-\mathrm{H}_{2} \mathrm{O}$, compared to our work including $\mathrm{NO}_{3}^{-}$. Thus Colberg et al. (2003) neither predict $\mathrm{AN}$ formation nor include the effect of nitrate on sulfate solid formation; their study lies on the $[X, 1]$ axis of Figs. 1a, b. These differences notwithstanding, the results of Colberg et al. (2003) agree with our predicted $\% \mathrm{H}_{2} \mathrm{O}$ (JJA, Fig. 8b), showing that solid formation is prevalent in the northern hemisphere, while aqueous aerosol is found in the equatorial region outside of Africa.
Figures 6 and 7 of Colberg et al. (2003) assume the aerosol follows the US of the hysteresis loop. Apart from these two figures, the bulk of the Colberg et al. (2003) paper comprises a trajectory analysis to account for the hysteresis loop, and their results then lie partway between our limiting cases of US versus LS hysteresis behavior. We nevertheless compare Fig. 12 of Colberg et al. (2003) to our JJA Fig. 8b for predictions of \%AS, \%LET, and \%AHS. The special case analyzed in Fig. 12 of Colberg et al. (2003) is the assumption that LET acts a good heterogeneous nucleus for AHS formation. This particular assumption facilitates comparisons with our LS treatment. The predictions of the two models agree that AHS regions are dominant in a band through the southern hemisphere. Letovicite is also predicted for the northern hemisphere. However, we predict extensive regions of AS, which Colberg et al. (2003) do not. As discussed earlier, a reasonable explanation is that we predict a more neutralized tropospheric aerosol than Adams et al. (1999), upon which Colberg et al. (2003) base their results.

\subsection{Chemical composition of residual aqueous layers}

The aqueous chemical compositions of particles following the LS of the hysteresis loop (Fig. 9) are described by three cases. (1) White regions, indicating complete 

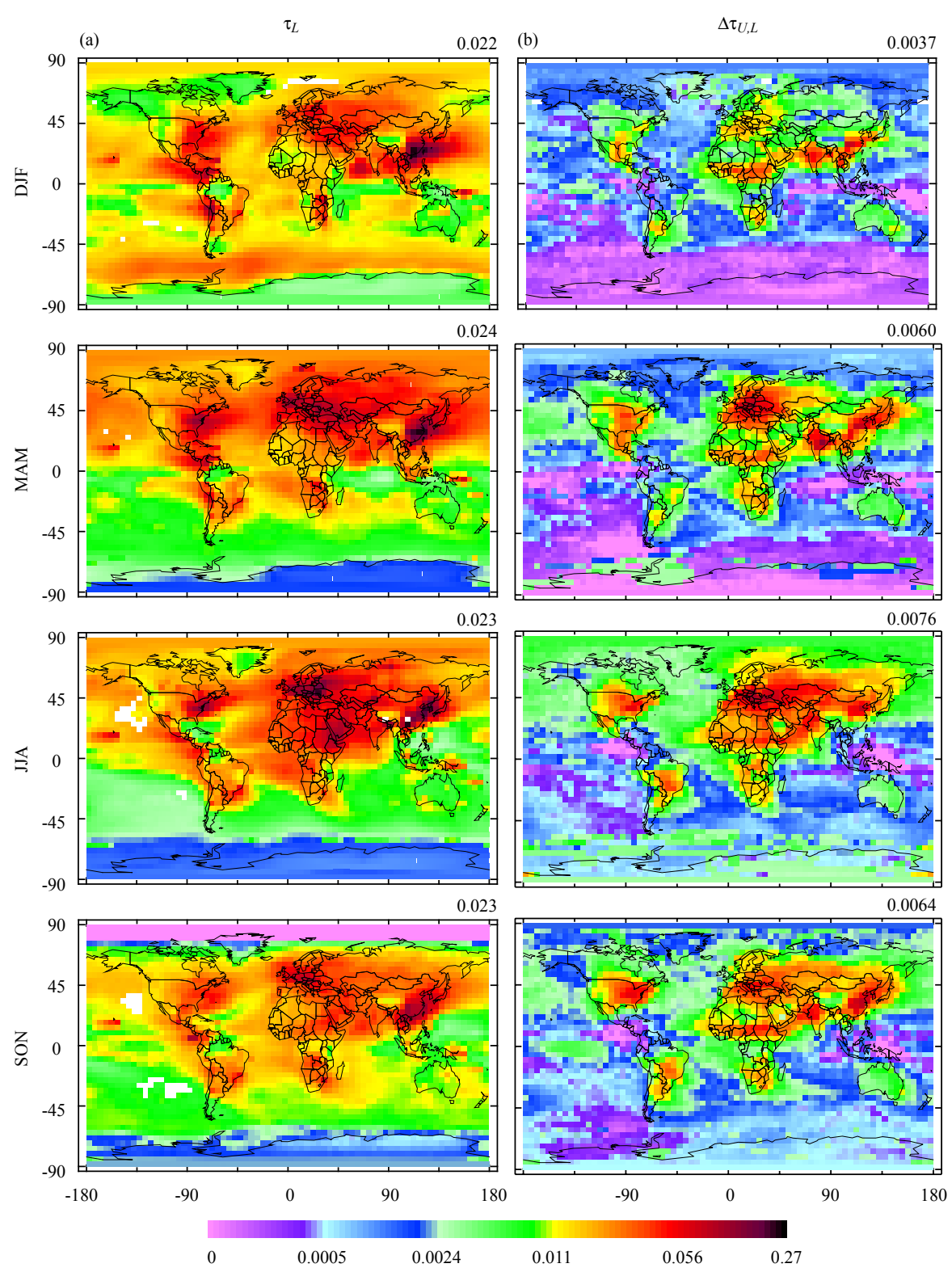

Fig. 10. (a) Seasonal column optical depth $\tau_{L}$ of SNA aerosol along the LS of the hysteresis loop at $20000 \mathrm{~cm}^{-1}(500 \mathrm{~nm})$. (b) Change in column optical depth $\Delta \tau_{U, L}$ when aerosol follows the US of the hysteresis loop. Global average values are shown to right above the figures. The dry mode diameter of the aerosol in each grid box is $82 \mathrm{~nm}$.

crystallization and no residual aqueous composition, have $\% \mathrm{H}_{2} \mathrm{O}=0$ (Fig. 8). (There is water chemisorbed to salt surfaces at atmospheric RH (Peters and Ewing, 1997; Finlayson-Pitts and Hemminger, 2000).) (2) When no crystallization is predicted, regions of Fig. 9 are identical to those of Fig. 7. These regions are especially prevalent in the BL over oceans. (3) The remaining regions show $[X, Y]$ of the residual aqueous phase when particles partially crystallize. Except for special cases when the aqueous phase and the solid have the same chemical composition, an initial aqueous composition $[X, Y]$ (Fig. 7) is altered when solids form
(Fig. 8) and remove material from the aqueous phase. In two-component systems, the lever rule provides the relationship between the amount of solid crystallized and the residual composition of the liquid phase (Hillert, 1998).

The LS aqueous residual of partially crystallized SNA particles is more acidic and sulfate-enriched than the US aqueous counterpart (cf. Figs. 7 and 9). Because the precipitating SNA solids are neutral, the residual aqueous phase must increase in acidity $(\Delta X<0)$. Increasing acidity in turn drives $\mathrm{HNO}_{3}(\mathrm{~g})$ volatilization, which leads to sulfate enrichment as given by $\Delta Y>0$. Specifically, $\Delta<X, Y>=$ 
Table 2. Particle optical properties in this study compared to the literature. Shown are global annual average properties, including optical depth and the effective mass scattering efficiency (optical depth divided by sulfate loading). Also shown are specific particle properties, including the mass scattering efficiency of crystalline ammonium sulfate particles and of aqueous ammonium sulfate particles at equilibrium with $80 \% \mathrm{RH}$. The entry in bold shows our calculation condition most closely approximating the usual treatment in literature. (The mode diameter is the geometric mean diameter. In our study, the Hatch-Choate relation between effective and geometric mean diameters is not perfect because we employ a discrete rather than a continuous size distribution, Hinds, 1999).

\begin{tabular}{|c|c|c|c|c|c|c|c|c|}
\hline & & $\begin{array}{l}\text { Wavelength } \\
\qquad(\mathrm{nm})\end{array}$ & $\begin{array}{l}\text { Mode diameter } \\
\text { (nm) }\end{array}$ & $\begin{array}{l}\text { Effective dry } \\
\text { diameter(nm) }\end{array}$ & $\begin{array}{c}\text { Annual global average } \\
\text { optical depth }\end{array}$ & $\begin{array}{l}\text { Annual global average } \beta \\
\qquad\left(\mathrm{m}^{2} \mathrm{~g}^{-1}\right)\end{array}$ & $\begin{array}{c}\beta(\text { dry }) \\
\left(\mathrm{m}^{2} \mathrm{~g}^{-1}\right)\end{array}$ & $\begin{array}{l}\beta(80 \%) \\
\left(\mathrm{m}^{2} \mathrm{~g}^{-1}\right)\end{array}$ \\
\hline \multicolumn{9}{|l|}{ Our study } \\
\hline Hysteresis & Nitrate? & & & & & & & \\
\hline Lower & Yes & 500 & 82 & 247 & 0.023 & 10.7 & $\mathrm{n} / \mathrm{a}$ & $\mathrm{n} / \mathrm{a}$ \\
\hline Lower & Yes & 500 & 164 & 493 & 0.021 & 9.7 & $\mathrm{n} / \mathrm{a}$ & $\mathrm{n} / \mathrm{a}$ \\
\hline Upper & Yes & 500 & 164 & 493 & 0.026 & 12.1 & $\mathrm{n} / \mathrm{a}$ & $\mathrm{n} / \mathrm{a}$ \\
\hline Upper & Yes & 500 & 246 & 740 & 0.019 & 8.8 & $\mathrm{n} / \mathrm{a}$ & $\mathrm{n} / \mathrm{a}$ \\
\hline Lower & No & 500 & 82 & 247 & 0.020 & 9.2 & 4.6 & 4.6 \\
\hline Lower & No & 500 & 164 & 493 & 0.018 & 8.5 & 5.2 & 5.2 \\
\hline Lower & No & 500 & 246 & 740 & 0.014 & 6.5 & 4.3 & 4.3 \\
\hline \multicolumn{9}{|l|}{ Literature } \\
\hline Boucher and Anderson (1995) & 589 & 56 & 186 & & & 3.1 & 8.9 & \\
\hline van Dorland et al. (1997) & $250-680$ & 42 & & & & 4.0 & 9.4 & \\
\hline Koch et al. (1999) & 550 & & 500 & 0.027 & 8.4 & 5.0 & 10.0 & \\
\hline Kiehl et al. (2000) & $350-700$ & 100 & 332 & & & 3.2 & 11.5 & \\
\hline Adams et al. (2001) & & 100 & 332 & & & 3.6 & 8.0 & \\
\hline Chin et al. (2002) & 500 & 89 & 312 & 0.040 & 11 & 4.0 & 16.0 & \\
\hline
\end{tabular}

$\{[-0.06,+0.05],[-0.43,+0.30],[-0.44,+0.06]\}$ on the LS of the hysteresis loop (Fig. 9) for the BL, MT, and UT, respectively, which compare to annual average base values on the US (Fig. 7) of $<X, Y>=\{[0.80,0.93],[0.69,0.70],[0.54,0.94]\}$.

In the MT and UT, aqueous nitrate is predicted to volatilize entirely on the LS (i.e., $<Y>=1.00$ ). The LS composition in UT in JJA is particularly extreme; the increased acidity yields nearly pure sulfuric acid as $\langle X, Y\rangle=[0.03,1.00]$ in the residual aqueous phase. The increased acidity accompanying partial crystallization indicates proton-catalyzed aqueous phase reactions proceed more rapidly throughout the MT and UT than anticipated by assuming particles follow the US of the hysteresis loop.

\section{Aerosol optical properties}

Our modeling work in Sect. 2 and Sect. 3 provides predictions of aerosol mass and phase; prediction of optical properties requires the additional input of particle diameter. Three scenarios are considered: particle size distributions having $82 \mathrm{~nm}, 164 \mathrm{~nm}$, and $246 \mathrm{~nm}$ dry mode diameters (geometric mean diameter). The geometric standard deviation is 2.0. A database is calculated for mass scattering efficiency $\left(\beta\left(\mathrm{m}^{2}\right.\right.$ $\left.\mathrm{g}^{-1}\right)$ ), single scatter albedo $(\omega)$, and asymmetry parameter $(g)$. With assumptions discussed below, $\{\beta, \omega, g\}$ depend only on dry mode diameter (82, 164, and $246 \mathrm{~nm}$ ) and, if aqueous, on increased diameter because of $\mathrm{H}_{2} \mathrm{O}, \mathrm{NH}_{3}$, and $\mathrm{HNO}_{3}$ condensation. For a predicted particulate dry mass loading $L\left(\mathrm{~g} \mathrm{~m}^{-3}\right)$ of a grid box and a $\beta$ value dependent on dry mode diameter and hygroscopic growth, the scattering efficiency $\left(\sigma\left(\mathrm{km}^{-1}\right)\right)$ is calculated as follows:

$\sigma_{\text {aerosol }}\left(\mathrm{km}^{-1}\right)=10^{3} \beta\left(\frac{\mathrm{m}^{2}}{\mathrm{~g}}\right) L\left(\frac{\mathrm{g} \cdot \text { particle }}{\mathrm{m}^{3} \cdot \text { air }}\right)$.

Application of Eq. (3) then yields a field of $\{\sigma, \omega, g\}$ predicted for each grid point of the model, with different results for particles on the two sides of the hysteresis loop. Summing $\sigma$ over altitude yields total column properties. Figure 10 shows the predicted LS column optical depth $\tau_{L}$ at $500 \mathrm{~nm}$ for the scenario of $82 \mathrm{~nm}$ dry mode diameter particles. Except for specific sensitivity studies on the effects of particle diameter (viz. Tables 2 and 4), the $82 \mathrm{~nm}$ dry mode is employed throughout our calculations. 
Table 3. Annual average irradiance differences (i.e., "forcings") for individual spectral bands and the combined spectrum for downwelling bottom-of-the-atmosphere (BOA $\downarrow$ ), upwelling bottom-of-the-atmosphere (BOA $\uparrow$ ), and upwelling top-of-the-atmosphere (TOA $\uparrow$ ). Differences between the LS of the hysteresis loop and the base case $\left(F_{L}\right)$, the US of the hysteresis loop and the base case $\left(F_{U}\right)$, and the percent difference between of the US as compared to the LS $\left(\Delta F_{U, L}\right)$ are given for BOA and TOA. The base case is a Rayleigh atmosphere without aerosol. For TOA the difference values are taken as lower/upper less base (i.e., reverse of BOA) to be consistent with the usual labels in the literature of "positive" and "negative" forcing. The annual global average solar intensity and the percent of solar intensity are given for each band. Calculations are for particles of $82 \mathrm{~nm}$ dry mode diameter in full sky without clouds.

\begin{tabular}{cccccccccccc}
\hline & & \multicolumn{4}{c}{$\mathrm{BOA} \downarrow\left(\mathrm{W} \mathrm{m}^{-2}\right)$} & \multicolumn{3}{c}{$\mathrm{BOA} \uparrow\left(\mathrm{Wm}^{-2}\right)$} & \multicolumn{3}{c}{$\mathrm{TOA} \uparrow\left(\mathrm{Wm} \mathrm{m}^{-2}\right)$} \\
Wavenumber $\left(\mathrm{cm}^{-1}\right)$ & $\mathrm{TOA} \downarrow\left(\mathrm{W} \mathrm{m}^{-2}\right)$ & $\% \mathrm{TOA} \downarrow$ & $F_{L}$ & $F_{U}$ & $\% \Delta F_{U, L}$ & $F_{L}$ & $F_{U}$ & $\% \Delta F_{U, L}$ & $F_{L}$ & $F_{U}$ & $\% \Delta F_{U, L}$ \\
\hline $31250-32260$ & 1.9 & 0.6 & -0.002 & -0.003 & 26 & $-2.0(-4)$ & $-2.41(-4)$ & 21 & $-9.2(-4)$ & $-1.16(-3)$ & 27 \\
$25000-31250$ & 20.5 & 6.0 & -0.056 & -0.069 & 24 & -0.005 & -0.006 & 19 & -0.050 & -0.063 & 24 \\
$14280-25000$ & 133.3 & 39.0 & -0.511 & -0.640 & 25 & -0.043 & -0.053 & 23 & -0.454 & -0.570 & 25 \\
$8200-14280$ & 109.2 & 32.0 & -0.226 & -0.276 & 22 & -0.025 & -0.033 & 30 & -0.211 & -0.256 & 21 \\
$4400-8200$ & 56.4 & 16.5 & -0.037 & -0.044 & 19 & -0.003 & -0.004 & 33 & -0.036 & -0.040 & 18 \\
$\mathbf{4 4 0 0 - 3 2 2 6 0}$ & $\mathbf{3 2 1 . 4}$ & $\mathbf{9 4 . 0}$ & $-\mathbf{0 . 8 3 1}$ & $-\mathbf{1 . 0 3 1}$ & $\mathbf{2 4}$ & $\mathbf{- 0 . 0 7 7}$ & $-\mathbf{0 . 0 9 7}$ & $\mathbf{2 6}$ & $-\mathbf{0 . 7 5 0}$ & $-\mathbf{0 . 9 3 0}$ & $\mathbf{2 4}$ \\
\hline
\end{tabular}

\subsection{Mie theory calculations}

Optical properties are calculated using Mie scattering theory for a spherical particle (van de Hulst, 1957; Bohren and Huffmann, 1983; Seinfeld and Pandis, 1998; Han and Martin, 2001; Hung and Martin, 2002). Table 1 shows spectral windows and refractive indices chosen for our study (Chou and Suarez, 1999). Eleven particle size bins and a log-normal distribution are employed (Seinfeld and Pandis, 1998). The effect of RH is to increase bin diameters due to hygroscopic growth. Optical properties of each bin are calculated with Mie theory, and the aerosol optical properties $\{\beta, \omega, g\}$ are calculated from a weighted average of the bin properties (Cess, 1985; Briegleb, 1992).

There are several simplifications in our treatment. Spherical particles of average refractive index are assumed. We omit a treatment of the variation of refractive indices with chemical content $[X, Y]$, extent of hydration, or crystalline phase. Any effects of change in particle shape or details of the internal structure of the particle upon crystallization are also neglected. Thus, calculated optical properties depend only on particle diameter, which in turn depends only on mode diameter and, if aqueous, on the hygroscopic growth factor.

Calculation of $\beta$ depends on particulate mass density, $\rho$ $\left(\mathrm{g} \mathrm{cm}^{-3}\right)$. Partial mass densities of $\rho=1.75$ for ions and of $\rho=1.0$ for water are assumed. The mass density of the particle is calculated as the weighted average of the ion and water content of the particle. The resulting $\beta$ is per mass of particle. Employing the mass fraction of sulfate in the particle, $\beta_{\text {sulf }}$ defined as "per gram $\mathrm{SO}_{4}^{2-}$ " can be calculated. Although our calculations in Eq. (3) employ $\beta$, henceforth in this paper for consistency with the literature we use $\beta$ to refer to $\beta_{\text {sulf }}$.

Our calculations of aerosol optical properties at $500 \mathrm{~nm}$ are summarized in Table 2 . The $82 \mathrm{~nm}$ dry mode diameter on the US of the hysteresis loop most closely resembles literature descriptions. For this case, we obtain $\beta=4.6 \mathrm{~m}^{2} \mathrm{~g}^{-1}$. sulfate at low RH and $\beta=17.7 \mathrm{~m}^{2} \mathrm{~g}^{-1}$. sulfate at $80 \% \mathrm{RH}$. Table 2 shows a good match between these values and those reported in the literature. For instance, a commonly employed $\beta$ value is $5 \mathrm{~m}^{2} \mathrm{~g}^{-1}$. sulfate for sulfate aerosol at low $\mathrm{RH}$ (Charlson et al., 1992).

In literature reports, there is significant variability in $\beta$, especially at $80 \% \mathrm{RH}$ (Table 2). Our value of $17.7 \mathrm{~m}^{2} \mathrm{~g}^{-1}$. sulfate is on the upper end. Boucher et al. (1998) establish $20.1 \mathrm{~m}^{2} \mathrm{~g}^{-1}$ as an upper limit for $\beta$ of monodisperse ammonium sulfate aerosol at $80 \% \mathrm{RH}$, using $n=1.40$ at $550 \mathrm{~nm}$. The differences in our study (viz. $500 \mathrm{~nm}$ and $n=1.46$ ) favor a small increase in the upper limit of $\beta$ (Hegg et al., 1993; Nemesure et al., 1995; Pilinis et al., 1995), although the value necessarily decreases for a polydisperse aerosol (as employed in our study). Our overestimate of $\beta$ increases at high $\mathrm{RH}$ because of the increasing difference between $n=1.46$ (characteristic of crystalline particles) and the refractive index of dilute particles (cf. Fig. 2 of Nemesure et al., 1995).

\subsection{Predicted column optical depths}

Figure 10a shows a global map of aerosol column optical depth at $500 \mathrm{~nm}$ for a SNA aerosol of $82 \mathrm{~nm}$ dry mode diameter following the LS of the hysteresis loop. The annual global average optical depth from SNA aerosol is $\tau_{\text {avg }}=0.023$ on the LS and 0.030 on the US. When nitrate is excluded, we obtain $\tau_{\text {avg }}=0.025$ for the US, which compares to 0.040 of Chin et al. (2002) and 0.0269 of Koch et al. (1999).

Aerosol optical depth (Fig. 10a) depends on many factors, including SNA aerosol mass, hygroscopic growth affected by $\mathrm{RH}$, and aerosol physical state affecting water and nitrate content. Of these, BL sulfate mass (Fig. 3) is the best predictor of optical depth in Fig. 10a: sulfate exceeds nitrate mass by a factor of six; sulfate mass attracts ammonium and water mass; and most sulfate mass is located in the BL. 
Table 4. Average global forcing by $82 \mathrm{~nm}, 164 \mathrm{~nm}$, and $246 \mathrm{~nm}$ dry mode diameter aerosols. Seasonal dependence is given for $82 \mathrm{~nm}$ dry mode. Other terms are explained in caption of Table 3. Calculations are in full sky without clouds.

\begin{tabular}{|c|c|c|c|c|c|c|c|c|c|}
\hline & \multicolumn{3}{|c|}{$\mathrm{BOA} \downarrow\left(\mathrm{W} \mathrm{m}^{-2}\right)$} & \multicolumn{3}{|c|}{$\mathrm{BOA} \uparrow\left(\mathrm{W} \mathrm{m}^{-2}\right)$} & \multicolumn{3}{|c|}{$\mathrm{TOA} \uparrow\left(\mathrm{W} \mathrm{m}^{-2}\right)$} \\
\hline & $F_{L}$ & $F_{U}$ & $\% \Delta F_{U, L}$ & $F_{L}$ & $F_{U}$ & $\% \Delta F_{U, L}$ & $F_{L}$ & $F_{U}$ & $\% \Delta F_{U, L}$ \\
\hline \multicolumn{10}{|l|}{$82 \mathrm{~nm}$} \\
\hline DJF & -0.748 & -0.860 & 15 & -0.063 & -0.074 & 17 & -0.682 & -0.783 & 15 \\
\hline MAM & -0.860 & -1.062 & 23 & -0.101 & -0.122 & 21 & -0.754 & -0.934 & 24 \\
\hline JJA & -0.930 & -1.208 & 30 & -0.083 & -0.111 & 34 & -0.841 & -1.091 & 30 \\
\hline SON & -0.788 & -0.993 & 26 & -0.061 & -0.080 & 30 & -0.724 & -0.910 & 26 \\
\hline $\begin{array}{c}\text { Annual } \\
164 \mathrm{~nm}\end{array}$ & -0.831 & -1.031 & 24 & $-\mathbf{0 . 0 7 7}$ & $-\mathbf{0 . 0 9 7}$ & 26 & -0.750 & -0.930 & 24 \\
\hline $\begin{array}{c}\text { Annual } \\
246 \mathrm{~nm}\end{array}$ & -0.816 & -0.994 & 22 & -0.082 & -0.101 & 23 & -0.739 & -0.898 & 22 \\
\hline Annual & -0.684 & -0.930 & 21 & -0.071 & -0.087 & 23 & -0.621 & -0.750 & 21 \\
\hline
\end{tabular}

After accounting for the predictor of BL sulfate mass, there are still a few additional observations to explain in the geographic distributions of $\tau_{L}$. For instance, BL sulfate aerosol mass (Fig. 3) is relatively high in western USA, northern and equatorial Africa, India, and Australia in DJF, while optical depths are relatively low (Fig. 10a). The explanation is that aerosol is crystalline over these regions (Fig. $8 \mathrm{a}, \% \mathrm{H}_{2} \mathrm{O}$ ), and thus the mass scattering efficiency is low.

Our global maps of column aerosol optical depth (Fig. 10a) can be compared to those in the literature, including Fig. 6a of van Dorland et al. (1997), Fig. 17a of Koch et al. (1999), and Fig. 4 (top, center) of Chin et al. (2002). These previous studies do not include nitrate aerosol. Van Dorland et al. (1997) present optical depth for anthropogenic sulfate while Koch et al. (1999) and Chin et al. (2002) show optical depth for combined anthropogenic and natural sources. There are other differences such as wavelength choices (viz. 250 to $680 \mathrm{~nm}$ window of van Dorland et al. (1997), $550 \mathrm{~nm}$ in Koch et al. (1999), and $500 \mathrm{~nm}$ by Chin et al. (2002) and by us) and other factors, including assumed particle size distributions, chemical composition, and hygroscopic growth. These differences notwithstanding, our global distributions agree well with van Dorland et al. (1997), Koch et al. (1999), and Chin et al. (2002).

The change in column optical depth $\Delta \tau_{U, L}$ between US and LS of the hysteresis loop is shown in Fig. 10b. The annual global average of $\Delta \tau_{U, L}$ is 0.0069 , which is a $30 \%$ increase over the LS. Regional predictions show the largest $\Delta \tau_{U, L}$ over eastern USA, Europe, India, east Asia, southern and equatorial Africa, and southeastern Brazil. A good predictor of $\Delta \tau_{U, L}$ geographic distributions is the extent of crystallization in the $\mathrm{BL}$, given by $\% \mathrm{H}_{2} \mathrm{O}$ (Fig. 8a). Some regions with low $\% \mathrm{H}_{2} \mathrm{O}$, including northern Africa, Canada, and Antarctica, nevertheless have low $\Delta \tau_{U, L}$. Because these regions have small $\tau_{U}, \Delta \tau_{U, L}$ is also necessarily small. Small $\tau_{U}$ arises from low aerosol loading and/or low RH.

An additional factor in the variation of $\Delta \tau_{U, L}$ is nitrate, which is necessary to explain high $\Delta \tau_{U, L}$ over Europe in MMA and JJA (Fig. 10b). In these seasons partial crystallization occurs (Fig. 8a, \% $\mathrm{H}_{2} \mathrm{O}$ ), which volatilizes the ammonium nitrate portion of the particles and thus reduces the aerosol mass and optical depth.

\subsection{Global annual average mass scattering efficiency}

Differences among model predictions of global annual average aerosol optical depth arise partly from differing treatments of aerosol optical properties (including hygroscopic growth), differing atmospheric aerosol mass burdens, and differing RH fields. The global annual average of the mass extinction efficiency normalizes for the effects of differing sulfate burdens. It is calculated as follows:

$$
\begin{aligned}
& \tau_{\text {avg }}=\sigma_{\text {avg }}\left(\mathrm{km}^{-1}\right) H_{\text {avg }}(\mathrm{km}) \\
& =\left(10^{3} \beta_{\text {avg }}\left(\frac{\mathrm{m}^{2}}{\mathrm{~g} \cdot \text { particle }}\right) L_{\text {avg }}\left(\frac{\mathrm{g} \cdot \text { particle }}{\mathrm{m}^{3} \cdot \text { air }}\right)\right) H_{\text {avg }}(\mathrm{km}) \frac{A\left(\mathrm{~km}^{2}\right)}{A\left(\mathrm{~km}^{2}\right)} \\
& =\frac{10^{6} \beta_{\text {avg }}\left(\frac{\mathrm{m}^{2}}{\mathrm{~g} \cdot \text { particle }}\right) M(\mathrm{Tg})}{A\left(\mathrm{~km}^{2}\right)}
\end{aligned}
$$

where $M(\mathrm{Tg})$ is the tropospheric sulfate burden as $\mathrm{SO}_{4}^{2-}, A$ is the surface area of Earth, and $H_{\text {avg }}$ is the average height of the troposphere.

Excluding nitrate in the optical depth, we obtain $\beta_{\text {avg }}=11.7 \mathrm{~m}^{2} \mathrm{~g}^{-1}$. sulfate on the US and $9.2 \mathrm{~m}^{2} \mathrm{~g}^{-1}$. sulfate on the LS of the hysteresis loop for $82 \mathrm{~nm}$ dry mode diameter aerosol. Including nitrate in the optical depth, we obtain $\% \Delta \beta_{\mathrm{avg}}=18.8$ on the US and $\% \Delta \beta_{\mathrm{avg}}=16.3$ on the LS. $\% \Delta \beta_{\text {avg }}$ is smaller for the LS because of volatilization of aerosol nitrate.

Results of $\beta_{\text {avg }}$ from our study and those from literature are given in Table 2. The $82 \mathrm{~nm}$ dry mode diameter on the US of the hysteresis loop most closely describes the common conditions employed in the literature. For this 

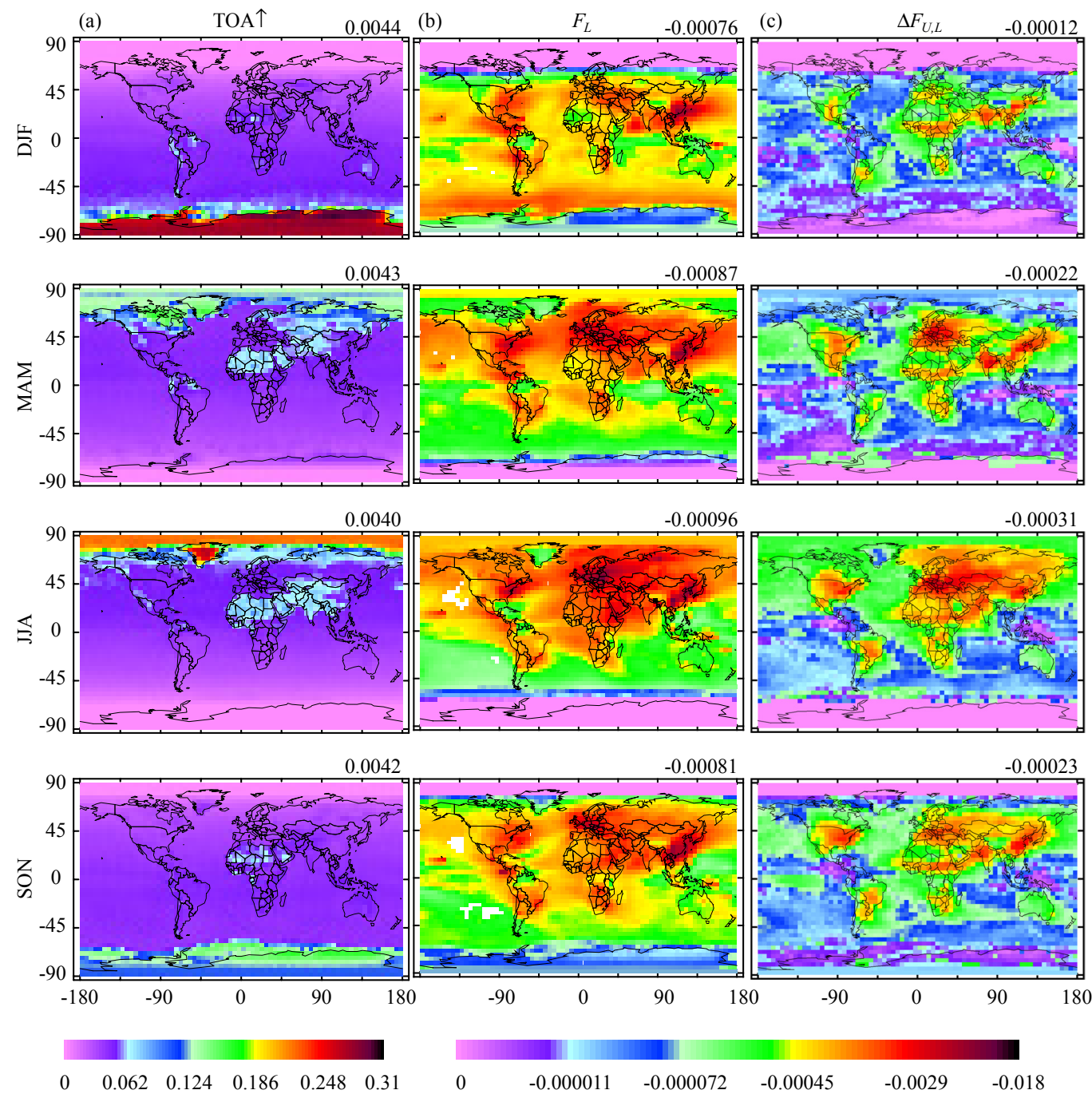

$\begin{array}{llllll}0 & -0.000011 & -0.000072 & -0.00045 & -0.0029 & -0.018\end{array}$

Fig. 11. Seasonally averaged upwelling top-of-the-atomsphere irradiance (TOA $\uparrow$ ) shown at $20000 \mathrm{~cm}^{-1}(500 \mathrm{~nm})$. Values are given as a percent of TOA $\downarrow$ irradiance at zero solar zenith angle. (a) Base case in the absence of SNA aerosol. (b) Change in TOA $\uparrow$ (i.e., "forcing") when aerosol follows the LS of the hysteresis loop. (c) Change in forcing for aerosol on the US rather than LS of the hysteresis loop. Units are fraction of solar intensity, which is $0.048 \mathrm{~W} \mathrm{~m}^{-2}\left(\mathrm{~cm}^{-1}\right)^{-1}$ at $20000 \mathrm{~cm}^{-1}$. Global average values are shown to right above figures. Calculated for full sky without clouds.

case, we obtain $\beta_{\text {avg }}=11.7 \mathrm{~m}^{2} \mathrm{~g}^{-1}$. sulfate with nitrate excluded. For comparison, $\beta_{\text {avg }}$ is $11 \mathrm{~m}^{2} \mathrm{~g}^{-1}$. sulfate in Chin et al. (2002), $8.4 \mathrm{~m}^{2} \mathrm{~g}^{-1}$.sulfate in Koch et al. (1999), and $8.5 \mathrm{~m}^{2} \mathrm{~g}^{-1}$. sulfate in the simplified treatment of Charlson et al. (1992). The differences arise from differing treatments of aerosol optical and physical properties and also differences among global RH fields.

\section{Aerosol direct radiative forcing}

The differences in aerosol optical depth on the LS versus US of the hysteresis loop (Fig. 10b) impact radiative transfer. To quantify the effects, baseline seasonal studies calculate bottom-of-the-atmosphere (BOA) and top-of-the- atmosphere (TOA) irradiances in the absence of all particulate matter (i.e., a Rayleigh atmosphere). Aerosol is then included, and irradiances are re-calculated for two cases: aerosol on the LS or US of the hysteresis loop. BOA $\downarrow$ and TOA $\uparrow$ forcings, as compared to the reference aerosol-free baseline studies, are determined (Figs. 11 and 12; Table 3). The sensitivity of the results on dry mode particle diameter is assessed (Table 4). The geographical dependence of TOA $\uparrow$ forcing is investigated (Table 5). The effect of clouds on full sky forcing is determined (Table 5).

\subsection{Radiative transfer model}

Full sky shortwave radiative transfer calculations are performed using a multi-layer multiple-scattering discrete- 

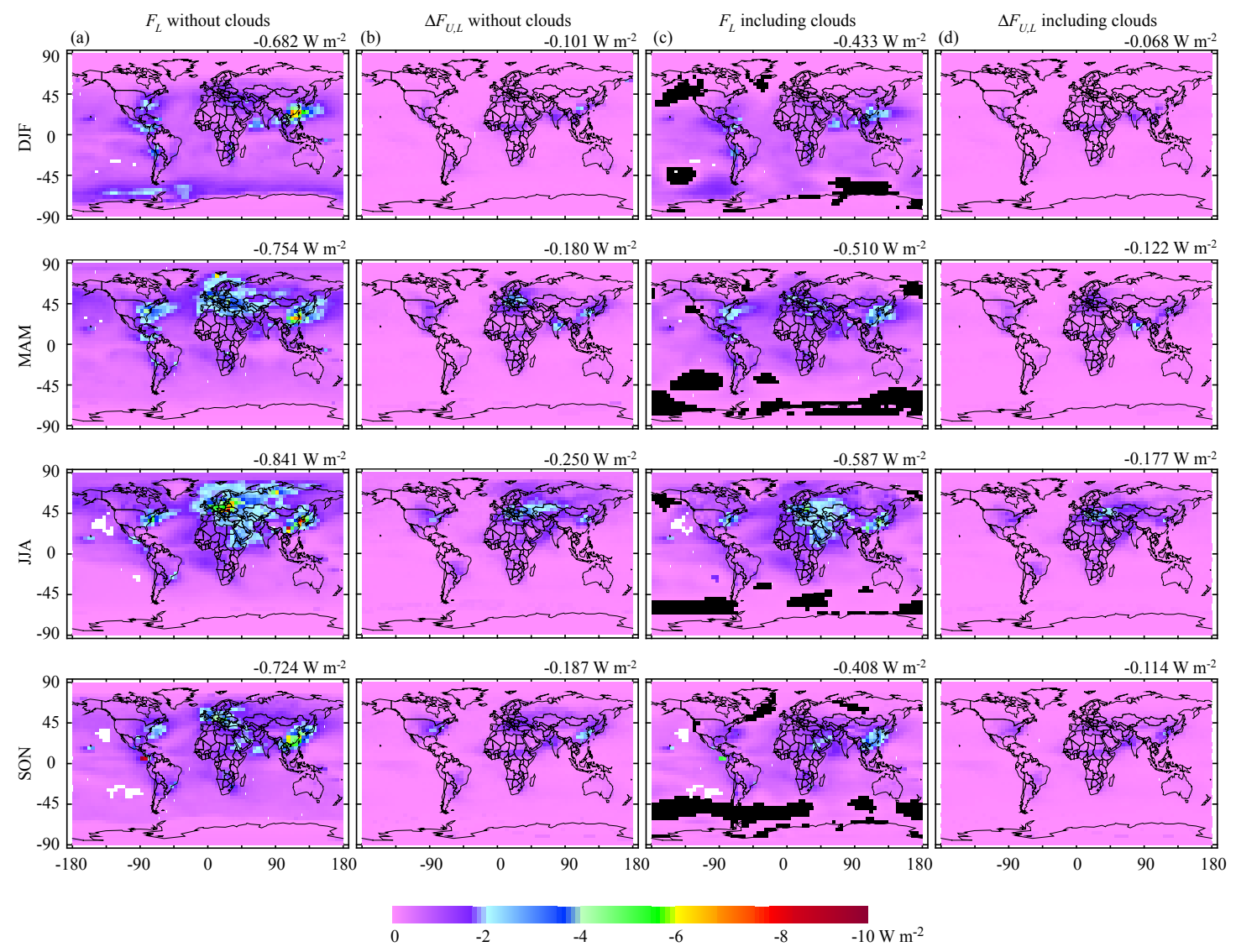

Fig. 12. Seasonally averaged TOA $\uparrow$ solar forcing. (a) Forcing on the LS of hysteresis loop $\left(F_{L}\right)$ in full sky without clouds. (b) Change in the forcing in $a$ for aerosol on the US of the hysteresis loop $\left(\Delta F_{U, L}\right)$. (c) Forcing on the LS of hysteresis loop $\left(F_{L}\right)$ in full sky including clouds (scheme II). (d) Change in the forcing in $c$ for aerosol on the US of the hysteresis loop $\left(\Delta F_{U, L}\right)$. Global average values are shown to right above figures. Regions of slight warming in $c$ are beyond the color scale and appear as black (Haywood and Shine, 1997; van Dorland et al., 1997; Boucher et al., 1998; Adams et al., 2001; Haywood and Boucher, 2000).

ordinate model (LIDORT) (Spurr et al., 2001; Spurr, 2002). LIDORT treats scattering in the plane-parallel approximation and includes a curved stratified atmosphere for attenuation of the solar beam. This pseudo-spherical approximation is essential for high solar zenith angles (Dahlback and Stamnes, 1991; Spurr, 2002). The model is run with 16 streams to compute the multiple scattering quadrature.

\subsubsection{Model inputs}

Optical properties in each atmospheric column are defined at the thirty vertical sigma pressure levels of the GEOS-CHEM grid. Altitudes are calculated using the surface pressure and assuming hydrostatic balance throughout the column. The optical properties $\{\sigma, \omega, g\}_{\text {total }}$ in each grid box are the weighted partial contributions of Rayleigh scattering, ozone absorption, and aerosol optical properties. For Rayleigh scattering, we take scattering coefficients and depolarization ratios from Bodhaine et al. (1999). For gaseous absorption, we include ozone in our calculations. Global $\mathrm{O}_{3}$ column profiles in the troposphere are obtained from GEOS-CHEM pre- dictions, which are then smoothly grafted to supplementary stratospheric profiles from the Fortuin-Kelder ozone climatology (Fortuin and Kelder, 1998). Ozone cross-sections are taken from Burrows et al. (1999). Calculations of aerosol optical properties are described in Sect. 4.1. The HenyeyGreenstein formulation is employed for aerosol scattering phase functions (Heyney-Greenstein, 1941; Boucher, 1998; Thomas and Stamnes, 1999).

Shortwave radiative transfer calculations are performed for $24 \mathrm{~h}$ time periods on 15 January (DJF), 15 April (MAM), 15 July (JJA), and 15 October (SON) for each column on the model grid in five spectral windows (Table 1). The calculations proceed at one hour time steps. The solar zenith angle in each calculation depends on the latitude, longitude, day of year, and time of day. Earth's surface is assumed Lambertian, with monthly-averaged wavelength-interpolated albedo data $\{0.122,0.117,0.101,0.104\}$ at $500 \mathrm{~nm}$ for DJF, MAM, JJA, and SON, respectively. 
Table 5. Geographical variation of the upwelling top-of-the atmosphere forcings for aerosol on the LS and US of the hysteresis loop ( $F_{L}$ and $\left.F_{U}\right)$ and their percent difference $\left(\Delta F_{U, L}\right)$. (a) Full sky calculations without clouds.

\begin{tabular}{|c|c|c|c|c|c|c|c|c|c|c|c|c|}
\hline & \multirow{2}{*}{\multicolumn{3}{|c|}{ Global }} & \multicolumn{9}{|c|}{ Northern Hemisphere } \\
\hline & & & & \multicolumn{3}{|c|}{ Mean } & \multicolumn{3}{|c|}{ Ocean } & \multicolumn{3}{|c|}{ Land } \\
\hline & $F_{L}$ & $F_{U}$ & $\% \Delta F_{U, L}$ & $F_{L}$ & $F_{U}$ & $\% \Delta F_{U, L}$ & $F_{L}$ & $F_{U}$ & $\% \Delta F_{U, L}$ & $F_{L}$ & $F_{U}$ & $\% \Delta F_{U, L}$ \\
\hline DJF & -0.682 & -0.783 & 15 & -0.755 & -0.908 & 20 & -0.786 & -0.866 & 10 & -0.713 & -0.966 & 35 \\
\hline MAM & -0.754 & -0.934 & 24 & -1.15 & -1.454 & 26 & -1.02 & -1.163 & 14 & -1.331 & -1.856 & 39 \\
\hline JJA & -0.841 & -1.091 & 30 & -1.375 & -1.801 & 31 & -1.082 & -1.265 & 17 & -1.781 & -2.54 & 43 \\
\hline SON & -0.724 & -0.910 & 26 & -1.002 & -1.295 & 29 & -0.849 & -0.975 & 15 & -1.212 & -1.737 & 43 \\
\hline \multirow[t]{4}{*}{ Annual } & -0.750 & -0.930 & 24 & -1.071 & -1.364 & 27 & -0.934 & -1.067 & 14 & -1.259 & -1.775 & 41 \\
\hline & & & & \multicolumn{9}{|c|}{ Southern Hemisphere } \\
\hline & & & & \multicolumn{3}{|c|}{ Mean } & \multicolumn{3}{|c|}{ Ocean } & \multicolumn{3}{|c|}{ Land } \\
\hline & & & & $F_{L}$ & $F_{U}$ & $\% \Delta F_{U, L}$ & $F_{L}$ & $F_{U}$ & $\% \Delta F_{U, L}$ & $F_{L}$ & $F_{U}$ & $\% \Delta F_{U, L}$ \\
\hline DJF & & & & -0.608 & -0.658 & 8 & -0.637 & -0.673 & 6 & -0.481 & -0.59 & 23 \\
\hline MAM & & & & -0.358 & -0.414 & 16 & -0.336 & -0.371 & 10 & -0.454 & -0.604 & 33 \\
\hline JJA & & & & -0.307 & -0.382 & 24 & -0.274 & -0.318 & 16 & -0.452 & -0.664 & 47 \\
\hline SON & & & & -0.446 & -0.525 & 18 & -0.427 & -0.48 & 12 & -0.531 & -0.73 & 37 \\
\hline \multirow[t]{3}{*}{ Annual } & & & & -0.430 & -0.495 & 15 & -0.419 & -0.461 & 10 & -0.479 & -0.647 & 35 \\
\hline & & & & \multicolumn{3}{|c|}{ United States } & \multicolumn{3}{|c|}{ Europe } & \multicolumn{3}{|c|}{ East Asia } \\
\hline & & & & $F_{L}$ & $F_{U}$ & $\% \Delta F_{U, L}$ & $F_{L}$ & $F_{U}$ & $\% \Delta F_{U, L}$ & $F_{L}$ & $F_{U}$ & $\% \Delta F_{U, L}$ \\
\hline DJF & & & & -0.857 & -1.02 & 19 & -0.851 & -1.105 & 30 & -2.663 & -3.346 & 26 \\
\hline MAM & & & & -1.649 & -2.24 & 36 & -2.723 & -4.229 & 55 & -4.301 & -5.716 & 33 \\
\hline JJA & & & & -1.627 & -2.444 & 50 & -3.601 & -5.36 & 49 & -4.123 & -5.254 & 27 \\
\hline SON & & & & -1.17 & -2.046 & 75 & -2.166 & -3.009 & 39 & -3.627 & -5.344 & 47 \\
\hline Annual & & & & -1.326 & -1.938 & 46 & -2.335 & -3.426 & 47 & -3.679 & -4.915 & 34 \\
\hline
\end{tabular}

\subsubsection{Cloud treatment}

Random overlap of stratus clouds is assumed (Morcrette and Fouquart, 1986; Briegleb, 1992; Thomas and Stamnes, 1999). GEOS Data Assimilation System (DAS) cloud fraction and cloud optical depth are employed for model pressures greater than 457 mbar. Clouds at lower pressures (<440 mbar), which are usually convective cumulus (Rossow et al., 1993), are omitted in our treatment. This heuristic correction to the random overlap calculation is applied because high altitude convective clouds, overlapping with cloud base at low altitude, must not be double-counted. The annual average global cloud fraction in our treatment is $60 \%$. The geographical distribution of cloud fraction (Table 5b) agrees with Table 3 of Rossow et al. (1993).

By increasing TOA albedo over parts of Earth, clouds reduce SNA aerosol radiative forcing. To quantify this effect, we contrast two schemes. Scheme I is cloud masking with the presumption of zero aerosol forcing in the presence of clouds. The resulting full sky cloud forcing $\left(F^{I}\right)$ is then:

$F^{I}=\frac{\sum_{\theta, \phi} F_{\mathrm{clr}}^{\theta, \phi} A^{\theta, \phi}\left(1-\bar{C}_{F}^{\theta, \phi}\right)}{\sum_{\theta, \phi} A^{\theta, \phi}}$, where the sum is over the longitude $(\theta)$ and latitude $(\phi)$ model columns, $F_{\text {clr }}$ is the column forcing calculated in the absence of clouds, $A$ is the footprint area of a column, and $\bar{C}_{F}$ is the random overlap column cloud fraction. By assuming clouds completely mask aerosols, scheme I provides an upper limit on the effect of clouds.

Our scheme II for forcing $\left(F^{I I}\right)$ treats clouds more realistically but is necessarily more empirical. Clouds are treated as another aerosol type, and Mie optical properties are calculated (Sect. 4.1). For a $16 \mu \mathrm{m}$ diameter water particle, we obtain $0.195<\beta<0.207 \mathrm{~m}^{2} \mathrm{~g}^{-1}$. water, $1>\omega>0.98$, and $0.86>g>0.85$ across the five spectral bands (Table 1), which is in good agreement with Morcrette and Fouquart (1986). In place of Eq. (3), the scattering efficiency $\sigma_{\text {cld }}\left(\mathrm{km}^{-1}\right)$ is calculated by dividing DAS cloud optical depth by grid box height. The grid box cloud fraction $\left(C_{F}\right)$ is also obtained from the DAS data set. To account for random cloud overlap in the column, we use $\sigma_{\text {cld }}^{\prime}=\sigma_{\text {cld }}\left(C_{F}\right)^{N}$ where $N$ is an empirical factor (Briegleb, 1992).

The factor $N$ is chosen to constrain average global cloud optical depth to observations, which are $\tau_{\text {avg }}=3.81$ and $\bar{C}_{F, \text { avg }}=62 \%$ (Rossow and Schiffer, 1999). The average 
Table 5. Continued. (b) Full sky calculations including clouds (scheme II). Calculated for 82 nm dry mode diameter.

\begin{tabular}{|c|c|c|c|c|c|c|c|c|c|c|c|c|}
\hline & \multicolumn{3}{|c|}{ Global $(0.40,0.65,0.61)^{*}$} & \multicolumn{3}{|c|}{ Mean $(0.46,0.64,0.60)$} & \multicolumn{3}{|c|}{$\begin{array}{c}\text { Northern Hemisphere } \\
\text { Ocean }(0.40,0.63,0.55)\end{array}$} & \multicolumn{3}{|c|}{ Land $(0.54,0.64,0.64)$} \\
\hline & $F_{L}$ & $F_{U}$ & $\% \Delta F_{U, L}$ & $F_{L}$ & $F_{U}$ & $\% \Delta F_{U, L}$ & $F_{L}$ & $F_{U}$ & $\% \Delta F_{U, L}$ & $F_{L}$ & $F_{U}$ & $\% \Delta F_{U, L}$ \\
\hline DJF & -0.433 & -0.501 & 16 & -0.461 & -0.561 & 22 & -0.497 & -0.55 & 11 & -0.411 & -0.575 & 40 \\
\hline MAM & -0.510 & -0.632 & 24 & -0.764 & -0.968 & 27 & -0.691 & -0.787 & 14 & -0.865 & -1.218 & 41 \\
\hline JJA & -0.587 & -0.764 & 30 & -0.95 & -1.251 & 32 & -0.713 & -0.828 & 16 & -1.278 & -1.834 & 44 \\
\hline SON & -0.408 & -0.522 & 28 & -0.561 & -0.732 & 30 & -0.467 & -0.542 & 16 & -0.691 & -0.993 & 44 \\
\hline \multirow[t]{3}{*}{ Annual } & -0.485 & -0.605 & 25 & -0.684 & -0.878 & 28 & -0.592 & -0.677 & 14 & -0.811 & -1.155 & 42 \\
\hline & & & & \multicolumn{9}{|c|}{ Southern Hemisphere } \\
\hline & & & & $F_{L}$ & $F_{U}$ & $\% \Delta F_{U, L}$ & $F_{L}$ & $F_{U}$ & $\% \Delta F_{U, L}$ & $F_{L}$ & $F_{U}$ & $\% \Delta F_{U, L}$ \\
\hline DJF & & & & -0.406 & -0.442 & 9 & -0.404 & -0.43 & 7 & -0.414 & -0.493 & 19 \\
\hline MAM & & & & -0.256 & -0.296 & 15 & -0.221 & -0.244 & 10 & -0.412 & -0.525 & 27 \\
\hline JJA & & & & -0.224 & -0.277 & 24 & -0.194 & -0.221 & 14 & -0.36 & -0.524 & 46 \\
\hline SON & & & & -0.255 & -0.313 & 22 & -0.222 & -0.259 & 17 & -0.403 & -0.552 & 37 \\
\hline \multirow[t]{3}{*}{ Annual } & & & & -0.285 & -0.332 & 16 & -0.260 & -0.289 & 11 & -0.397 & -0.524 & 32 \\
\hline & & & & \multicolumn{3}{|c|}{$\begin{array}{c}\text { United States } \\
(0.47,0.57, \mathrm{n} / \mathrm{a})\end{array}$} & \multicolumn{3}{|c|}{$\begin{array}{c}\text { Europe } \\
(0.40,0.46, \mathrm{n} / \mathrm{a})\end{array}$} & \multicolumn{3}{|c|}{$\begin{array}{c}\text { East Asia } \\
(0.46,0.59, \mathrm{n} / \mathrm{a})\end{array}$} \\
\hline & & & & $F_{L}$ & $F_{U}$ & $\% \Delta F_{U, L}$ & $F_{L}$ & $F_{U}$ & $\% \Delta F_{U, L}$ & $F_{L}$ & $F_{U}$ & $\% \Delta F_{U, L}$ \\
\hline DJF & & & & -0.279 & -0.328 & 18 & -0.227 & -0.287 & 26 & -1.127 & -1.399 & 24 \\
\hline MAM & & & & -1.013 & -1.372 & 35 & -1.354 & -2.132 & 57 & -2.785 & -3.638 & 31 \\
\hline JJA & & & & -1.171 & -1.773 & 51 & -2.084 & -3.313 & 59 & -2.522 & -3.269 & 30 \\
\hline SON & & & & -0.575 & -1.008 & 75 & -0.598 & -0.895 & 50 & -2.178 & -3.215 & 48 \\
\hline Annual & & & & -0.759 & -1.12 & 48 & -1.066 & -1.657 & 55 & -2.153 & -2.88 & 34 \\
\hline
\end{tabular}

global cloud optical depth is:

$$
\tau_{\mathrm{avg}}=\frac{\sum_{\theta, \phi} \bar{C}_{F}^{\theta, \phi} \bar{\tau}^{\theta, \phi} A^{\theta, \phi}}{\sum_{\theta, \phi} \bar{C}_{F}^{\theta, \phi} A^{\theta, \phi}},
$$

where $\bar{\tau}^{\theta, \phi}$ is the column cloud optical depth. Application of $\sigma_{\text {cld }}^{\prime}=\sigma_{\text {cld }}\left(C_{F}\right)^{N}$ is equivalent to setting the cloud fraction of each grid box to $100 \%$ and hence also of each column (i.e., $\left.\bar{C}_{F}^{\theta, \phi}=1\right)$. In doing so, the cloud optical depth must be reduced horizontally to allow an equivalent amount of light to pass through and reduced vertically to mimic a random overlap treatment. Both factors are embodied within $N$; however, the vertical treatment is approximate. In practice we constrain $N$ so that:

$$
\begin{aligned}
& 0.62 \times 3.81=1.00 \times 2.36=\frac{\sum_{\theta, \phi} A^{\theta, \phi} \bar{\tau}^{\theta, \phi}}{\sum_{\theta, \phi} A^{\theta, \phi}} \\
& =\frac{\sum_{\theta, \phi}\left(A^{\theta, \phi} \sum_{z} \tau_{z}^{\theta, \phi}\right)}{\sum_{\theta, \phi} A^{\theta, \phi}}=\frac{\sum_{\theta, \phi}\left(A^{\theta, \phi} \sum_{z} z \sigma_{z}^{\theta, \phi}\left(C_{F, z}^{\theta, \phi}\right)^{N}\right)}{\sum_{\theta, \phi} A^{\theta, \phi}} .
\end{aligned}
$$

Equation (6b) follows from Eq. (6a) with $\bar{C}_{F}^{\theta, \phi}=1$. This fictitious world has $100 \%$ cloud cover and hence its optical depth is taken as 2.36 to be overall approximately equivalent to Earth. By application of Eq. (6b), we obtain $N=0.39$. Briegleb (1992) obtains $N=1.5$, but $N$ decreases with increasing model vertical resolution. Briegleb distributes clouds across 3 levels as compared to 14 levels in our treatment.

\subsection{Calculated forcings}

\subsubsection{Full sky without clouds}

The global annual average radiative TOA $\uparrow$ forcing in the absence of clouds due to SNA aerosol on the LS of the hysteresis loop $\left(F_{L}\right)$ is $-0.750 \mathrm{~W} \mathrm{~m}^{-2}$, which compares to $-0.930 \mathrm{~W} \mathrm{~m}^{-2}$ for aerosol on the US $\left(F_{U}\right)$. The difference $\Delta F_{U, L}$ is $24 \%$. (The symbol $F$ as used by us refers specifically to TOA forcing.) For BOA $\downarrow$ and BOA $\uparrow$ the respective differences are $24 \%$ and $26 \%$. The spectral dependence for TOA $\uparrow$ forcing ranges from $27 \%$ near the UV to $18 \%$ in the near-IR (Table 3). The explanation is that $\beta$ increases more for aqueous particles with increasing wavenumber than for crystalline particles; however, the precise relationship 
depends on the dry mode diameter, hygroscopic growth properties, and the global RH fields. Differences between BOA $\downarrow$ and TOA $\uparrow$ forcing arise from the absorptive component of the atmosphere because the two forcings would be equal in a purely scattering atmosphere.

Forcing is sensitive to the assumed dry mode particle diameter (Table 4). $\quad F_{L}$ decreases from -0.750 to $-0.621 \mathrm{~W} \mathrm{~m}^{-2}$ as particle dry diameter increases from 82 to $246 \mathrm{~nm}$. Similarly, $F_{U}$ decreases from -0.930 to $-0.750 \mathrm{~W} \mathrm{~m}^{-2}$. There is thus a strong sensitivity to the presumed dry particle size. However, the sensitivity of the percent difference between $F_{L}$ and $F_{U}$ is much smaller. $\Delta F_{U, L}$ falls from 24 to $21 \%$ with this change in diameter, and so $\Delta F_{U, L}$ is independent to a first approximation of the choice of dry size diameter.

The greatest LS forcings (Fig. $11 \mathrm{~b} ; 20000 \mathrm{~cm}^{-1}$ ) occur over geographic regions having high aerosol optical depth (Fig. 10a). Thus, optical depth is the leading indicator of $F_{L}$. There is an additional slight modulation due to the albedo of the underlying surface and the extent of solar irradiation. For instance, in winter there is little forcing over the Arctic even though there is significant optical depth, which is explained mainly by the absence of solar irradiance. As a second example, the forcing over northern Africa is disproportionately low for the optical depth. The high reflectivity of northern Africa reduces the incremental effect of additional high reflectivity aerosol.

The change in forcing (Fig. 11c) when SNA aerosol lies along the US of the hysteresis loop, as compared to the LS, closely parallels $\Delta \tau_{U, L}$ (Fig. 10b). The close relationship between change in forcing and optical depth breaks down in a few regions, such as over highly reflective northern Africa or weakly irradiated winter upper latitudes.

Forcings integrated for the entire solar spectrum (Fig. 12a, b) have similar patterns to the study at $20000 \mathrm{~cm}^{-1}$ (Figs. $11 \mathrm{~b}, \mathrm{c}$ ). As a global annual average, $F_{L}=-0.750$, $F_{U}=-0.930$, and $\Delta F_{U, L}=24 \%$. In the northern hemisphere, $F_{L}=-1.071, F_{U}=-1.364$, and $\Delta F_{U, L}=27 \%$, while in the southern hemisphere, $F_{L}=-0.430, F_{U}=-0.495$, and $\Delta F_{U, L}=15 \%$ (Table 5a). The absolute magnitude of northern hemisphere forcing is greater because of larger industrial emissions, while the difference $\Delta F_{U, L}$ is also larger because of the greater land area, which favors crystallization (Sect. 3.1.1).

Largest forcing occurs over the USA, Europe, and East Asia. Annual average forcing is as large as $-4.915 \mathrm{~W} \mathrm{~m}^{-2}$ over East Asia (Table 5a). The differences $\Delta F_{U, L}$ are $46 \%$, $47 \%$, and $34 \%$ over these three respective geographic regions, which are values consistent with the overall northern hemisphere land difference of $41 \%$. The slightly smaller $\Delta F_{U, L}$ over East Asia arises because the fraction of aerosol mass having $\% \Delta \sigma_{U, L}>0$ occurs at a lower RH over East Asia than over Europe or USA (cf. Fig. 2 at $50 \%$ versus $60 \%$ RH). This analysis shows that aerosol phase could affect annual average aerosol direct radiative forcing over highly populated regions of the world by as much as 34 to $47 \%$ for clear sky conditions. The seasonal dependence could be even greater: $\Delta F_{U, L}$ over the USA ranges from $19 \%$ in DJF to $75 \%$ in SON, which closely parallels the seasonal dependence of $\% \mathrm{H}_{2} \mathrm{O}$ (Fig. 8a) and $\Delta \tau_{U, L}$ (Fig. 10b). The seasonal dependence arises from predicted $[X, Y]$ occurring inside a critical susceptibility window for which $\% \Delta \sigma_{U, L}>0$ over 55 to $80 \%$ RH (cf. Fig. 2 at $60 \%$ RH). USA DJF aerosol usually has $[X, Y]$ yielding $\% \Delta \sigma_{U, L}=0$ over 55 to $80 \% \mathrm{RH}$ : greater acidification and hence reduced $\% \Delta \sigma_{U, L}$ is apparent in Fig. 7 for the BL in DJF. DJF $[X, Y]$ having $\% \Delta \sigma_{U, L}>0$ occurs with only $25 \%$ frequency over the range 55 to $80 \%$ RH. In contrast, predicted aerosol $[X, Y]$ yields $67 \%$ frequency of $\% \Delta \sigma_{U, L}>0$ over 55 to $80 \% \mathrm{RH}$ in SON, while MAM and JJA have 59 and $65 \%$ frequencies, respectively.

\subsubsection{Full sky including clouds}

The global annual average forcing is $F_{L}=-0.319$ (0.43), $F_{U}=-0.421(0.45)$, and $\Delta F_{U, L}=32 \%$ for full sky calculations employing scheme I. In comparison, scheme II yields $F_{L}=-0.485$ (0.65), $F_{U}=-0.605(0.65)$, and $\Delta F_{U, L}=25 \%$ (Table 5b). The values in parentheses are the cloud factors, defined as the ratio of forcing in the presence of clouds to forcing in their absence (Boucher and Anderson, 1995). Scheme I provides a maximum effect for clouds. Further discussion relates exclusively to scheme II clouds.

As a global annual average, the cloud factor for $F_{L}$ and $F_{U}$ is 0.65 . Other authors report global annual average cloud factors of 0.39 (Charlson et al., 1991), 0.64 (Kiehl and Briegleb, 1993), 0.61 (Boucher and Anderson, 1995), and 0.74 (Chuang et al., 1997). Due to the seasonal and geographic variability of cloud coverage, the effect of clouds is similarly variable (Fig. 12c). The annual average cloud factor ranges from 0.46 over Europe to 0.83 over land in the southern hemisphere (Table 5b). The seasonal value over the USA ranges from 0.33 in DJF to 0.72 in JJA. In Europe, the cloud factor varies from 0.27 in DJF to 0.58 in JJA. In East Asia, the cloud factor is 0.42 in DJF and 0.65 in MAM. The geographic variability of our annual average cloud factor is in close agreement with that of Boucher and Anderson (1995) (Table 5b), despite differences in cloud treatment and the use of cloud cover obtained from general circulation model (Boucher and Anderson) as opposed to assimilated data.

Compared to clear full sky calculations (Table 5a), clouds cause a systematic increase of 1 to $2 \%$ in $\Delta F_{U, L}$ (Table $5 \mathrm{~b}$ ). The difference in Europe is as high as $11 \%$ in SON. The US and LS of the hysteresis loop coalesce at sufficiently high RH (i.e., $\Delta F_{U, L}=0$; Fig. 1c), and clouds correlate with high $\mathrm{RH}$. The average $\Delta F_{U, L}$ in clear sky includes terms at low $\mathrm{RH}\left(\Delta F_{U, L}>0 \%\right)$ and high RH $\left(\Delta F_{U, L}=0 \%\right)$. The effect of clouds is to favor a weighting in the average of low $\mathrm{RH}$ $\Delta F_{U, L}$ at the expense of high RH $\Delta F_{U, L}$, and a slight increase in the global average $\Delta F_{U, L}$ results. 
Table 6. Summary of results for CTM runs including both anthropogenic and natural sulfate and nitrate emissions, natural sulfate and nitrate emissions alone, and anthropogenic and natural sulfate emissions (no nitrate aerosol). Anthropogenic sulfate and nitrate results are ascribed by difference. Shown are (1) the sulfate, nitrate, and ammonium tropospheric burdens, (2) the areal-weighted average values of $\langle X, Y>$ on the US of the hysteresis loop and of percent sulfate and nitrate mass found in the BL as AS, LET, AHS, and AN on the LS of the hysteresis loop, (3) percent nitrate mass vaporized when solids form, (4) percent aerosol water remaining after solids form, (5) global average optical depth, and (6) global average full sky forcing with and without clouds. Table entries are global annual averages. Calculated for $82 \mathrm{~nm}$ dry mode diameter.

\begin{tabular}{|c|c|c|c|c|c|}
\hline & \multicolumn{3}{|c|}{ Sulfate and Nitrate } & \multicolumn{2}{|c|}{ Sulfate } \\
\hline & $\begin{array}{c}\text { Anthropogenic } \\
\text { and Natural } \\
\text { (1) }\end{array}$ & $\begin{array}{c}\text { Natural } \\
(2)\end{array}$ & $\begin{array}{l}\text { Ascribed } \\
\text { Anthropogenic } \\
=(1)-(2)\end{array}$ & $\begin{array}{l}\text { Anthropogenic } \\
\text { and Natural } \\
\text { (3) }\end{array}$ & $\begin{array}{l}\text { Ascribed } \\
\text { Nitrate } \\
=(1)-(3)\end{array}$ \\
\hline \multicolumn{6}{|l|}{ Particulate Burdens } \\
\hline Sulfate (Tg S) & 0.37 & 0.11 & +0.26 & 0.37 & 0.00 \\
\hline Nitrate $(\operatorname{Tg~N})$ & 0.046 & 0.017 & +0.03 & $\mathrm{n} / \mathrm{a}$ & +0.046 \\
\hline Ammonium (Tg N) & 0.29 & 0.074 & +0.21 & 0.22 & +0.07 \\
\hline \multicolumn{6}{|c|}{ Average Composition $\langle X, Y\rangle$ (upper side of hysteresis loop) } \\
\hline Boundary Layer & {$[0.80,0.93]$} & {$[0.83,0.92]$} & {$[-0.03,+0.01]$} & {$[0.75,1]$} & {$[+0.05,-0.07]$} \\
\hline Free Troposphere & {$[0.54,0.94]$} & {$[0.45,0.87]$} & {$[+0.09,+0.07]$} & {$[0.50,1]$} & {$[+0.04,-0.06]$} \\
\hline Upper Troposphere & {$[0.69,0.70]$} & {$[0.54,0.86]$} & {$[+0.15,-0.16]$} & {$[0.57,1]$} & {$[+0.12,-0.30]$} \\
\hline \multicolumn{6}{|c|}{ Solid Phases (boundary layer) } \\
\hline$<\%$ AS $>$ & 27.9 & 33.3 & -5.4 & 40.3 & -12.4 \\
\hline$<\%$ LET $>$ & 4.36 & 1.86 & +2.5 & 4.63 & -0.27 \\
\hline$<\% \mathrm{AHS}>$ & 0.89 & 0.67 & +0.22 & 0.99 & -0.1 \\
\hline$<\%$ AN $>$ & 2.27 & 2.94 & -0.67 & $\mathrm{n} / \mathrm{a}$ & +2.27 \\
\hline$<\% \mathrm{AN}>\uparrow$ as gas & 22.6 & 37.3 & -14.7 & $\mathrm{n} / \mathrm{a}$ & +22.6 \\
\hline$<\% \mathrm{H}_{2} \mathrm{O}>$ & 70.5 & 67.0 & +3.5 & 58 & +12.5 \\
\hline \multicolumn{6}{|l|}{ Optical Depth } \\
\hline Lower Side & 0.023 & 0.009 & +0.014 & 0.020 & +0.003 \\
\hline Upper Side & 0.030 & 0.010 & +0.020 & 0.025 & +0.005 \\
\hline \multicolumn{6}{|c|}{$\begin{array}{l}\text { Full Sky TOA } \uparrow \text { Forcing }\left(\mathbf{W ~ m}^{-2}\right) \\
\text { Without clouds }\end{array}$} \\
\hline$F_{L}$ & $-0.750^{a}$ & -0.294 & -0.456 & -0.653 & -0.097 \\
\hline$F_{U}$ & -0.930 & -0.340 & -0.590 & -0.817 & -0.113 \\
\hline$\% \Delta F_{U, L}$ & $24^{a}$ & 16 & $\mathrm{n} / \mathrm{a}$ & 25 & $\mathrm{n} / \mathrm{a}$ \\
\hline \multicolumn{6}{|c|}{ Including clouds, scheme I } \\
\hline$F_{L}$ & $-0.319(0.43)^{b}$ & $-0.106(0.36)$ & -0.213 & $-0.276(0.42)$ & -0.043 \\
\hline$F_{U}$ & $-0.421(0.45)$ & $-0.129(0.38)$ & -0.292 & $-0.361(0.44)$ & -0.060 \\
\hline$\% \Delta F_{U, L}$ & 32 & 23 & $\mathrm{n} / \mathrm{a}$ & 31 & $\mathrm{n} / \mathrm{a}$ \\
\hline \multicolumn{6}{|c|}{ Including clouds, scheme II } \\
\hline$F_{L}$ & $-0.485(0.65)$ & $-0.171(0.58)$ & -0.314 & $-0.424(0.65)$ & -0.061 \\
\hline$F_{U}$ & $-0.605(0.65)$ & $-0.201(0.59)$ & -0.404 & $-0.529(0.65)$ & -0.076 \\
\hline$\% \Delta F_{U, L}$ & 25 & 18 & $\mathrm{n} / \mathrm{a}$ & 25 & $\mathrm{n} / \mathrm{a}$ \\
\hline
\end{tabular}

\section{Sensitivity studies}

6.1 Anthropogenic influence: current emissions compared to natural conditions

Anthropogenic influence is assessed by differencing the results of a model run having both anthropogenic and natural emissions from a run having only natural emissions (Table 6). The anthropogenic SNA aerosol burden is $0.26 \mathrm{Tg} \mathrm{S}$ for sulfate $\left(1.53 \mathrm{mg} \mathrm{SO}_{4}^{2-} \mathrm{m}^{-2}\right), 0.03 \mathrm{Tg} \mathrm{N}$ for nitrate, and $0.21 \mathrm{Tg} \mathrm{N}$ for ammonium. This aerosol contributes 0.014 to the LS global annual average optical depth and 0.020 on the US. The corresponding forcings are $F_{L}=-0.456$ and $F_{U}=-0.590$ without clouds. Including clouds, $F_{L}=-0.314$ and $F_{U}=-0.404$, with associated normalized direct radiative forcings $(G)$ of $G_{L}=-205 \mathrm{~W}\left(\mathrm{~g} \mathrm{SO}_{4}^{2-}\right)^{-1}$ and $G_{U}=-264$ $\mathrm{W}\left(\mathrm{g} \mathrm{SO}_{4}^{2-}\right)^{-1}$. Inclusion of nitrate in our calculation, as compared to the usual approach in the literature of sulfateonly calculations, overstates our $G_{U, L}$ by approximately $10 \%$.

Our anthropogenic results can be compared to Table 6.4 of the IPCC report (Ramaswamy et al., 2001). The median and mean radiative forcings from 19 studies are $-0.38 \mathrm{~W} \mathrm{~m}^{-2}$ and $-0.45 \mathrm{~W} \mathrm{~m}^{-2}$, respectively, which compare to our values 
of $F_{L}=-0.314$ and $F_{U}=-0.404$. Comparison of normalized direct radiative forcing accounts for the variability of sulfate burdens among the models. Our $G_{U, L}$ values agree very well with Chin and Jacob (1996), who report $-246 \mathrm{~W}$ $\left(\mathrm{g} \mathrm{SO}_{4}^{2-}\right)^{-1}$. Our values are slightly higher than the median value of $-171 \mathrm{~W}\left(\mathrm{~g} \mathrm{SO}_{4}^{2-}\right)^{-1}$ and the mean value of $-212 \mathrm{~W}$ $\left(\mathrm{g} \mathrm{SO}_{4}^{2-}\right)^{-1}$ in Ramaswamy et al. (2001), which is consistent with our high $\beta$ values (Sects. 4.1 and 4.3).

\subsection{Effect of nitrate: sulfate only calculations}

With the exception of Adams et al. (2001), Jacobson (2001a), and Metzger et al. (2002), previous studies exclude nitrate. To assess the influence of nitrate on our predictions and allow for comparisons to the broad range of previous studies, we execute model runs in which only sulfate emissions are included (Table 6). As expected from the constraints of the model run, predicted solid phases shift away from AN towards AS: $<\%$ AS $>$ shifts from 27.9 to $40.3 \%$ in the BL. There are negligible changes in $<\%$ LET $>$ and $<\%$ AHS $>$ because ammonium nitrate forms significantly only in $\mathrm{NH}_{3}$ rich regions, which necessarily favor AS over LET and AHS.

In the absence of clouds, $F_{L}\left(\mathrm{SO}_{4}^{2-} ; \mathrm{NO}_{3}^{-}\right)=-0.750$ and $F_{L}\left(\mathrm{SO}_{4}^{2-}\right)=-0.653$. The nitrate contribution to forcing is inferred by subtraction: $F_{L}\left(\mathrm{NO}_{3}^{-}\right)=-0.097$. Nitrate thus increases sulfate-only forcing by $\Delta F_{L}\left(\mathrm{NO}_{3}^{-}\right)=14.9 \%$. Similar calculations yield $F_{U}\left(\mathrm{SO}_{4}^{2-} ; \mathrm{NO}_{3}^{-}\right)=-0.930$, $F_{U}\left(\mathrm{SO}_{4}^{2-}\right)=-0.817, \quad F_{U}\left(\mathrm{NO}_{3}^{-}\right)=-0.113, \quad$ and $\Delta F_{U}\left(\mathrm{NO}_{3}^{-}\right)=13.8 \%$. However, $\Delta F_{U, L}\left(\mathrm{SO}_{4}^{2-}\right)$ is nearly unchanged from $\Delta F_{U, L}\left(\mathrm{SO}_{4}^{2-} ; \mathrm{NO}_{3}^{-}\right)$, viz. $\Delta F_{U, L}\left(\mathrm{SO}_{4}^{2-}\right)=25 \%$. In the presence of clouds (scheme II), $\Delta F_{L}\left(\mathrm{NO}_{3}^{-}\right)=14.4 \%$ and $\Delta F_{U}\left(\mathrm{NO}_{3}^{-}\right)=14.3 \% . \Delta F_{U, L}$ is again nearly unchanged at $25 \%$.

$\Delta F_{U, L}\left(\mathrm{SO}_{4}^{2-}\right)$ changes little because of two coincidentally compensating factors. In the full run including nitrate, $\Delta F_{U, L}\left(\mathrm{SO}_{4}^{2-} ; \mathrm{NO}_{3}^{-}\right)=25 \%$, which partitions into $19 \%$ from the loss of $\mathrm{H}_{2} \mathrm{O}$ and $6 \%$ from volatilization of $\mathrm{AN}$ (footnote $a$, Table 6$)$. In the run without nitrate, $\Delta F_{U, L}\left(\mathrm{SO}_{4}^{2-}\right)$ could be expected to be $19 \%$ because $\mathrm{AN}$ volatilization is not possible. However, the absence of nitrate also increases $<\% \mathrm{AS}>$ from 27.9 to $40.3 \%$ in the BL, which results in an increasing effect of hysteresis on aerosol optical properties (Fig. 2) and thus increasing $\Delta F_{U, L}\left(\mathrm{SO}_{4}^{2-}\right)$. Thus, $\Delta F_{U, L}\left(\mathrm{SO}_{4}^{2-}\right)$ increases from $19 \%$ to $25 \%$ and appears nearly unchanged. The close numerical counterbalancing of the decrease by AN volatilization and the increase by rising $<\% \mathrm{AS}>$ appears fortuitous.

Adams et al. (2001) report $F_{U}\left(\mathrm{SO}_{4}^{2-}\right)=-1.48$, $F_{U}\left(\mathrm{NO}_{3}^{-}\right)=-0.30$, and $\Delta F_{U}\left(\mathrm{NO}_{3}^{-}\right)=20.2 \%$ (Table 1 therein). Direct comparison of our forcings with those of Adams et al. (2001) is complicated by differences in aerosol burdens. The normalized direct radiative forcings of Adams et al. (2001) are $G_{U}=-316 \mathrm{~W}$ (g
$\left.\mathrm{SO}_{4}^{2-}\right)^{-1}$ and $G_{U}=-411 \mathrm{~W}\left(\mathrm{~g} \mathrm{NO}_{3}^{3-}\right)^{-1}$. We obtain $G_{U}=-245 \mathrm{~W}\left(\mathrm{~g} \mathrm{SO}_{4}^{2-}\right)^{-1}$ and $G_{U}=-190 \mathrm{~W}\left(\mathrm{~g} \mathrm{NO}_{3}^{3-}\right)^{-1}$, which are calculated from our values of $F_{U}\left(\mathrm{SO}_{4}^{2-}\right)=-0.529$ and $F_{U}\left(\mathrm{NO}_{3}^{-}\right)=-0.076$ and from a sulfate burden of $2.16 \mathrm{mg} \mathrm{m}^{-2}(0.37 \mathrm{Tg} \mathrm{S})$ and a nitrate burden of $0.40 \mathrm{mg} \mathrm{m}^{-2}$ $(0.046 \mathrm{Tg} \mathrm{N})$ (Table 6). Adams et al. (2001) (page 1109) discuss reasons for the high values of their normalized forcings, the main effect being low cloud coverage in their calculations.

6.3 Factors governing susceptibility of forcing to aerosol phase

\subsubsection{Relative humidity cutoff}

Subgrid scale variation in $\mathrm{RH}$ and hence in aerosol optical properties is not directly treated in global models (Adams et al., 2001). One heuristic correction is to limit hygroscopic growth to $85 \%$ relative humidity (i.e., an RH cutoff), with the reasoning that high $\mathrm{RH}$ at the subgrid scale correlates with cloud coverage and thus that forcing by these high RH particles is masked. The effect of the imposed cutoff is large because hygroscopic growth increases exponentially at high RH. Adams et al. (2001) point out that the estimate of forcing varies in their work from -0.8 to $-1.5 \mathrm{~W} \mathrm{~m}^{-2}$ as the RH cutoff varies from 85 to $99 \%$ (Fig. 3 therein). Adams et al. (2001) choose a 99\% RH cutoff for their base case study. In comparison, we employ GMAO assimilated RH without an RH cutoff for our base case.

Compared to the base case, an $\mathrm{RH}$ cutoff reduces the global annual average $\tau_{U, L}$ and $F_{U, L}$ (Fig. 13). The limiting behavior at high RH contrasts with the exponential increase predicted by Adams et al. (2001). Two factors are responsible for this difference. The first arises from the use of assimilated $\mathrm{RH}$ as opposed to GCM simulated $\mathrm{RH}$, the latter being biased to high $\mathrm{RH}$ as compared to measurements (Ghan et al., 2001). The second and major factor is associated with our use of off-line monthly $\mathrm{RH}$ values, which are lower than the instantaneous on-line RH used by Adams et al. (2001). There is a low frequency occurrence of $\mathrm{RH}>95 \%$ in our simulation (Fig. 14a) and thus a correspondingly minor impact on $F_{U, L}$.

$\Delta F_{U, L}$ increases from $25 \%$ to $27 \%$ as the RH cutoff drops from 99 to $80 \%$ (Fig. 13). The explanation is similar to the increase in $\Delta F_{U, L}$ when clouds are present (Sect. 5.2.2), which is readily understood upon realizing that clouds act as a high RH mask. The effect of the RH cutoff is to favor a weighting in the average of low RH $\Delta F_{U, L}$ at the expense of high RH $\Delta F_{U, L}$, and a slight increase in the global average $\Delta F_{U, L}$ results.

\subsubsection{Relative humidity histogram analysis}

To explore the factors in the global model most influencing $\Delta \sigma_{U, L}$ and hence $\Delta F_{U, L}$, we group model grid boxes into 

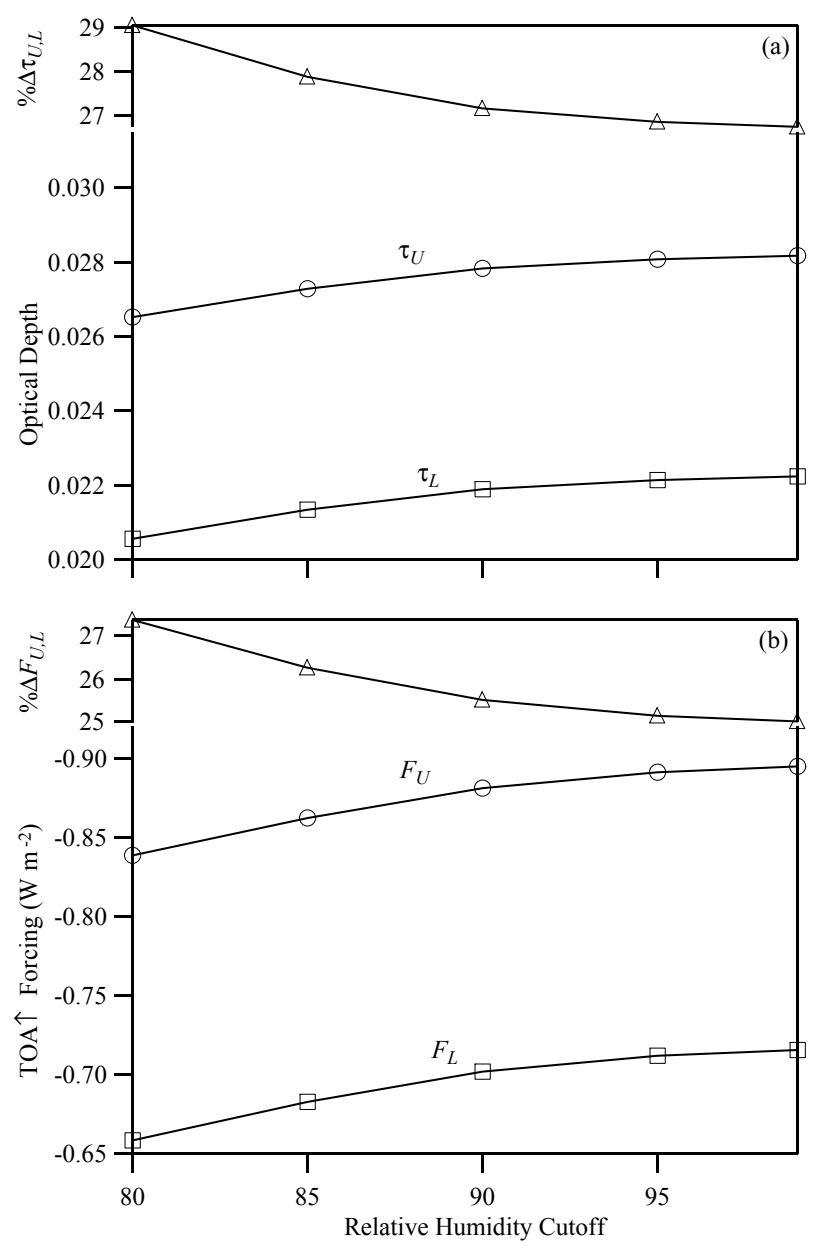

Fig. 13. Dependence of global annual average optical depth and TOA $\uparrow$ forcing on RH cutoff. (a) Optical depths $\tau_{U, L}$ on US and LS of the hysteresis loop and their percent difference. (b) Same but for TOA $\uparrow$ forcings $F_{U, L}$. Calculated for full sky without clouds. Excluding this figure, all calculations in this study employ no cutoff.

5\% RH bins. Although the greatest $\sigma_{L}$ occur at high $\mathrm{RH}$ (Fig. 14b), most tropospheric volume lies between 40 and $60 \%$ RH (Fig. 14a). Within each RH bin, there is variation in $\sigma_{L}$ because of differences in aerosol loading and in hygroscopic growth (dependent on $[X, Y]$ ). Box-and-whisker plots at $10,25,50,75$, and $90 \%$ frequency levels (weighted by grid box volume) describe the $\sigma_{L}$ distribution. Although $\sigma_{L}$ is greatest at high RH, $\Delta \sigma_{U, L}=0$ because the US and LS of the hysteresis loop are identical (Fig. 1c). The greatest susceptibility to phase occurs from 60 to $65 \%$ in both the absolute $\Delta \sigma_{U, L}$ (Fig. 14c) and the relative $\% \Delta \sigma_{U, L}$ (Fig. 14d). Outlying large $\% \Delta \sigma_{U, L}$ values also occur from 65 to $75 \%$ RH for a few grid boxes, viz. those having $[X, Y]$ near $[1$, 1] (Fig. 2). Consideration together of volume occurrence (Fig. 14a) and $\Delta \sigma_{U, L}$ (Fig. 14c) leads to the conclusion that grid boxes having 50 to $70 \% \mathrm{RH}$ contribute most to the global annual average $\Delta \tau_{U, L}$. Furthermore, the contribution

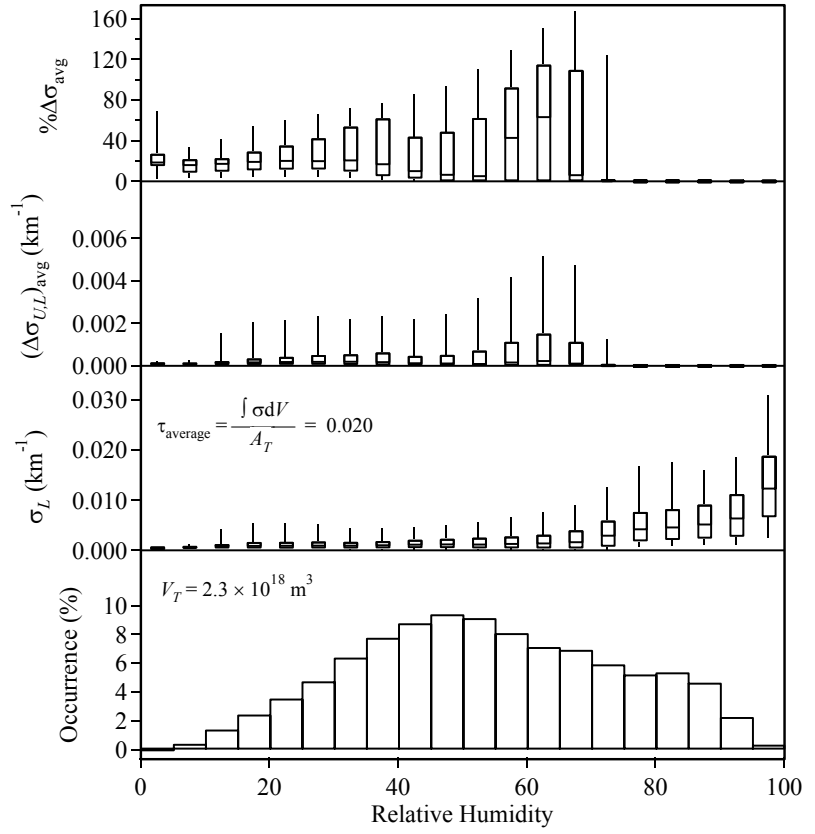

Fig. 14. Histograms showing contributions of RH ranges to (a) tropospheric volume, (b) LS scattering efficiency, (c) change in scattering efficiency on US versus LS, and (d) percent change in scattering efficiency on US versus LS. The lowest 12 layers of the model (600 mbar), which are representative of $90 \%$ of the LS annual average optical depth, are included in the analysis. In $b$ to $d$, boxand-whisker plots show $10 \%, 25 \%, 50 \%, 75 \%$, and $90 \%$ frequency among model grid boxes (weighted by grid box volume).

to $\Delta \tau_{U, L}$ by the last quantile dominates relative to the first three quantiles. The last quantile of grid boxes have high $\Delta \sigma_{U, L}$ and correspond to $[X, Y]$ near $[1,1]$ and/or cold temperatures.

\subsubsection{Other factors}

Other factors influencing the results of our study are readily identified, and in some cases we can predict whether $\Delta F_{U, L}$ will increase or decrease. For instance, the number of solids included in the LS behavior directly influences forcing. At tropospheric temperatures, there are seven solids in the SNA system. However, according to laboratory studies, the crystallization of some of these solids such as AHS and AN occurs less readily than others such as AS and LET. ISORROPIA itself includes only four solids. On the one hand, if all seven solids crystallize, then the difference between the LS and US of the hysteresis loop increases, which suggests our $\Delta F_{U, L}$ values are lower limits. On the other hand, if fewer solids crystallize (say just LET and AS), then the difference between LS and US behavior decreases, which suggests our $\Delta F_{U, L}$ values are upper limits. This uncertainty notwithstanding, laboratory studies show AS crystallizes most readily of all the seven solids and, as 
mentioned above, Figs. 2 and 5a together demonstrate that AS is the solid most strongly affecting the magnitude of $\Delta F_{U, L}$. The other important solid affecting $\Delta F_{U, L}$ is AN due to its volatilization. On the LS, if AS is allowed to crystallized but AN is not, then the increase in ionic strength of the residual aqueous liquid following AS crystallization still drives the partial volatilization of $\mathrm{NH}_{3}$ and $\mathrm{HNO}_{3}$. We thus suggest that our reported $\Delta F_{U, L}$ is a central value dependent mostly on AS crystallization and AN volatilization; consideration of the occurrence of other solids perturbs this central value.

Our use of constant refractive indices independent of composition and hydration state (Sect. 4.1) systematically overstates the scattering efficiency on the US of the hysteresis loop, implying that $\Delta F_{U, L}$ is an upper limit. As stated in Sect 6.3.2, optical depth and hence forcing is most strongly influenced by particles in the 50 to $70 \% \mathrm{RH}$ range, for which the refractive index is estimated to be 1.43 and 1.40 , respectively (cf. Fig. 2 for $\mathrm{NH}_{4} \mathrm{HSO}_{4}$ (aq) in Nemesure et al. (1995)), as compared to 1.46 for the crystalline particles. Using the analysis of Hegg et al. (1993) (Eq. 2 therein), we conclude that scattering on the US of the hysteresis loop is reduced by $11 \%$ and $22 \%$ at $50 \%$ and $70 \% \mathrm{RH}$, respectively. In comparison, the reduction on the LS of the hysteresis loop is smaller because the mass of the aqueous phase is smaller (cf. Fig. 1c for the $[0.8,0.8]$ composition). We conclude that the decrease in refractive index with increasing water content reduces scattering efficiency more on the US than on the LS. Therefore, the reported $\Delta F_{U, L}$, which does not account for this effect, is an upper limit.

In some cases, the change in $\Delta F_{U, L}$ is uncertain, even though the directions of change for $F_{U}$ and $F_{L}$ are individually clear. For example, we employ monthly RH averages with off-line radiative transfer calculations, rather than on-line RH simulation coupled to on-line radiative transfer. Inaccuracies introduced by the use of monthly $\mathrm{RH}$ are discussed by Haywood and Boucher (2000) (page 519) and Ramaswamy et al. (2001) (page 368). Although the use of monthly RH underestimates $F_{U}$ and $F_{L}$, the effect on $\Delta F_{U, L}$ is unclear. $F_{U}$ and $F_{L}$ are principally underestimated because of underprediction of the occurrence of highly scattering aqueous particles a high $\mathrm{RH}$, yet $\Delta F_{U, L}=0$ at high RH.

Our study limits aerosol chemical composition to $\mathrm{SO}_{4}^{2-}-\mathrm{NO}_{3}^{-}-\mathrm{NH}_{4}^{+}-\mathrm{H}^{+}-\mathrm{H}_{2} \mathrm{O}$, yet authentic atmospheric aerosols have a more complex internally mixed chemistry. More detailed descriptions of aerosol direct radiative forcing include soot, organic molecules, dust, and sea salt (Tegen et al., 1996; Haywood et al., 1997; Haywood and Shine, 1997; Tegen et al., 1997; Haywood and Ramaswamy, 1998; Jacobson, 2001b; Sokolik et al., 2001; Chin et al., 2002; Menon et al., 2002). Particularly affecting $\Delta F_{U, L}$ are dissolved low molecular weight organic molecules, which are commonly internally mixed with anthropogenic sulfates and nitrates. Dissolved organic molecules typically decrease hygroscopicity and decrease, increase, or leave unchanged CRH (Cruz and Pandis, 2000; Prenni et al., 2001; Brooks et al., 2002, 2003; Choi and Chan, 2002). Insoluble components such as mineral dust particles do not affect hygroscopicity directly but do serve as effective heterogeneous nuclei, thus increasing $\mathrm{CRH}$ and decreasing the $\mathrm{RH}$ hysteresis window over which $\Delta F_{U, L} \neq 0$ (Han and Martin, 1999; Martin et al., 2001; Han et al., 2002).

Given the complexity of atmospheric particles, the sulfate, nitrate, and ammonium system represents a baseline in that it is the largest anthropogenic input to the accumulation mode on a mass basis and the most significant anthropogenic cooling contribution to light scattering on a global basis. Although this baseline has considerable uncertainty associated with it, the results of the current work provide important quantitative progress. This baseline can be employed in future work as a metric to evaluate perturbations by the effects of organic molecules, mineral dusts, and soot on CRH and DRH and the related atmospheric effects.

Knowledge of the molecular composition of atmospheric particle-phase organic molecules is limited. Furthermore, there is limited laboratory data on the role of organic molecules in phase transitions. These two facts hinder predictions of the effects of organic molecules on the phase transitions of sulfate, nitrate, and ammonium particles. Nevertheless, calling upon the limited laboratory data, literature reports, and several assumptions, we provide below an initial estimate.

Based upon the IPCC SC1 scenario for 2000 (Table 5.14, Penner et al., 2001), the atmospheric burden comprises $0.78 \mathrm{Tg} \mathrm{S}$ as sulfate, $0.09 \mathrm{Tg} \mathrm{N}$ as nitrate, and $0.42 \mathrm{Tg} \mathrm{N}$ as ammonium. (These values compare to our respective estimates of $0.37,0.05$, and $0.29 \mathrm{Tg}$, see Sect. 2.2.) The $\mathrm{SC} 1$ scenario then provides $(0.15+1.52=1.67) \mathrm{Tg}$ of organic molecules (i.e., the sum of carbon, hydrogen, and oxygen). As an upper limit of the effect of organic molecules, we assume that they are water soluble and internally mixed with the inorganic constituents. We assume that the organic molecules do not crystallize. We do not consider heterogeneous nucleation and the possible effects of surfactants, which could influence the hygroscopic properties and the physical state of the particles. Further work is needed to determine the accuracy of these assumptions.

For phase transitions, instead of mass, the appropriate concentration scale is mole fraction because the deliquescence water activity of an ideal solution is linear in mole fraction. Using molecular weights for sulfur (32), nitrogen (14), and organic molecules (150), we obtain relative global mole burdens of 2.4 for sulfate, 0.64 for nitrate, and 1.1 for organics. (We omit ammonium because we assume that the sulfate and nitrate occur as molecular units combined with ammonium or proton.) The organic molecular weight of 150 is chosen assuming an average monomeric chemical unit of $\mathrm{CH}_{2} \mathrm{O}$ and an average of five units in each molecule. This estimate seems reasonable considering the organic molecules commonly identified in atmospheric aerosol particles; nevertheless, this 
estimate is a source of uncertainty in our analysis. Following from the relative global mole burdens, the average organic mole fraction is calculated as $(1.1) /(2.4+0.64+1.1)$ or 0.27 , which appears to provide an upper limit because the actual extent of internal mixing and water solubility are below $100 \%$.

Based on the above analysis and assumptions, we conclude that the inorganic system represents a baseline, to which the organic molecules are a perturbation of up to 0.27 . For mole fractions below 0.35 , the changes in DRH and CRH due to organic molecules are anticipated to be minor (Brooks et al., 2002; Braban and Abbatt, 2003; Parsons et al., 2003). In this case, the CRH and DRH values depend first on the inorganic composition, which is then modified slightly by the organic molecules. We conclude that the inorganic system is a baseline for estimating the major effects on hygroscopic growth between the upper and lower sides (US and LS) of the hysteresis loop.

The above analysis for organic molecules assumes a globally averaged aerosol particle chemical composition. In reality, there is great variability among individual atmospheric particles as well as large regional differences such as organic enriched particles coming from biomass burning in Africa versus sulfate enriched outflows from heavy coal usage in China. Certainly, there exist individual particles having high organic content. For these particles, the hygroscopic and phase transition properties depend upon the concentrations and the physicochemical properties of the organic molecules.

Water insoluble organic inclusions inside sulfate particles influence aerosol direct radiative forcing. Especially important is black carbon (soot) because it absorbs solar radiation and contributes to atmospheric warming by aerosol particles (Jacobson, 2000). Due to a lens effect, the warming efficiency $\left(\mathrm{W} \mathrm{m}^{-2}\left(\mathrm{~g} \mathrm{C} \mathrm{m}^{-2}\right)^{-1}\right)$ increases when black carbon inclusions occur inside sulfate particles. A typical example is a $100 \mathrm{~nm}$ sulfate particle having a $40 \mathrm{~nm}$ black carbon inclusion. The additional warming typically partially offsets the cooling by sulfate, so the net effect is a less negative forcing.

For the purposes of this paper, we wish to assess how the relative warming efficiency of black carbon inclusions depends on the phase of the host particle. Figures 2a, 4a, and 5 of Lesins et al. (2002) are instructive. A base case is an externally mixed aerosol having $90 \%$ AS and $10 \%$ black carbon particles, in which the AS particles follow the US of the hysteresis loop. In comparison, when the aerosol particles are internally mixed, the single scattering albedo is $8 \%$ less for US behavior and $23 \%$ less for LS behavior at $80 \% \mathrm{RH}$ (Fig. 2a, Lesins et al., 2002). On the one hand, the darker LS particles favor increased warming. On the other hand, the scattering efficiency of LS particles is lower, which limits the amount of light absorbed and hence warming. The warming efficiency of black carbon is thus anticipated to depend on phase, although there are convoluted effects of a decrease in scattering efficiency with an increase in absorption. A radiative transfer model yields normalized aerosol direct radiative forcing of $G_{L}=-25 \mathrm{~W} \mathrm{~g}^{-1}$ and $G_{U}=-80 \mathrm{~W} \mathrm{~g}^{-1}$ for black carbon internally mixed with sulfate. In comparison, $G_{L}=-50 \mathrm{~W} \mathrm{~g}^{-1}$ and $G_{U}=-90 \mathrm{~W} \mathrm{~g}^{-1}$ for black carbon externally mixed with sulfate. (The calculations are for a specific scenario of surface albedo and particle number size distribution at $80 \%$ RH; see Fig. 5, Lesins et al., 2002.) The percentage differences between $G_{U}$ and $G_{L}$ are $220 \%$ versus $80 \%$ for black carbon internally versus externally mixed with sulfate. This analysis suggests that $\Delta F_{U, L}$ reported by us for global aerosol direct radiative forcing is a lower limit; $\Delta F_{U, L}$ is expected to increase when black carbon internally mixes with sulfate.

The complexity of real atmospheric aerosol versus our simplified model treatment is one reason for the discrepancies between observed and predicted $[X, Y]$ in Fig. 5. Although the best agreement is obtained for USA, the mean difference $\left(\Delta X^{2}+\Delta Y^{2}\right)^{1 / 2}$ is 0.26 (Fig. $5 \mathrm{~b}$ ). Some of the difference is explained by our approach for obtaining measured $\left[\mathrm{H}^{+}\right]$by charge balance because a fraction of the measured $\left[\mathrm{NO}_{3}^{-}\right]$is neutralized by other cations (e.g. $\mathrm{Na}^{+}$and $\mathrm{Ca}^{2+}$ ), which has the effect of shifting the locus of $[X, Y]_{\text {observed }}$ towards greater neutralization and thus into better agreement with $[X, Y]_{\text {predicted }}$. The difference is important because phase depends strongly on $[X, Y]$. A random translation of 0.26 in Fig. 1a leads to significant variations in predicted phase. On the other hand, there are uncertainties in $[X, Y]_{\text {predicted }}$, the largest being the accuracy in state-of-theart ammonia emissions (Park et al., 2003).

\section{Conclusions}

The effect of crystalline versus aqueous sulfate-nitrateammonium tropospheric particles on annual average global aerosol direct radiative forcing is significant. The effect on forcing arises from the loss to the gas-phase of aerosol water, nitrate, and ammonium on the LS of the hysteresis loop; this loss reduces particle diameter and light scattering on the LS of the hysteresis loop, thus allowing more solar energy to reach the Earth's surface as compared to the US of the hysteresis loop. Retained aerosol $\mathrm{H}_{2} \mathrm{O}$ mass is $78 \%$, retained crystalline and aqueous aerosol nitrate mass is 33\%, and retained crystalline and aqueous aerosol ammonium mass is 95\%. Depending upon dry mode particle size, cloud treatment, anthropogenic versus natural emissions, and the inclusion of nitrate, the difference $\Delta F_{U, L}$ ranges from 21 to $32 \%$. The large magnitude of $\Delta F_{U, L}$ arises in large part because of the correlation in clustering towards the $[1,1]$ AS pole of both aerosol particle chemical composition (Fig. 5a) and the susceptibility of the extinction coefficient to particle phase (Fig. 2). Compared to the other solids, formation of AS is most important because it is thermodynamically stable at the highest RH values, where the US deviates most strongly from the LS of the hysteresis loop. The regional and seasonal 
$\Delta F_{U, L}$ ranges from $6 \%$ over the southern hemisphere ocean in DJF to $75 \%$ over the USA in SON.

Our study establishes seasonal and regional susceptibilities and governing factors of SNA aerosol phase and predicts the impacts on global aerosol direct radiative forcing. Because the limiting scenarios of LS versus US behavior are calculated, we establish a central value for the upper limit of SNA aerosol on global aerosol direct radiative forcing. Given the significant differences we find between $F_{U}$ and $F_{L}$, further global modeling employing prognostic treatments of aerosol phase to account for RH history is highly warranted, especially in light of field observations showing that atmospheric particles possess an array of behavior intermediate to the US and LS extremes and generally crystallize at sufficiently low relative humidities (Charlson et al., 1974a, b; Hänel and Lehmann, 1981; Rood et al., 1987, 1989; Shaw and Rood, 1990; Koloutsou-Vakakis and Rood, 1994; Pitchford and McMurry, 1994; ten Brink et al., 1996; Dougle et al., 1998) (see further in Sect. VI of Martin, 2000).

\section{Notation}

$\begin{aligned} & {[X, Y] } \text { a particle composition of } X \text { and } Y . \\ &<X, Y>\quad \text { expectation value given by the average of } \\ & \\ & \text { a population of } X \text { and } Y \text { (often the } \\ & \text { average is weighted by the longitude-latitude } \\ & \text { area of a grid box and is thus an expectation } \\ & \text { value of a geographic distribution; aerosol } \\ & \text { mass is not included in the average). }\end{aligned}$

Acknowledgements. Discussions with A. Bertram about the effects of organic molecules on the phase transitions of ammonium-sulfatenitrate particles were very stimulating. We are grateful for support received from the National Science Foundation Atmospheric Chemistry Program and the New York Community Trust Merck Fund. Research at the Smithsonian Astrophysical Observatory was supported by Smithsonian Institution internal funding.

\section{References}

Adams, P. J., Seinfeld, J. H., and Koch, D. M.: Global concentrations of tropospheric sulfate, nitrate, and ammonium aerosol simulated in a general circulation model, J. Geophys. Res., 104, 13 791-13 823, 1999.

Adams, P. J., Seinfeld, J. H., Koch, D., Mickley, L., and Jacob, D.: General circulation model assessment of direct radiative forcing by the sulfate-nitrate-ammonium-water inorganic aerosol system, J. Geophys. Res., 106, 1097-1111, 2001.

Ansari, A. S. and Pandis, S. N.: The effect of metastable equilibrium states on the partitioning of nitrate between the gas and aerosol phases, Atmos. Environ., 34, 157-168, 2000.

Barth, M. C., Rasch, P. J., Kiehl, J. T., Benkovitz, C. M., and Schwartz, S. E.: Sulfur chemistry in the National Center for Atmospheric Research Community Climate Model: Description, evaluation, features, and sensitivity to aqueous chemistry, J. Geophys. Res., 105, 1387-1415, 2000.
Bodhaine, B. A., Wood, N. B., Dutton, E. G., and Slusser, J. R.: On Rayleigh optical depth calculations, J. Atmos. Ocean. Technol., 16, 1854-1861, 1999.

Bohren, C. F. and Huffmann, D. R.: Absorption and scattering of light by small particles, Wiley, New York, 1983.

Boucher, O. and Anderson, T. L.: General circulation model assessment of the sensitivity of direct climate forcing by anthropogenic sulfate aerosols to aerosol size and chemistry, J. Geophys. Res., 100, $26117-26134,1995$.

Boucher, O.: On aerosol direct shortwave forcing and the HenyeyGreenstein phase function, J. Atmos. Sci., 55, 128-134, 1998.

Boucher, O., Schwartz, S., E., Ackerman, T. P., et al.: Intercomparison of models representing direct shortwave radiative forcing by sulfate aerosols, J. Geophys. Res., 103, 16979-16998, 1998.

Braban, C. and Abbatt, J. P.: Effect of Dicarboxylic Acids on the Phase Transitions of Model Tropospheric Aerosols, American Geophysical Union Fall Meeting, San Francisco, 2003.

Briegleb, B. P.: Delta-Eddington Approximation for solar-radiation in the NCAR community climate model, J. Geophys. Res., 97, 7603-7612, 1992.

Brooks, S. D., Wise, M. E., Cushing, M., and Tolbert, M. A.: Deliquescence behavior of organic/ammonium sulfate aerosol, Geophys. Res. Lett., 29, 1917, 2002.

Brooks, S. D., Garland, R. M., Wise, M. E., Prenni, A. J., Cushing, M., Hewitt, E., and Tolbert, M. A.: Phase changes in internally mixed maleic acid/ammonium sulfate aerosols, J. Geophys. Res. 108, 4487, 2003.

Burrows, J. P., Richter, A., Dehn, A., Deters, B., Himmelmann, S., and Orphal, J.: Atmospheric remote-sensing reference data from GOME - 2. Temperature-dependent absorption cross sections of $\mathrm{O}_{3}$ in the 231-794 nm range, J. Quant. Spectrosc. Radiat. Transf., 61, 509-517, 1999.

Cess, R. D.: Nuclear war: Illustrative effects of atmospheric smoke and dust upon solar radiation, Clim. Change, 7, 237-251, 1985.

Charlson, R. J., Porch, W. M., Waggoner, A. P., and Ahlquist, N. C.: Background aerosol light scattering characteristics: nephelometric obserevations at Mauna Loa observatory compared with results at other remote locations, Tellus, 3, 345-360, 1974a.

Charlson, R. J., Vanderpol, A. H., Covert, D. S., Waggoner, A. P., and Ahlquist, N. C.: $\mathrm{H}_{2} \mathrm{SO}_{4} /\left(\mathrm{NH}_{4}\right)_{2} \mathrm{SO}_{4}$ background aerosol: Optical detection in St. Louis region, Atmos. Environ., 8, $1257-$ 1267, 1974b.

Charlson, R. J., Langner, J., Rodhe, H., Leovy, C. B., and Warren, S. G.: Perturbation of the northern-hemisphere radiative balance by backscattering from anthropogenic sulfate aerosols, Tellus Ser. A-Dyn. Meteorol. Oceanol., 43, 152-163, 1991.

Charlson, R. J., Schwartz, S. E., Hales, J. M., Cess, R. D., Coakley, J. A., Hansen, J. E., and Hofmann, D. J.: Climate forcing by anthropogenic aerosols, Science, 255, 422-430, 1992.

Chin, M., Jacob, D. J., Gardner, G. M., Foreman-Fowler, M. S., Spiro, P. A., and Savoie, D. L.: A global three dimensional model of tropospheric sulfate, J. Geophys. Res., 101, 18667-18690, 1996.

Chin, M., Rood, R. B., Lin, S. J., Muller, J. F., and Thompson, A. M.: Atmospheric sulfur cycle simulated in the global model GOCART: Model description and global properties, J. Geophys. Res., 105, 24 671-24 687, 2000.

Chin, M., Ginoux, P., Kinne, S., Torres, O., Holben, B. N., Duncan, B. N., Martin, R. V., Logan, J. A., Higurashi, A., and Nakajima, 
T.: Tropospheric aerosol optical thickness from the GOCART model and comparisons with satellite and sun photometer measurements, J. Atmos. Sci., 59, 461-483, 2002.

Chin, M. A. and Jacob, D. J.: Anthropogenic and natural contributions to tropospheric sulfate: A global model analysis, J. Geophys. Res., 101, 18 691-18699, 1996.

Choi, M. Y. and Chan, C. K.: The effects of organic species on the hygroscopic behaviors of inorganic aerosols, Environ. Sci. Technol., 36, 2422-2428, 2002.

Chou, M.-D. and Suarez, M. J.: A solar radiation parameterization for atmospheric studies (http://nsipp.gsfc.nasa.gov/reports/ volume_15.pdf), NASA/TM-1999-104606, Vol. 15, 1999.

Chuang, C. C., Penner, J. E., Taylor, K. E., Grossman, A. S., and Walton, J. J.: An assessment of the radiative effects of anthropogenic sulfate, J. Geophys. Res., 102, 3761-3778, 1997.

Clegg, S. L., Brimblecombe, P., and Wexler, A. S.: Thermodynamic model of the system $\mathrm{H}^{+} / \mathrm{NH}_{4}^{+} / \mathrm{SO}_{4}^{2-} / \mathrm{NO}_{3}^{-} / \mathrm{H}_{2} \mathrm{O}$ at tropospheric temperatures, J. Phys. Chem. A, 102, 2137-2154, 1998.

Colberg, C. A., Luo, B. P., Wernli, H., Koop, T., and Peter, T.: A novel model to predict the physical state of atmospheric $\mathrm{H}_{2} \mathrm{SO}_{4} / \mathrm{NH}_{3} / \mathrm{H}_{2} \mathrm{O}$ aerosol particles, Atmos. Chem. Phys., 3, 909-924, 2003.

Cruz, C. N. and Pandis, S. N.: Deliquescence and hygroscopic growth of mixed inorganic-organic atmospheric aerosol, Environ. Sci. Technol., 34, 4313-4319, 2000.

Dahlback, A. and Stamnes, K.: A new spherical model for computing the radiation-field available for photolysis and heating at twilight, Planet Space Sci., 39, 671-683, 1991.

Dentener, F. J. and Crutzen, P. J.: Reaction of $\mathrm{N}_{2} \mathrm{O}_{5}$ on Tropospheric aerosols: Impact on the global distributions of $\mathrm{NO}_{\mathrm{x}}, \mathrm{O}_{3}$, and OH, J. Geophys. Res., 98, 7149-7163, 1993.

Dougle, P. G., Veefkind, J. P., and ten Brink, H. M.: Crystallisation of mixtures of ammonium nitrate, ammonium sulfate, and soot, J. Aerosol Sci., 29, 375-386, 1998.

EPA, U. S.: Clean Air Status and Trends Network (CASTNET), 1998 Annual Report, August 1999.

Finlayson-Pitts, B. J. and Hemminger, J. C.: Physical chemistry of airborne sea salt particles and their components, J. Phys. Chem. A, 104, 11 463-11 477, 2000.

Fortuin, J. P. F. and Kelder, H.: An ozone climatology based on ozonesonde and satellite measurements, J. Geophys. Res., 103, 31 709-31 734, 1998.

Ghan, S. J., Easter, R. C., Chapman, E. G., Abdul-Razzak, H., Zhang, Y., Leung, L. R., Laulainen, N. S., Saylor, R. D., and Zaveri, R. A.: A physically based estimate of radiative forcing by anthropogenic sulfate aerosol, J. Geophys. Res., 106, 52795293, 2001.

Han, J. and Martin, S. T.: Heterogeneous nucleation of the efflorescence of $\left(\mathrm{NH}_{4}\right)_{2} \mathrm{SO}_{4}$ particles internally mixed with $\mathrm{Al}_{2} \mathrm{O}_{3}$, $\mathrm{TiO}_{2}$, and $\mathrm{ZrO}_{2}$, J. Geophys. Res., 104, 3543-3553, 1999.

Han, J. H. and Martin, S. T.: An aerosol chemical reactor for coating metal oxide particles with $\left(\mathrm{NH}_{4}\right)_{2} \mathrm{SO}_{4}-\mathrm{H}_{2} \mathrm{SO}_{4}-\mathrm{H}_{2} \mathrm{O}, 1$. New particle formation, Aerosol Sci. Technol., 34, 363-372, 2001.

Han, J. H., Hung, H. M., and Martin, S. T.: The size effect of hematite and corundum inclusions on the efflorescence relative humidities of aqueous ammonium nitrate particles, J. Geophys. Res., 107, 4086, 2002.

Hänel, G. and Lehmann, M.: Equilibrium size of aerosol parti- cles and relative humidity: new experimental data from various aerosol types and their treatment for cloud physics application, Cont. Atmos. Phys., 54, 57-71, 1981.

Haywood, J. and Boucher, O.: Estimates of the direct and indirect radiative forcing due to tropospheric aerosols: A review, Rev. Geophys., 38, 513-543, 2000.

Haywood, J. M., Roberts, D. L., Slingo, A., Edwards, J. M., and Shine, K. P.: General circulation model calculations of the direct radiative forcing by anthropogenic sulfate and fossil-fuel soot aerosol, J. Clim., 10, 1562-1577, 1997.

Haywood, J. M. and Shine, K. P.: Multi-spectral calculations of the direct radiative forcing of tropospheric sulphate and soot aerosols using a column model, Q. J. R. Meteorol. Soc., 123, 1907-1930, 1997.

Haywood, J. M. and Ramaswamy, V.: Global sensitivity studies of the direct radiative forcing due to anthropogenic sulfate and black carbon aerosols, J. Geophys. Res., 103, 6043-6058, 1998.

Hegg, D., Larson, T., and Yuen, P. F.: A theoretical study of the effect of relative humidity on light scattering by tropospheric aerosols, J. Geophys. Res., 98, 18 435-18 439, 1993.

Henyey, L. C. and Greenstein, J. L.: Diffuse radiation in the galaxy, Astrophys. J., 93, 70-83, 1941.

Hillert, M.: Phase Equilibria, Phase Diagrams, and Phase Transformations: Their Thermodynamic Basis, Cambridge University Press, Cambridge, 1998.

Hinds, W. C.: Aerosol Technology: Properties, Behavior, and Measurement of Airborne Particles, Wiley, New York, 1999.

Hjellbrekke, A. G.: Data Report 1998. Part 2: Monthly and Seasonal Summaries (EMEP/CCC-Report 4/2000), Kjeller, Norwegian Institute for Air Research, July, 2000.

Houghton, J. T., Ding, Y., Griggs, D. J., Noguer, M., Linden, P. J., Dai, X., Maskell, K., and Johnson, C. A.: Climate Change 2001: The Scientific Basis, Cambridge University Press, Cambridge, 2001.

$\mathrm{Hu}$, J. H. and Abbatt, J. P. D.: Reaction probabilities for $\mathrm{N}_{2} \mathrm{O}_{5}$ hydrolysis on sulfuric acid and ammonium sulfate aerosols at room temperature, J. Phys. Chem., 101, 871-878, 1997.

Hung, H. M. and Martin, S. T.: Infrared spectroscopic evidence for the ice formation mechanisms active in aerosol flow tubes, Appl. Spectrosc., 56, 1067-1081, 2002.

Jacob, D. J.: Heterogeneous chemistry and tropospheric ozone, Atmos. Environ., 34, 2131-2159, 2000.

Jacobson, M. Z.: A physically based treatment of elemental carbon optics: Implications for global direct forcing of aerosols, Geophys. Res. Lett., 27, 217-220, 2000.

Jacobson, M. Z.: Global direct radiative forcing due to multicomponent anthropogenic and natural aerosols, J. Geophys. Res., 106, 1551-1568, 2001a.

Jacobson, M. Z.: Strong radiative heating due to the mixing state of black carbon in atmospheric aerosols, Nature, 409, 695-697, 2001b.

Kane, S. M., Caloz, F., and Leu, M. T.: Heterogeneous uptake of gaseous $\mathrm{N}_{2} \mathrm{O}_{5}$ by $\left(\mathrm{NH}_{4}\right)_{2} \mathrm{SO}_{4}, \mathrm{NH}_{4} \mathrm{HSO}_{4}$, and $\mathrm{H}_{2} \mathrm{SO}_{4}$ aerosols, J. Phys. Chem. A, 105, 6465-6470, 2001.

Kiehl, J. T. and Briegleb, B. P.: The relative roles of sulfate aerosols and greenhouse gases in climate forcing, Science, 260, 311-314, 1993.

Kiehl, J. T., Schneider, T. L., Rasch, P. J., Barth, M. C., and Wong, J.: Radiative forcing due to sulfate aerosols from simulations 
with the National Center for Atmospheric Research Community Climate Model, Version 3, J. Geophys. Res., 105, 1441-1457, 2000.

Koch, D., Jacob, D., Tegen, I., Rind, D., and Chin, M.: Tropospheric sulfur simulation and sulfate direct radiative forcing in the Goddard Institute for Space Studies general circulation model, J. Geophys. Res., 104, 23 799-23 822, 1999.

Koelemeijer, R. B. A., de Haan, J. F., and Stammes, P.: A database of spectral surface reflectivity in the range $335-772 \mathrm{~nm}$ derived from 5.5 years of GOME observations, J. Geophys. Res., 108, 4070, 2003.

Koloutsou-Vakakis, S. and Rood, M. J.: The $\left(\mathrm{NH}_{4}\right)_{2} \mathrm{SO}_{4}-\mathrm{Na}_{2} \mathrm{SO}_{4}-\mathrm{H}_{2} \mathrm{O}$ system: comparison of deliquescence humidities measured in the field and estimated from laboratory measurements and thermodynamic modeling, Tellus, 46B, 1-15, 1994.

Lesins, G., Chylek, P., and Lohmann, U.: A study of internal and external mixing scenarios and its effect on aerosol optical properties and direct radiative forcing, J. Geophys. Res., 107, 4094, 2002.

Liao, H., Adams, P. J., Chung, S. H., Seinfeld, J. H., Mickley, L. J., and Jacob, D. J.: Interactions between tropospheric chemistry and aerosols in a unified general circulation model, J. Geophys. Res., 108, 4001, 2003.

Liu, H. Y., Jacob, D. J., Bey, I., and Yantosca, R. M.: Constraints from $\mathrm{Pb}-210$ and $\mathrm{Be}-7$ on wet deposition and transport in a global three-dimensional chemical tracer model driven by assimilated meteorological fields, J. Geophys. Res., 106, 12 109-12 128, 2001

Martin, S. T.: Phase transitions of aqueous atmospheric particles, Chem. Rev., 100, 3403-3453, 2000.

Martin, S. T., Han, J. H., and Hung, H. M.: The size effect of hematite and corundum inclusions on the efflorescence relative humidities of aqueous ammonium sulfate particles, Geophys. Res. Lett., 28, 2601-2604, 2001.

Menon, S., Hansen, J., Nazarenko, L., and Luo, Y. F.: Climate effects of black carbon aerosols in China and India, Science, 297, 2250-2253, 2002.

Metzger, S., Dentener, F., Krol, M., Jeuken, A., and Lelieveld, J.: Gas/aerosol partitioning - 2. Global modeling results, J. Geophys. Res., 107, 4313, 2002.

Morcrette, J. J. and Fouquart, Y.: The overlapping of cloud layers in shortwave radiation parameterizations, J. Atmos. Sci., 43, 321328, 1986.

Mozurkewich, M. and Calvert, J. G.: Reaction probability of $\mathrm{N}_{2} \mathrm{O}_{5}$ on aqueous aerosols, J. Geophys. Res., 93, 15 889, 1988.

Nemesure, S., Wagener, R., and Schwartz, S. E.: Direct shortwave forcing of climate by the anthropogenic sulfate aerosol: Sensitivity to particle size, composition, and relative humidity, J. Geophys. Res., 100, 26 105-26116, 1995.

Nenes, A., Pandis, S. N., and Pilinis, C.: ISORROPIA: A new thermodynamic equilibrium model for multiphase multicomponent inorganic aerosols, Aquat. Geochem., 4, 123-152, 1998.

Park, R. J., Jacob, D. J., Field, B.D., Yantosca, R. M., and Chin, M.: Natural and transboundary pollution influences on sulfatenitrate-ammonium aerosols in the United States: implications for policy, submitted December 2003.

Parsons, M. T., Fok, A., Mak, J., Lipetz, S. R., Pant, A., Bertram, A. K., Haddrell, A., Agnes, G. R.: Deliquescence and Ef- florescence of Organic and Mixed Organic-Inorganic Particles: An FTIR/Optical Microscopy Approach, American Geophysical Union Fall Meeting, San Francisco, 2003.

Penner, J. E., Andreae, M., Annegarn, H., et al.: Aerosols, their Direct and Indirect Effects, in In Climate Change 2001: The Scientific Basis. Contribution of Working Group I to the Third Assessment Report of the Intergovernmental Panel on Climate Change, edited by Houghton, J. T., Ding, Y., Griggs, D. J., Noguer, M., Linden, P. J., Dai, X., Maskell, K., and Johnson, C. A., pp. 289348, Cambridge University Press, 2001.

Penner, J. E., Zhang, S. E., Chin, M., et al.: A comparison of modeland satellite-derived aerosol optical depth and reflectivity, J. Atmos. Sci., 59, 441-460, 2002.

Peters, S. J. and Ewing, G. E.: Thin film water on $\mathrm{NaCl}(100)$ under ambient conditions: An infrared study, Langmuir, 13, 63456348, 1997.

Pilinis, C., Pandis, S. N., and Seinfeld, J. H.: Sensitivity of direct climate forcing by atmospheric aerosols to aerosol-size and composition, J. Geophys. Res., 100, 18 739-18 754, 1995.

Pitchford, M. L. and McMurry, P. H.: Relationship between measured water vapor growth and chemistry of atmospheric aerosol for Grand Canyon, Arizona, in winter 1990, Atmos. Environ., 28, 827-839, 1994.

Potukuchi, S. and Wexler, A. S.: Identifying solid-aqueous phase transitions in atmospheric aerosols: I. Neutral-acidity solutions, Atmos. Environ., 29, 1663-1676, 1995a.

Potukuchi, S. and Wexler, A. S.: Identifying solid-aqueous-phase transitions in atmospheric aerosols, II. Acidic solutions, Atmos. Environ., 29, 3357-3364, 1995b.

Prenni, A. J., DeMott, P. J., Kreidenweis, S. M., Sherman, D. E., Russell, L. M., and Ming, Y.: The effects of low molecular weight dicarboxylic acids on cloud formation, J. Phys. Chem. A, 105, $11240-11248,2001$.

Ramaswamy, V., Boucher, O., Haigh, J., Hauglustaine, D., Haywood, J. M., Myhre, G., Nakajima, T., Shi, G. Y., and Solomon, S.: Radiative forcing of Climate Change, in In Climate Change 2001: The Scientific Basis. Contribution of Working Group I to the Third Assessment Report of the Intergovernmental Panel on Climate Change, edited by Houghton, J. T., Ding, Y., Griggs, D. J., Noguer, M., Linden, P. J., Dai, X., Maskell, K., and Johnson, C. A., pp. 349-416, Cambridge University Press., 2001.

Rood, M. J., Covert, D. S., and Larson, T. V.: Temperature and humidity controlled nephelometry: Improvements and calibration, Aerosol Sci. Technol., 7, 57-65, 1987.

Rood, M. J., Shaw, M. A., Larson, T. V., and Covert, D. S.: Ubiquitous nature of ambient metastable aerosol, Nature, 337, 537-539, 1989.

Rossow, W. B. and Schiffer, R. A.: Advances in Understanding Clouds from ISCCP, Bull. Am. Met. Soc., 80, 2261-2287, http://isccp.giss.nasa.gov/climanal1.html, 1999.

Rossow, W. B., Walker, A. W., and Garder, L. C.: Comparison of ISCCP and other cloud amounts, J. Clim., 6, 2394-2418, 1993.

Seinfeld, J.: National Research Council, Panel on Aerosol Radiative Forcing and Climate Change. A Plan for a research program on aerosol radiative forcing and climate change, National Academy Press, Washington, D.C., 1996.

Seinfeld, J. H. and Pandis, S. N.: Atmospheric Chemistry and Physics, Wiley, New York, 1998.

Shaw, M. A. and Rood, M. J.: Measurements of the crystallization 
humidities of ambient aerosol particles, Atmos. Environ., 24A, 1837-1841, 1990.

Sokolik, I. N., Winker, D. M., Bergametti, G., Gillette, D. A., Carmichael, G., Kaufman, Y. J., Gomes, L., Schuetz, L., and Penner, J. E.: Introduction to special section: Outstanding problems in quantifying the radiative impacts of mineral dust, J. Geophys. Res., 106, 18 015-18 027, 2001.

Spiro, P. A., Jacob, D. J., and Logan, J. A.: Global inventory of sulfur emissions with $1^{\circ} \times 1^{\circ}$ resolution, J. Geophys. Res., 97, 6023-6036, 1992.

Spurr, R. J. D., Kurosu, T. P., and Chance, K. V.: A linearized discrete ordinate radiative transfer model for atmospheric remotesensing retrieval, J. Quant. Spectrosc. Radiat. Transf., 68, 689735, 2001.

Spurr, R. J. D.: Simultaneous derivation of intensities and weighting functions in a general pseudo-spherical discrete ordinate radiative transfer treatment, J. Quant. Spectrosc. Radiat. Transf., 75, 129-175, 2002.

Tegen, I., Lacis, A., and Fung, I.: The influence on climate forcing of mineral aerosols from disturbed soils, Nature, 380, 419-422, 1996.

Tegen, I., Hollrig, P., Chin, M., Fung, I., Jacob, D., and Penner, J.: Contribution of different aerosol species to the global aerosol extinction optical thickness: Estimates from model results, J. Geophys. Res., 102, 23 895-23 915, 1997. ten Brink, H. M., Veefkind, J. P., Waijers-Ijpelaan, A., and van der Hage, J. C.: Aerosol light-scattering in the Netherlands, Atmos. Environ., 30, 4251-4261, 1996.

Thomas, G. E. and Stamnes, K.: Radiative Transfer in the Atmosphere and Ocean, Cambridge University Press, Cambridge, 1999.

van de Hulst, H. C.: Light scattering by small particles, Wiley, New York, 1957.

van Dorland, R., Dentener, F. J., and Lelieveld, J.: Radiative forcing due to tropospheric ozone and sulfate aerosols, J. Geophys. Res., 102, 28 079-28 100, 1997.

Wang, Y. H., Jacob, D. J., and Logan, J. A.: Global simulation of tropospheric $\mathrm{O}_{3}-\mathrm{NO}_{\mathrm{x}}$ hydrocarbon chemistry 1 . Model formulation, J. Geophys. Res., 103, 10713-10 725, 1998.

Wesely, M. L.: Parameterization of surface resistances to gaseous dry deposition in regional-scale numerical-models, Atmos. Environ., 23, 1293-1304, 1989.

Wexler, A. S. and Clegg, S. L.: Atmospheric aerosol models for systems including the ions $\mathrm{H}^{+}, \mathrm{NH}_{4}^{+}, \mathrm{Na}^{+}, \mathrm{SO}_{4}^{2-}, \mathrm{NO}_{3}^{-}, \mathrm{Cl}^{-}, \mathrm{Br}^{-}$, and $\mathrm{H}_{2} \mathrm{O}, \quad \mathrm{J}$. Geophys. Res., 107, 4207, 2002.

Zhang, Y., Seigneur, C., Seinfeld, J. H., Jacobson, M., Clegg, S. L., and Binkowski, F. S.: A comparative review of inorganic aerosol thermodynamic equilibrium modules: similarities, differences, and their likely causes, Atmos. Environ., 34, 117-137, 2000. 